\title{
FEW DOMINANT NATIVE WOODY SPECIES: HOW SUBTROPICAL RAINFOREST SUCCESSIONAL PROCESS ACTS ON ABANDONED PASTURES IN SOUTHERN BRAZIL
}

\author{
MAÇANEIRO, J. P. ${ }^{1 *}-$ GASPER, A. L. ${ }^{2}-$ SCHORN, L. A. ${ }^{3}-$ GALVÃO, F. ${ }^{1}$ \\ ${ }^{1}$ Departamento de Engenharia Florestal, Universidade Federal do Paraná Box. \\ 80210-170 Curitiba, Brazil \\ ${ }^{2}$ Departamento de Ciências Naturais, Fundação Universidade Regional de Blumenau Box. \\ 89030-103 Blumenau, Brazil \\ ${ }^{3}$ Departamento de Engenharia Florestal, Fundação Universidade Regional de Blumenau Box. \\ 89030-000 Blumenau, Brazil \\ *Corresponding author \\ e-mail: jpmacaneiro@gmail.com; phone: +55-47-3221-6043 \\ (Received $4^{\text {th }}$ Jul 2017; accepted $26^{\text {th }}$ Sep 2017)
}

\begin{abstract}
In Brazil, a high number of woody species have been used for forest restoration plantings. However, this action is widely questionable due to the no re-establishment of a considered "normal" successional trajectory. In this study, we analyzed subtropical rainforest natural regeneration at abandoned pastures and we showed that vegetation is characterized, predominantly, by few high dominant native woody species, highlighting especially Vernonanthura discolor (Asteraceae), Myrsine coriacea (Primulaceae), and Piptocarpha regnellii (Asteraceae). Our results also indicate that these high dominance species favor the lowest diversity of natural regeneration. In this regard, we suggest implementing actions that provide improvements and facilitate natural processes of ecological succession by planting dominant native woody species. This takes into consideration the re-establishment of a considered "normal" successional trajectory.
\end{abstract}

Keywords: forest regeneration; "normal" successional trajectory; dominant species; species diversity; CSR ecological strategies

\section{Introduction}

The subtropical forests are exposed to a continuous degradation process, due to anthropic landscapes changes (Ribeiro et al., 2009; Vibrans et al., 2013a). These landscapes are mainly pastures mosaics, crops and urban areas fringed by small forest patches (Tabarelli et al., 2010). The forests conversion into cattle raising pastures is known for reducing biological diversity, interrupting the ecological processes (TinocoOjanguren et al., 2013), and also reducing water infiltration into the soil due to soil compaction by animals trampling, what increases superficial runoff and soil erosion (Kunz et al., 2013). In these areas, natural regeneration of native species is limited by a variety of processes coming from the conversion forest-pasture, including land degradation (Holl and Aide, 2011), unfavorable microclimate (Pröll et al., 2015), lower seed dispersion (Reid et al., 2015) and competition from invasive exotic species (Mantoani and Torezan, 2016).

There are $\sim 177.282,00 \mathrm{~km}^{2}$ of potential areas for forest restoration in Brazil (Rodrigues et al., 2011). These areas are generally situated in highly fragmented forest regions and present low agricultural potential due to massive livestock farming (Rodrigues et al., 2009). Such as in other Brazilian regions, Santa Catarina Atlantic 
Forest is composed of secondary forest physiognomy with different regeneration stages, being rare the remaining with primary forests (Reis et al., 1992). The whole area has suffered destructive extractivism and disorderly soil occupation for agriculture and livestock expansion (Vibrans et al., 2013b). Although, secondary forests are important for global biological diversity conservation (Gibson et al., 2011), in Southern Brazil there are few studies on species diversity of natural regeneration at the secondary succession process of subtropical forests (Meyer et al., 2013; Fiorentin et al., 2015).

If we understand the secondary succession process of abandoned pastures and priority areas indicated for restoration in Brazil (see Rodrigues et al., 2011; Brasil, $2012 ; 2017)$, we can show potential species to be used in the forest regeneration projects (Martins, 2013; Maçaneiro et al., 2016a; Mota et al., 2017; Turchetto et al., 2017). For example, species that colonize abandoned pastures are typical from disturbed environments, once they frequently occur in open areas (such as clearings) or, on the edge of forests, where environmental conditions are unfavorable for most of the demanding plants (Chazdon and Guariguata, 2016). Besides this, those species are adapted to local environmental conditions, characterizing native regeneration vegetation in the initial stages and, therefore, being recommended for use on subtropical forests restoration (Kageyama and Reis, 1993; Meli et al., 2014; Mota et al., 2017).

Heliophytic and light demanding plants are among the species prepared to take place at abandoned pastures (Chazdon, 2008; Cheung et al., 2009). They are highly adapted to unfavorable microclimate conditions (higher light levels) and degraded soil (compacted and low in nutrients) (Holl and Aide, 2011). These species are also often described as single-dominants or monodominants (see Connell and Lowman, 1989; Hart et al., 1989), since they occur in large numbers, have relative density or relative dominance between 50-100\%, and dominate the forest canopy. Some studies were developed in Santa Catarina with the purpose to understand both the natural regeneration composition and structure of the Atlantic Forest (see Schorn and Galvão, 2009; Siminski, 2009; Meyer et al., 2013; Fiorentin et al., 2015; Higuchi et al., 2015; Maçaneiro et al., 2016a). Those studies verified that successional trajectories vary in function of the land use and the anthropic history. Although its descriptive content focus, those researches contribute to meta-analysis studies and also serves as basis for forest restoration projects in similar areas (Mota et al., 2017; Turchetto et al., 2017). However, none of these studies emphasized the relationship between natural regeneration dominant species and diversity in abandoned pastures.

The use of a large number of woody species in plantations for forest regeneration purpose is a widely questionable action, although it is a traditional practice in Brazil (Naeem, 2006; Wright et al., 2009; Durigan et al., 2010; Durigan and Engel, 2015). For instance, a degraded ecosystem is a highly organizaded system opened to matter and energy flows, with dissipative structure, presenting internal (among the system components) and external interactions (with the landscape) (Aumond and Maçaneiro, 2014). In this context, the answer for how many species would be necessary in order to have a stable community and a functional ecosystem must take into account how a considered "normal" successional trajectory re-establishment happens (see Suding and Gross, 2006; Naeem, 2006; Durigan and Engel, 2015). Furthermore, there are few woody species that seems to dominate at the beginning of forest succession of the subtropical forests (see Klein, 1980; Schorn and Galvão, 2009; Siminski, 2009; Meyer et al., 2013). In this regard, the aim of this study was to analyze natural regeneration woody species composition, structure, diversity, and abundance at abandoned pastures 
in order to respond tree key issues: (1) How many and which are the species growing at a four-year abandoned pasture? The pasture mentioned was used by cattle raising for more than a half century. (2) Do distribution abundance patterns of the natural regeneration woody species present important implications to the choice of new species for forest restoration projects?

\section{Material and Methods}

\section{Study area}

The study area is inserted in Faxinal do Bepe locality, Serra do Itajaí National Park, state of Santa Catarina, Southern Brazil. The area is within the limits of Itajaí river watershed, being the river Warnow a sub-watershed. Faxinal do Bepe has a total area of $\sim 250$ ha, altitude which varies of 700 to $1,039 \mathrm{~m}$ s.n.m. and is located between $27^{\circ} 05^{\prime}$ $27^{\circ} 07^{\prime}$ 'S e $49^{\circ} 11^{\prime}$ - 49 $19^{\circ}$ ' W (Figure 1).

The climate is Cfa - humid subtropical climate, without dry season and with hot summer (Alvares et al., 2014). The average annual temperature range between 16-18 ${ }^{\circ} \mathrm{C}$, with temperature average monthly varying between $12-14{ }^{\circ} \mathrm{C}$ in the coldest month (July) and $20-23{ }^{\circ} \mathrm{C}$ in the warmer months (January and February). The annual relative humidity varies between $82-84 \%$ and the total annual rainfall is between 1,500-1,700 $\mathrm{mm}$ well distributed during the year (Pandolfo et al., 2002).

The predominant vegetation is Subtropical Upper Hills Broadleaved Evergreen Rainforest (sensu Oliveira-Filho, 2015), hereafter referred to as Subtropical Rainforest, inserted at Atlantic Forest Domain. Regarding the natural resources historical use, after the year 1953, it has initiated the colonization and occupation process at Faxinal do Bepe, that lasted until 2004. At that period, large part of the forests were submitted to selective logging and posterior conversion to vast pasture areas that, currently, are found abandoned and at an initial regeneration stage.

\section{Data collection}

We selected three four-year abandoned pastures which were at an initial regeneration stage (Figures 1 and 2). Each area was constituted by a slope with the same historical use. We used plots arranged in transects (Soares et al., 2012), to represent the possible greatest variation throughout the three areas with abandoned pastures. At each area we distributed, systematically, 15 sample plots of $10 \times 20 \mathrm{~m}\left(200 \mathrm{~m}^{2}\right)$, corresponding to $3,000 \mathrm{~m}^{2}$ sampling area and making up $20 \%$ of the total studied. We disposed these sample plots in three transects, all of them starting at the base of the slope and ending at the top of the slope. We distanced these sample plots approximately $25 \mathrm{~m}$ each other and $35 \mathrm{~m}$ from the transects. At each sample plot we sampled the upper layer, characterized by live individuals with diameter at breast height $(\mathrm{DBH}) \geq 5 \mathrm{~cm}$. Inside each sample plot we inserted a $10 \times 10 \mathrm{~m}\left(100 \mathrm{~m}^{2}\right)$ subplot, to sample lower layer, characterized by individuals with height $\geq 50 \mathrm{~cm}$ and $\mathrm{DBH}<5 \mathrm{~cm}$.

We identified botanical material collected by comparison with exsiccates deposited at the Dr. Roberto Miguel Klein Herbarium of Fundação Universidade Regional de Blumenau (FURB) and, also, through taxonomic literature and FURB experts consultation. We used the species classification system proposed by APG IV (2016) and PPG I (2016). 


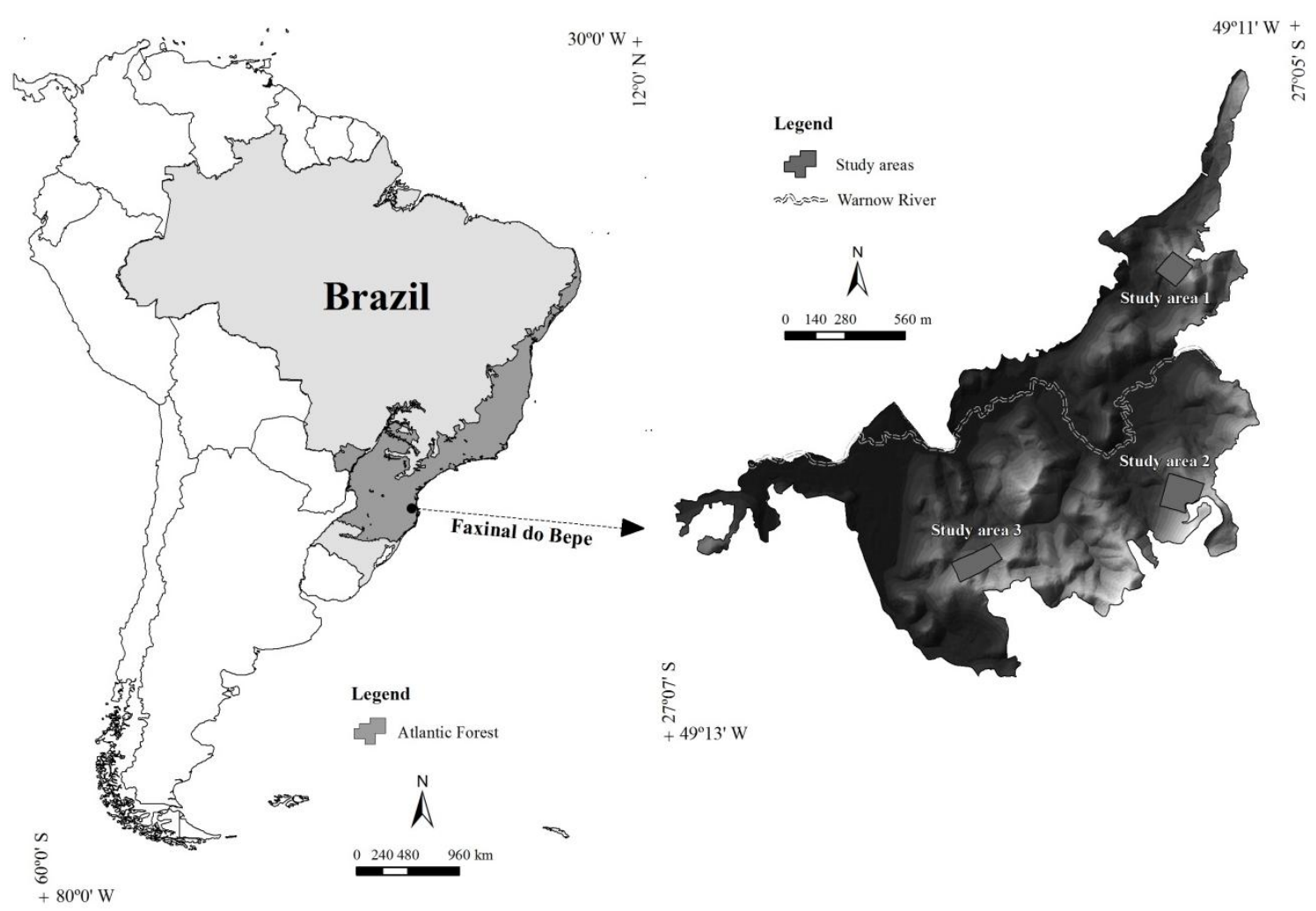

Figure 1. Studied area at Faxinal do Bepe, Serra do Itajai National Park, Santa Catarina State, Southern Brazil.

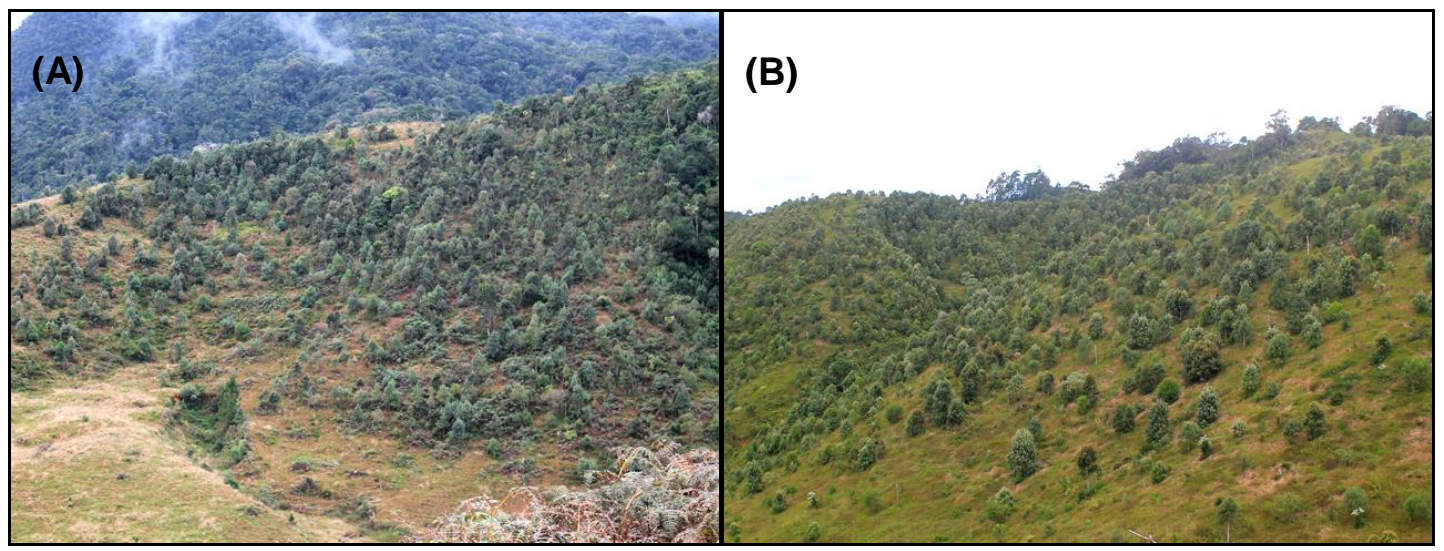

Figure 2. Photos of studied areas 1 (A) and 3 (B) at Faxinal do Bepe, Serra do Itajai National Park, Santa Catarina State, Southern Brazil.

\section{Data analysis}

We calculated, for upper layer, Mueller-Dombois and Ellenberg (2002) structural parameters, in other words, density, dominance and frequency absolute and relative, and importance value for each species. For lower layer, besides the parameter described above, we calculated absolute and relative height classes and the natural regeneration importance value for each species (Hosokawa et al., 
2008). Afterward, we classified these species by CRS ecological strategy (see Grime et al., 1997), adopting the methodology suggested by Pierce et al. (2013) into the following categories: $\mathrm{C}$ - competitor specie with high potential growth rate and rapidly biomass expanding; $\mathrm{S}$ - stress-tolerant specie and slow-growing; $\mathrm{R}$ - ruderal specie with premature reproduction for prolonged period.

We verified species abundance distribution patterns (PDSA) of the natural regeneration by Whittaker diagram (Magurran, 2004). Similarities or differences between PDSA layers analyzed were verified by Kolmogorov-Smirnov test for two sample plots, at the significance level $\alpha=0.01$ (Sokal and Rohlf, 2011). The Whittaker diagram is considered a useful tool to analyze species PSDA into plant communities, once contrasting patterns between species richness and vegetation uniformity can be clearly observed (Krebs, 2014; Maçaneiro et al., 2016b).

We estimated the vegetation heterogeneity (Krebs, 2014) by Shannon index ( $H^{\prime}$, Napier's logarithms) and Simpson index (1-D). Afterwards, we converted these indexes to the effective number of species - ENS (see Jost, 2006) by the following expressions: Shannon index $=\exp \left(H^{\prime}\right)$ and Simpson index $=1 /(1-(1-D))$. Indexes $H^{\prime}$ and 1-D conversion into real diversity (effective number of species) giving it a set of common behaviors and properties, easily interpretable. After this conversion, the diversity is always measured as species number, regardless of the index used (Jost, 2010). Additionally, we used Pearson correlation coefficient and scatterplots to verify the relationship between the diversity and abundance of dominant woody species at the layers. First, we correlated relative density (DR\%) of the specie with the greatest individual number of each sample plot with its respective $H^{\prime}$ e 1-D converted into ENS. Next, we investigated the statistical significance $(\alpha=0.01)$ of the correlations through $t$ test for correlation existence (Zar, 2010). Finally, we constructed dispersion graphics between diversity evidences (axis y) and $D R \%$ (axis x), and inserted a linear trend line for the relation between $H^{\prime}$ and $D R \%$, and 1-D and $D R \%$, both converted into ENS.

\section{Results}

We sampled 1,079 individuals belonging to 45 woody species (Table 1) in both layers. The natural regeneration presented 497.8 ind.ha $^{-1}$ and monodominance of Vernonanthura discolor $(D R>50 \%)$, in the upper layer. Besides Vernonanthura discolor, Piptocarpha regnellii, Piptocarpha axillaris, Myrsine coriacea and Piptocarpha angustifolia $(V I=266.2 \%)$ also characterize the upper layer.

In the lower layer, we found density of 1,402.2 ind.ha ${ }^{-1}$ and the mains species that characterized the vegetation structure were Vernonanthura discolor, Myrsine coriacea, Clethra scabra, Piptocarpha regnellii and Piptocarpha axillaris $(R N R=$ $186.2 \%)$. Similar to what was found on the upper layer, Vernonanthura discolor, Myrsine coriacea, Piptocarpha regnellii and Piptocarpha axillaris also were the main species at the lower layer (Table 1).

We observed that woody species presented different ecological regeneration strategies (Table 1). However, competitors and stress tolerant plants (S/SC) were predominant at the analyzed layers (upper layer $=64.4 \%$; lower layer $=70.5 \%$ ). 
Table 1. Phytosociological parameters for woody species in two layers of natural regeneration of a Subtropical Rainforest in Southern Brazil.

\begin{tabular}{|c|c|c|c|c|c|c|c|c|}
\hline \multicolumn{9}{|c|}{ Upper layer } \\
\hline Species & $D A$ & $D R$ & $\boldsymbol{F A}$ & $F R$ & DoA & DoR & VI & ES \\
\hline Vernonanthura discolor (Spreng.) H.Rob. & 256.7 & 51.6 & 88.9 & 31.0 & 1.88 & 57.1 & 139.7 & $\mathrm{~S} / \mathrm{SC}$ \\
\hline Piptocarpha regnellii (Sch.Bip.) Cabrera & 87.8 & 17.6 & 46.7 & 16.3 & 0.67 & 20.3 & 54.2 & $\mathrm{~S} / \mathrm{SC}$ \\
\hline Piptocarpha axillaris (Less.) Baker & 58.9 & 11.8 & 42.2 & 14.7 & 0.25 & 7.5 & 34.1 & $\mathrm{~S} / \mathrm{SC}$ \\
\hline Myrsine coriacea (Sw.) R.Br. ex Roem. \& Schult. & 31.1 & 6.3 & 33.3 & 11.6 & 0.13 & 3.8 & 21.7 & $\mathrm{~S} / \mathrm{SC}$ \\
\hline Piptocarpha angustifolia Dusén ex Malme & 27.8 & 5.6 & 22.2 & 7.8 & 0.14 & 4.2 & 17.5 & $\mathrm{~S} / \mathrm{SC}$ \\
\hline Clethra scabra Pers. & 10.0 & 2.0 & 15.6 & 5.4 & 0.03 & 0.8 & 8.2 & $\mathrm{~S} / \mathrm{SC}$ \\
\hline $\begin{array}{l}\text { Symphyopappus itatiayensis (Hieron.) R.M.King } \\
\text { \& H.Rob. }\end{array}$ & 6.7 & 1.3 & 11.1 & 3.9 & 0.05 & 1.4 & 6.6 & $\mathrm{R} / \mathrm{CSR}$ \\
\hline Baccharis semiserrata DC. & 7.8 & 1.6 & 8.9 & 3.1 & 0.06 & 1.9 & 6.5 & $\mathrm{~S}$ \\
\hline Ocotea puberula (Rich.) Nees & 3.3 & 0.7 & 6.7 & 2.3 & 0.01 & 0.3 & 3.3 & SR/CSR \\
\hline Annona emarginata (Schltdl.) H.Rainer & 3.3 & 0.7 & 2.2 & 0.8 & 0.03 & 1.0 & 2.5 & $\mathrm{~S} / \mathrm{SC}$ \\
\hline Ocotea odorifera (Vell.) Rohwer & 1.1 & 0.2 & 2.2 & 0.8 & 0.04 & 1.2 & 2.2 & $\mathrm{~S} / \mathrm{SC}$ \\
\hline Baccharis dracunculifolia DC. & 1.1 & 0.2 & 2.2 & 0.8 & 0.01 & 0.2 & 1.2 & $\mathrm{~S}$ \\
\hline Solanum lacerdae Dusén & 1.1 & 0.2 & 2.2 & 0.8 & 0.004 & 0.1 & 1.1 & $\mathrm{~S} / \mathrm{SC}$ \\
\hline Aspidosperma tomentosum Mart. & 1.1 & 0.2 & 2.2 & 0.8 & 0.003 & 0.1 & 1.1 & $\mathrm{~S} / \mathrm{SC}$ \\
\hline Total & 497.8 & 100.0 & 286.7 & 100.0 & 3.30 & 100.0 & 300.0 & - \\
\hline \multicolumn{9}{|c|}{ Lower layer } \\
\hline Species & $D A$ & $D R$ & $\boldsymbol{F A}$ & $F R$ & CAT & $C R T$ & $R N R$ & ES \\
\hline Vernonanthura discolor (Spreng.) H.Rob. & 433.3 & 30.9 & 84.4 & 16.1 & 51.8 & 31.0 & 78.0 & $\mathrm{~S} / \mathrm{SC}$ \\
\hline Myrsine coriacea (Sw.) R.Br. ex Roem. \& Schult. & 177.8 & 12.7 & 55.6 & 10.6 & 18.9 & 11.3 & 34.6 & $\mathrm{~S} / \mathrm{SC}$ \\
\hline Clethra scabra Pers. & 126.7 & 9.0 & 51.1 & 9.7 & 15.4 & 9.2 & 28.0 & $\mathrm{~S} / \mathrm{SC}$ \\
\hline Piptocarpha regnellii (Sch.Bip.) Cabrera & 115.6 & 8.2 & 48.9 & 9.3 & 13.9 & 8.3 & 25.9 & $\mathrm{~S} / \mathrm{SC}$ \\
\hline Piptocarpha axillaris (Less.) Baker & 113.3 & 8.1 & 37.8 & 7.2 & 13.7 & 8.2 & 23.5 & $\mathrm{~S} / \mathrm{SC}$ \\
\hline Piptocarpha angustifolia Dusén ex Malme & 57.8 & 4.1 & 28.9 & 5.5 & 7.0 & 4.2 & 13.8 & $\mathrm{~S} / \mathrm{SC}$ \\
\hline Miconia tristis Spring & 53.3 & 3.8 & 20.0 & 3.8 & 6.0 & 3.6 & 11.2 & $\mathrm{~S} / \mathrm{SC}$ \\
\hline $\begin{array}{l}\text { Symphyopappus itatiayensis (Hieron.) R.M.King } \\
\text { \& H.Rob. }\end{array}$ & 33.3 & 2.4 & 20.0 & 3.8 & 4.4 & 2.7 & 8.8 & $\mathrm{R} / \mathrm{CSR}$ \\
\hline Myrsine umbellata Mart. & 35.6 & 2.5 & 20.0 & 3.8 & 4.0 & 2.4 & 8.7 & $\mathrm{~S} / \mathrm{SC}$ \\
\hline Solanum americanum Mill. & 53.3 & 3.8 & 4.4 & 0.8 & 6.4 & 3.8 & 8.5 & $\mathrm{~S} / \mathrm{SC}$ \\
\hline Baccharis semiserrata DC. & 31.1 & 2.2 & 13.3 & 2.5 & 2.7 & 1.6 & 6.3 & $\mathrm{~S} / \mathrm{SC}$ \\
\hline Miconia sellowiana Naudin & 13.3 & 1.0 & 13.3 & 2.5 & 1.8 & 1.1 & 4.6 & $\mathrm{~S} / \mathrm{SC}$ \\
\hline Solanum mauritianum Scop. & 13.3 & 1.0 & 13.3 & 2.5 & 1.7 & 1.0 & 4.5 & $\mathrm{~S} / \mathrm{SC}$ \\
\hline Ocotea puberula (Rich.) Nees & 13.3 & 1.0 & 8.9 & 1.7 & 1.7 & 1.0 & 3.7 & SR/CSR \\
\hline Baccharis oblongifolia (Ruiz \& Pav.) Pers. & 8.9 & 0.6 & 6.7 & 1.3 & 1.2 & 0.7 & 2.6 & $\mathrm{~S} / \mathrm{SC}$ \\
\hline Baccharis dracunculifolia DC. & 6.7 & 0.5 & 6.7 & 1.3 & 1.0 & 0.6 & 2.3 & $\mathrm{~S} / \mathrm{SC}$ \\
\hline Ficus luschnathiana (Miq.) Miq. & 6.7 & 0.5 & 6.7 & 1.3 & 1.0 & 0.6 & 2.3 & $\mathrm{~S} / \mathrm{SC}$ \\
\hline Campomanesia guaviroba (DC.) Kiaersk. & 8.9 & 0.6 & 4.4 & 0.8 & 1.4 & 0.8 & 2.3 & $\mathrm{~S} / \mathrm{SC}$ \\
\hline Solanum lacerdae Dusén & 6.7 & 0.5 & 6.7 & 1.3 & 0.9 & 0.5 & 2.3 & $\mathrm{~S} / \mathrm{SC}$ \\
\hline Annona emarginata (Schltdl.) H.Rainer & 6.7 & 0.5 & 6.7 & 1.3 & 0.9 & 0.5 & 2.3 & $\mathrm{~S} / \mathrm{SC}$ \\
\hline Inga vera subsp. affinis (DC.) T.D.Penn. & 6.7 & 0.5 & 6.7 & 1.3 & 0.8 & 0.5 & 2.2 & $\mathrm{~S} / \mathrm{SC}$ \\
\hline Myrcia splendens (Sw.) DC. & 8.9 & 0.6 & 4.4 & 0.8 & 1.0 & 0.6 & 2.1 & $\mathrm{~S} / \mathrm{SC}$ \\
\hline Syagrus romanzoffiana (Cham.) Glassman & 6.7 & 0.5 & 4.4 & 0.8 & 0.9 & 0.5 & 1.8 & $\mathrm{~S} / \mathrm{SC}$ \\
\hline Miconia сависи Hoehne & 4.4 & 0.3 & 4.4 & 0.8 & 0.7 & 0.4 & 1.6 & $\mathrm{~S} / \mathrm{SC}$ \\
\hline Alchornea triplinervia (Spreng.) Müll.Arg. & 4.4 & 0.3 & 4.4 & 0.8 & 0.5 & 0.3 & 1.5 & $\mathrm{~S} / \mathrm{SC}$ \\
\hline Ocotea elegans $\mathrm{Mez}$ & 6.7 & 0.5 & 2.2 & 0.4 & 0.9 & 0.5 & 1.4 & $\mathrm{~S} / \mathrm{SC}$ \\
\hline Aspidosperma tomentosum Mart. & 4.4 & 0.3 & 2.2 & 0.4 & 0.7 & 0.4 & 1.2 & $\mathrm{~S} / \mathrm{SC}$ \\
\hline Zanthoxylum rhoifolium Lam. & 4.4 & 0.3 & 2.2 & 0.4 & 0.7 & 0.4 & 1.2 & $\mathrm{~S} / \mathrm{SC}$ \\
\hline Casearia sylvestris $\mathrm{Sw}$. & 4.4 & 0.3 & 2.2 & 0.4 & 0.7 & 0.4 & 1.2 & SC/CSR \\
\hline Cyathea phalerata Mart. & 4.4 & 0.3 & 2.2 & 0.4 & 0.6 & 0.4 & 1.1 & S \\
\hline Guatteria australis A.St.-Hil. & 2.2 & 0.2 & 2.2 & 0.4 & 0.3 & 0.2 & 0.8 & $\mathrm{~S} / \mathrm{SC}$ \\
\hline
\end{tabular}


Critoniopsis quinqueflora (Less.) H.Rob.

Solanum variabile Mart.

Dalbergia brasiliensis Vogel

Leandra carassana (DC.) Cogn.

Miconia inconspicua Miq.

Miconia lymanii Wurdack

Cedrela fissilis Vell.

Rubus brasiliensis Mart.

Handroanthus chrysotrichus (Mart. ex DC.)

Mattos

Jacaranda puberula Cham.

Nectandra oppositifolia Nees

Leandra glazioviana Cogn.

Campomanesia reitziana D.Legrand

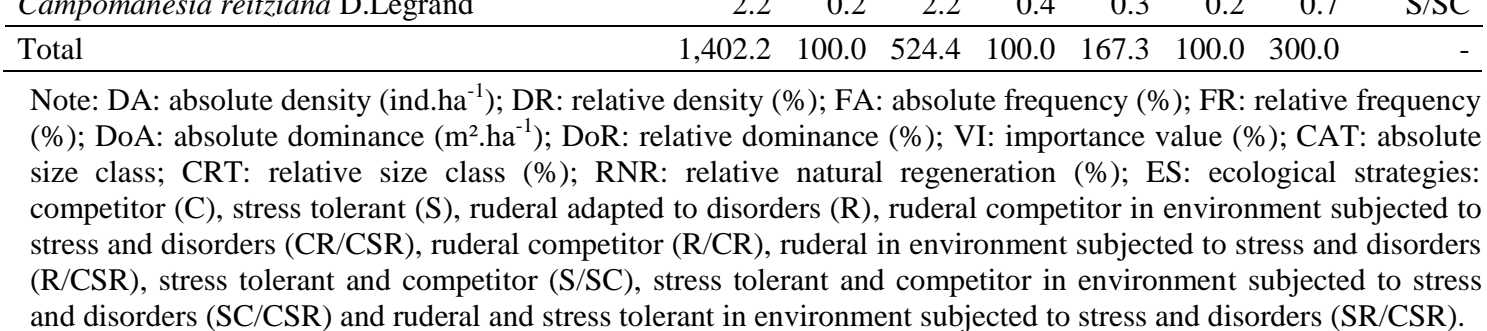

Differences between vegetation layers are particularly visible at the community structure (Figure 3). We verified PDSA significantly different throughout the analyzed layers (Kolmogorov-Smirnov, $D=0.68 ; p<0.01$ ). However, Whittaker diagram showed that natural regeneration is characterized by few high dominant woody species, highlighting Vernonanthura discolor, Myrsine coriacea and Piptocarpha regnellii.

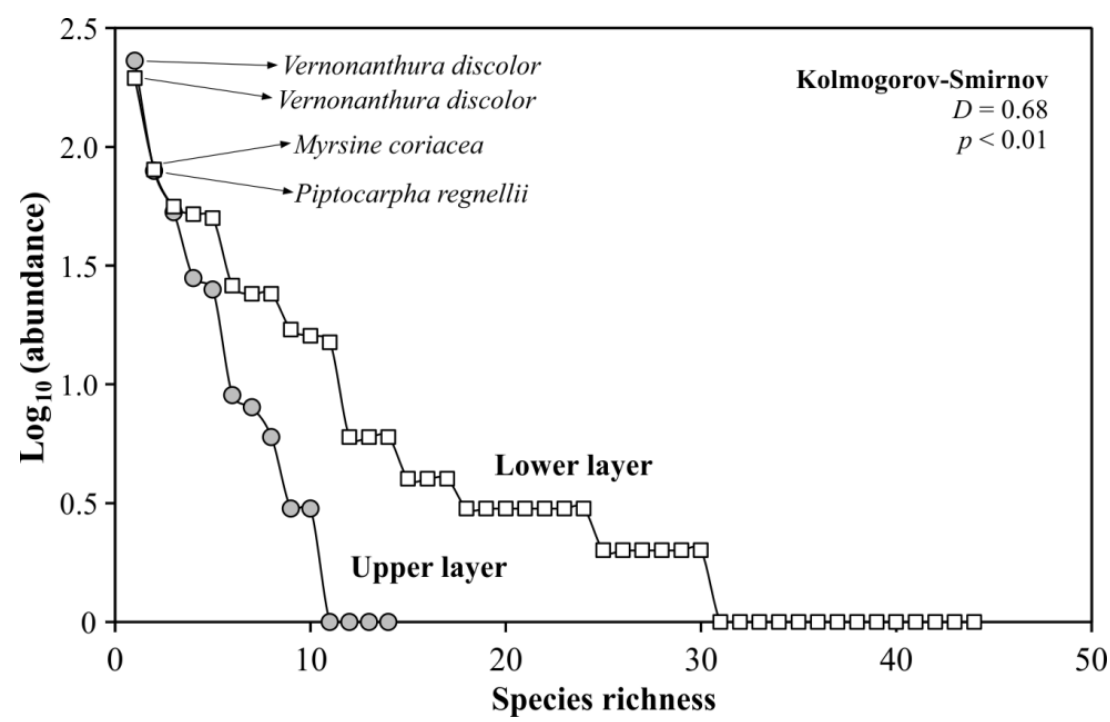

Figure 3. Whittaker diagram for two layers of natural regeneration of a Subtropical Rainforest in Southern Brazil.

We found highly significant correlations (Pearson, $r>-0.79 ; p<0.01$ ) between diversity index (Shannon and Simpson) and relative density of the mostly abundant woody species at the sample plots analyzed (Table 2, Figure 4). 
Table 2. Pearson coefficient correlation ( $r$ ) between diversity indexes and relative density of the most abundant woody specie at the sample plots in two layers of natural regeneration of a Subtropical Rainforest in Southern Brazil.

\begin{tabular}{lcccc}
\hline Diversity index & ENS & $\boldsymbol{R}^{\mathbf{2}}$ & $\boldsymbol{r}$ & $\boldsymbol{p}$ \\
\hline Upper layer & & & & \\
Shannon & 4.78 & 0.62 & -0.79 & $<0.0001$ \\
Simpson & 3.16 & 0.79 & -0.89 & $<0.0001$ \\
Lower layer & & & & $<0.0001$ \\
Shannon & 13.00 & 0.68 & -0.82 & $<0.0001$ \\
Simpson & 7.21 & 0.78 & -0.88 & \\
\hline
\end{tabular}

ENS $=$ effective number of species.
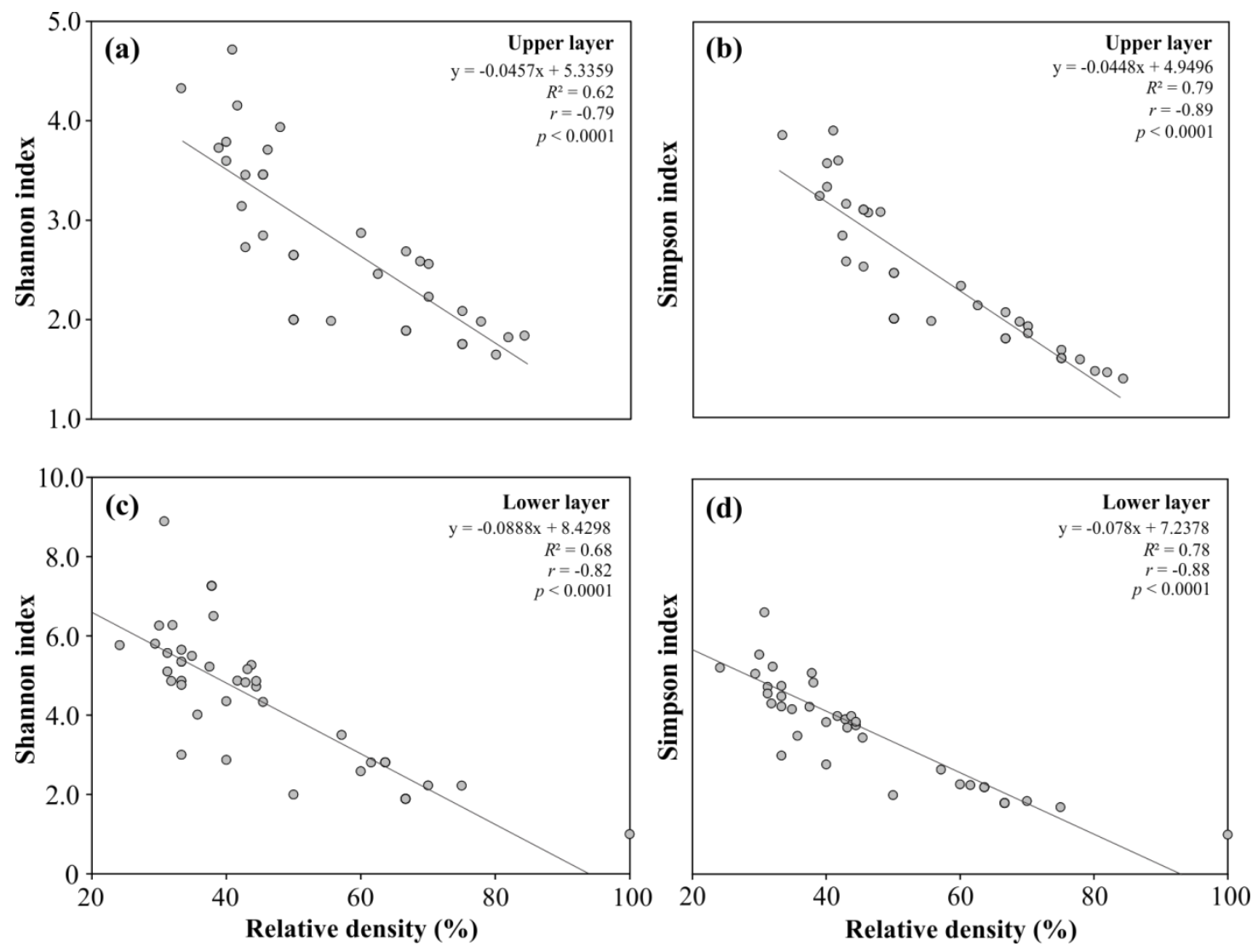

Figure 4. Relation between diversity indexes and relative density of the most abundant woody species on upper layer $(a, b)$ and lower $(c, d)$. Each point represents one of 45 sample plots of the natural regeneration of a Subtropical Rainforest in Southern Brazil.

\section{Discussion}

Our study revealed that natural regeneration of Subtropical Rainforest at abandoned pastures is characterized by few highly dominant woody species. These species have specific ecological strategies as stress physiological tolerance and competitive capacity for resources. The ecological strategies of native species are closely related to the successional process (Munoz et al., 2016), where the temporal changes of colonizers and locally persistent and more demanding species are observed at the forest ecosystem affected by a disruption (for example, clearings). In this context, ecological succession 
benefit species with physiological tolerance to stress or with competitive capacity (Caccianiga et al., 2006). Furthermore, the environmental type where the plants are subjected (for example, plains and slopes) can also influence changes at ecological strategies that species have among forest succession. For example, Navas et al. (2010) verified changes between ruderal plants to competitor plants at not stressful ambient and where vital resources are unlimited, whereas at stressful environments and with limited resources ruderal plants tend to be replaced by stress tolerant plants. At the present study, components connected to geomorphology (relief, slope, elevation) and pedology (soil types, water availability) might possibly be acting as environmental filters, as at an environmental gradient relief and soil conditions vary among the slope, enabling influence plants ecological strategies (Thuiller, 2013; Maçaneiro et al., 2016c; Munoz et al., 2016).

Dominant native woody species are common in stressful environments (Peh et al., 2011; Nascimento et al., 2015), like initial successional stage in tropical (Morais et al., 2013) and subtropical rainforests (Klein, 1980; Schorn and Galvão, 2009; Siminski, 2009; Meyer et al., 2013). For example, Steege et al. (2013) determined that Amazon watershed is represented by 16,000 woody species, but that only $227(1.4 \%)$ represent half of all registered woody species. In secondary forests in the initial succession stage, dominant woody species generally are the first plants to grow due to its rapid growth and strong adaptation to local conditions, may formatting dense groupings that characterize young forests canopy (Klein, 1980; 1984; Kageyama and Reis, 1993; Chazdon, 2008; Schorn and Galvão, 2009; Chazdon, 2014; Chazdon and Guariguata, 2016). The establishment of these species during the forest regeneration also contributes to ecosystem resiliency, since they bring mutualist species that generate greater heterogeneity and diversity (Howe, 2016; McAlpine et al., 2016). These species form small patches that provides favorable microclimate for more demanding species grow (Scervino and Torezan, 2015) and attracts seeds dispersing agents, which provides improvement on soil conditions and facilitate forest regeneration (Bechara et al., 2016). Therefore, dominant native woody species generally occur in the initial succession stage of subtropical rainforest and are beneficial for forest regeneration, as observed on this study.

We verified that highly dominant woody species generate lowest natural regeneration diversity, especially on upper layer. In subtropical rainforests, the species located on the upper layer act as environmental filters for those species in lower layer species (see Carvalho et al., 2016; Boukili and Chazdon, 2017). These studies showed that some regenerating woody species are favored by mature species and that the future forest structure is related to the environmental filters. Beyond species, several biotic and abiotic factors act as environmental filters (for example, seeds dispersal, seedlings competition with exotic grasses, predation and germination seedlings, soil chemical and physical characteristics, decaying tree trunks, luminous intensity, herbivory etc), which selected or exclude determined woody species at biological communities (Holl, 2000; Christie and Armesto, 2003; Lortie et al., 2004; Chazdon, 2014; Reid et al., 2015; Chazdon and Guariguata, 2016). However, these environmental filters can help to understand what processes maintain biological diversity and explaining species distribution among environmental gradients (Elith and Leathwick, 2009; Lewis et al., 2014; Maçaneiro et al., 2016c).

Besides that, convert the natural regeneration in a true diversity (effective number of species) will depend on the uniformity vegetation level or on the diversity index 
applied. Considering the characteristics of diversity index in relation to rare species (Magurran, 2004; Jost, 2006; Melo, 2008; Buckland et al., 2011), our study presented that Shannon and Simpson's index are strongly influenced by dominant species. This issue is important when considering the woody species selection for subtropical rainforests regeneration projects, once at the present Brazil suffers with lack environmental legislation and also technical/scientific consistent criteria for species recommendation, leading many projects to use high diversity of species in the forest restoration plantings, what is widely questionable (Naeem, 2006; Wright et al., 2009; Durigan et al., 2010). Our results show that few species can establish themselves in an explored environment by more than half century of intensive use. In this context, implementing actions that provide improvements and facilitate the ecological natural succession processes through dominant native woody species with high density of seedlings are important for the initial stages of subtropical rainforests restauration, since it considers basic principles of "normal" ecological succession (see Suding and Gross, 2006; Naeem, 2006; Durigan and Engel, 2015), besides being an initiative much more affordable, enabling smallholder farmers to restore degraded pastures.

In Neotropical forest restorations, multiple techniques have been used for ecosystem reconstruction with the maximum biodiversity possible, especially planting a high diversity woody species (Rodrigues et al., 2009; Martins, 2013; Bechara et al., 2016; Chazdon and Guariguata, 2016). However, generally the diversity of native species available in tree seedlings nurseries is limited and determined by availability of regional fruits and seeds (Palma and Laurence, 2015; Turchetto et al., 2017). In this study, we observed that some of the most important species are common in all vegetation layers, presenting potential for restoration plantings, especially on open areas as new abandoned pastures, since the are species tolerant to stress and competitors for resources (for example, Vernonanthura discolor, Myrsine coriacea, Piptocarpha regnellii, Piptocarpha axillaris, Piptocarpha angustifolia, Clethra scabra and Symphyopappus itatiayensis). Another combination of species that we observed occurs only on low layer, presenting potential for restoration plantings in order to enrichment, at abandoned pasture areas in succession advanced stages (for example, Ficus luschnathiana, Campomanesia guaviroba, Inga vera subsp. affinis, Myrcia splendens, Syagrus romanzoffiana, Miconia cabucu and Alchornea triplinervia, among several others). Thus, due to structure importance and ecological strategies that these species have in Southern Brazil Subtropical Rainforest natural regeneration, we recommend preferentially this species (or this kind of species) for restoration plantings at abandoned pastures.

In this study, we indicate evidences about how the high dominance of some species (for example, Vernonanthura discolor, Piptocarpha regnellii and Myrsine coriacea) favor the lowest diversity of natural regeneration. However, this standard must be seen as facilitator of forest restoration, once these species presents huge adaptation to local conditions and provide the biggest soil cover and improvement in environmental conditions for more exigent new woody species colonization. These results encourage a further analysis about how these species contribute ecologically for abandoned pastures restorations. Therefore, we suggest the addition of species functional attributes in new vegetation studies, since additional information about ecological strategies of dominant woody species may indicate standards that accelerates the ecological successional process of subtropical rainforests. 
Acknowledgements. The authors are grateful to Banco Nacional de Desenvolvimento Econômico e Social (BNDES) and Fundação de Apoio à Pesquisa Científica e Tecnológica do Estado de Santa Catarina (FAPESC), for financial assistance and to Coordenação de Aperfeiçoamento de Pessoal de Nível Superior (CAPES) and Conselho Nacional de Desenvolvimento Científico e Tecnológico (CNPq) for their research fellowship grant (306216/2013-2). We also thank Marta Helena Cúrio de Caetano from FURB Idiomas and Daiana Vogel for English review.

\section{REFERENCES}

[1] Alvares, C. A., Stape, J. L., Sentelhas, P. C., Gonçalves, J. L. M., Sparovek, G. (2014): Köppen's climate classification map for Brazil. - Meteorologische Zeitschrift 22(6): 711728.

[2] APG IV. (2016): An update of the Angiosperm Phylogeny Group classification for the orders and families of flowering plants: APG IV. - Botanical Journal of the Linnean Society 181(1): 1-20.

[3] Aumond, J. J., Maçaneiro, J. P. (2014): Systemic approach and roughness application to cause emerging properties in the restoration of degraded soils. - Ciência Florestal 24(3): 759-770.

[4] Bechara, F. C., Dickens, S. J., Farrer, E. C., Larios, L., Spotswood, E. N., Mariotte, P., Suding, K. N. (2016): Neotropical rainforest restoration: comparing passive, plantation and nucleation approaches. - Biodiversity and Conservation 25(11): 2021-2034.

[5] Boukili, V. K., Chazdon, R. L. (2017): Environmental filtering, local site factors and landscape context drive changes in functional trait composition during tropical forest succession. - Perspectives in Plant Ecology, Evolution and Systematics 24(2): 37-47.

[6] Brasil. (2012): Lei No 12.651, de 25 de maio de 2012. http://www.planalto.gov.br/ccivil_03/_ato2011-2014/2012/lei/L12651compilado.htm

[7] Brasil. (2017): Decreto $\mathrm{N}^{\circ} 8.972$ de 23 de janeiro de 2017. http://www.planalto.gov.br/ccivil_03/_Ato2015-2018/2017/Decreto/D8972.htm

[8] Buckland, S. T., Studeny, A. C. Magurran, A. E., Newson, S. E. (2011): Biodiversity monitoring: The relevance of detectability. - In: Magurran, A. E., McGill, B. J. (ed.) Biological diversity: Frontiers in measuring biodiversity. Oxford: University Press.

[9] Caccianiga, M., Luzzaro, A., Pierce, S., Ceriani, R. M., Cerabolini, B. (2006): The functional basis of a primary succession resolved by CSR classification. - Oikos 112(1): 10-20.

[10] Carvalho, E. S., Pimenta, J. A., Bianchini, E. (2016): Ferns influence on the woody species seedling bank in semideciduous forest, Southern Brazil. - Acta Scientiarum. Biological Sciences 38(3): 347-354.

[11] Chazdon, R. L. (2008): Beyond deforestation: restoring forests and ecosystem services on degraded lands. - Science 320(5882): 1458-1460.

[12] Chazdon, R. L. (2014): Second growth: the promise of tropical forest regeneration in an age of deforestation. University of Chicago Press. Chicago.

[13] Chazdon, R. L., Guariguata, M. R. (2016): Natural regeneration as a tool for large-scale forest restoration in the tropics: prospects and challenges. - Biotropica 48(6): 716-730.

[14] Cheung, K. C., Marques, M. C. M., Liebsch, D. (2009): Relationship between herbaceous vegetation and regeneration of woody species in abandoned pastures in the Atlantic Rain Forest in Southern Brazil. - Acta Botanica Brasilica 23(4): 1048-1056.

[15] Christie, D. A., Armesto, J. J. (2003): Regeneration microsites and tree species coexistence in temperate rain forests of Chiloé Island, Chile. - Journal of Ecology 91(5): 776-784.

[16] Connell, J. H., Lowman, M. D. (1989): Low-diversity tropical rain forests: some possible mechanisms for their existence. - The American Naturalist 134(1): 88-119. 
[17] Durigan, G., Engel, V. L., Torezan, J. M., Melo, A. C. G., Marques, M. C. M., Martins, S. V., Reis, A., Scarano, F. R. (2010): Legal rules for ecological restoration: an additional barrier to hinder the success of initiatives?. - Revista Árvore 34(3): 471-485.

[18] Durigan, G., Engel, V. L. (2015): Restauração de Ecossistemas no Brasil: onde estamos e para onde podemos ir? - In: Martins, S. V. (ed.), Restauração Ecológica de Ecossistemas Degradados. Viçosa: Editora UFV.

[19] Elith, J., Leathwick, J. R. (2009): Species distribution models: ecological explanation and prediction across space and time. - Annual Review of Ecology, Evolution, and Systematics 40(1): 677-697.

[20] Fiorentin, L. D., Téo, S. J., Schneider, C. R., Costa, R. H., Batista, S. (2015): Floristic analysis and spatial pattern of natural regeneration in an Ombrophilous Mixed Forest area, municipality of Caçador, Santa Catarina State, Brazil. - Floresta e Ambiente 22(1): 60-70.

[21] Gibson, L., Lee, T. M., Koh, L. P., Brook, B. W., Gardner, T. A., Barlow, J., Peres, C. A., Bradshaw, C. J. A., Laurance, W. F., Lovejoy, T. E., Sodhi, N. S. (2011): Primary forests are irreplaceable for sustaining tropical biodiversity. - Nature 478(7367): 378381.

[22] Grime, J. P., Thompson, K., Hunt, R., Hodgson, J. G., Cornelissen, J. H. C., Rorison, I. H., Hendry, G. A. F., Ashenden, T. W., Askew, A. P., Band, S. R., Booth, R. E., Bossard, C. C., Campbell, B. D., Cooper, J. E. L., Davison, A. W., Gupta, P. L.,Hall, W.,Hand, D. W.,Hannah, M. A., Hillier, S. H., Hodkinson, D. J., Jalill, A., Liu, Z., Mackey, J. M. L., Matthews, N., Mowforth, M. A., Neal, A. M., Reader, R. J., Reiling, K., Ross-Fraser, W., Spencer, R. E., Sutton, F., Tasker, D. E., Thorpe, P. C., Whitehouse, J. (1997): Integrated screening validates primary axes of specialisation in plants. - Oikos 79(2): 259-281.

[23] Hart, T. B., Hart, J. A., Murphy, P. G. (1989): Monodominant and species-rich forests os the humid tropics: causes for their co-occurrence. - The American Naturalist 133(5): 613633.

[24] Higuchi, P., Silva, A. C., Buzzi Junior, F., Negrinii, M., Ferreira, T. S., Souza, S. T., Santos, K. F., Vefago, M. B. (2015): Determinant factors on natural regeneration in a fragment of araucaria forest on Santa Catarina State plateau. - Scientia Forestalis 43(106): 251-259.

[25] Holl, K. D., Loik, M. E., Lin, E. H. V., Samuels, I. V. (2000): Tropical Montane Forest Restoration in Costa Rica: Overcoming Barriers to Dispersal and Establishment. Restoration Ecology 8(4): 339-349.

[26] Holl, K. D., Aide, T.M. (2011): When and where to actively restore ecosystems? - Forest Ecology and Management 261(10): 1558-1563.

[27] Hosokawa, R. T., Moura, J.B., Cunha, U. S. (2008): Introdução ao manejo e economia de florestas. - Curitiba: Editora UFPR.

[28] Howe, H. F. (2016): Making dispersal syndromes and networks useful in tropical conservation and restoration. - Global Ecology and Conservation 6(1): 152-178.

[29] Jost, L. (2006): Entropy and diversity. - Oikos 113(2): 363-375.

[30] Jost, L. (2010): The relation between evenness and diversity. - Diversity 2(2): 207-232.

[31] Kageyama, P., Reis, A. (1993): Areas of secondary vegetation in the Itajai Valley, Santa Catarina, Brazil. Perspectives for management and conservation. - Forest Genetic Resources 21(1): 37-40.

[32] Klein, R. M. (1980): Ecologia da flora e vegetação do Vale do Itajaí. - Sellowia 33(1): 165-389.

[33] Klein, R. M. (1984): Aspectos dinâmicos da vegetação do sul do Brasil. - Sellowia 36(1): 5-54.

[34] Kunz, M., Gonçalvez, A. D. M. A., Reichert, J. M., Guimarães, R. M. L., Reinert, D. J., Rodrigues, M. F. (2013): Soil compaction in a soy-dairy cattle system on a clayey oxisol under no-tillage and chisel plowing. - Revista Brasileira de Ciência do Solo 37(6): 16991708 . 
[35] Krebs, C. J. (2014): Ecological methodology. - California: Benjamin/Cummings.

[36] Lewis, R. J., Pakeman, R. J., Marrs, R. H. (2014): Identifying the multi-scale spatial structure of plant community determinants of an important national resource. - Journal of Vegetation Science 25(1): 184-197.

[37] Lortie, C. J., Brooker, R. W., Choler, P., Kikvidze, Z., Michalet, R., Pugnaire, F. I., Callaway, R. M. (2004): Rethinking plant community theory. - Oikos 107(2): 433-438.

[38] Maçaneiro, J. P., Seubert, R.C., Heilmann, A., Schorn, L. A. (2016a): Regeneration of a Mixed Ombrophilous Forest on the Santa Catarina Plateau. - Biotemas 29(4): 31-42.

[39] Maçaneiro, J. P., Oliveira, L. Z., Eisenlohr, P. V., Schorn, L. A. (2016b): Paradox between species diversity and conservation: a Subtropical Atlantic Forest reserve in Brazil has similar tree species diversity to unprotected sites in the same region. - Tropical Conservation Science 9(4): 1-19.

[40] Maçaneiro, J. P., Oliveira, L. Z., Seubert, R. C., Eisenlohr, P. V., Schorn, L. A. (2016c): More than environmental control at local scales: do spatial processes play an important role on floristic variations in Subtropical Forests? - Acta Botanica Brasilica 30(2): 183192.

[41] Magurran, A. E. (2004): Measuring Biological Diversity. - Oxford: Blackwell Science.

[42] Mantoani, M. C., Torezan, J. M. D. (2016): Regeneration response of Brazilian Atlantic Forest woody species to four years of Megathyrsus maximus removal. - Forest Ecology and Management 359(1): 141-146.

[43] Martins, S. V. (2013): Recuperação de Áreas Degradadas: ações em áreas de preservação permanente, voçorocas, taludes rodoviários e de mineração. Viçosa: Editora UFV.

[44] Mcalpine, C., Catterall, C. P., Nally, R. M., Lindenmayer, D., Reid, J. L., Holl, K. D., Hobbs, R. J. (2016): Integrating plant-and animal-based perspectives for more effective restoration of biodiversity. - Frontiers in Ecology and the Environment 14(1): 37-45.

[45] Meli, P., Martinez-Ramos, M., Rey-Benayas, J., Carabias, J. (2014): Combining ecological, social and technical criteria to select species for forest restoration. - Applied Vegetation Science 17(4): 744-753.

[46] Melo, A. S. 2008. O que ganhamos "confundindo" riqueza de espécies e equabilidade em um índice de diversidade?. - Biota Neotropica 8(3): 21-27.

[47] Meyer, L., Gasper, A. L., Sevegnani, L., Schorn, L. A., Vibrans, A. C., Lingner, D. V., Verdi, M., Santos, A. S., Dreveck, S., Korte, A. (2013): Natural regeneration of the Dense Ombrophylous Forest in Santa Catarina. - In: Vibrans, A. C., Sevegnani, L., Gasper, A. L., Lingner, D. V. (ed.) Inventário Florístico Florestal de Santa Catarina: Floresta Ombrófila Densa. Blumenau: Edifurb.

[48] Morais, R. F., Silva, E. C. S., Metelo, M. R. L., Morais, F. F. (2013): Floristic composition and structure of the plant community of different phytophysiognomies in the Pantanal of Poconé, Mato Grosso. - Rodriguésia 64(4): 775-790.

[49] Mota, T. J. R. C., Carvalho, F. A., Ivanauskas, N. M., Eisenlohr, P. V. (2017): On the relevance of floristic and quantitative studies to the restoration of degraded areas: the case of the Atlantic Forest hotspot. - AIMS Environmental Science 4(1): 42-53.

[50] Mueller-Dombois, D., Ellenberg, H. (2002): Aims and methods of vegetation ecology. New Jersey: The Blackburn Press.

[51] Munoz, F., Violle, C., Cheptou, P. O. (2016): CSR ecological strategies and plant mating systems: outcrossing increases with competitiveness but stress-tolerance is related to mixed mating. - Oikos 125(9): 1296-1303.

[52] Naeem, S. (2006): Biodiversity and ecosystem functioning in restored ecosystems: extracting principles for a synthetic perspective. - In: Falk, D. A., Palmer, M. A., Zedler, J. B. (ed.) Foundations of Restoration Ecology. Washington: Island Press.

[53] Nascimento, M. T., Marimon, B. S., Marimon-Junior, B. H., Cunha, C. N., Villela, D. M. (2015): Florestas monodominantes no Brasil: estudos de caso. - In: Eisenlohr, P. V., Felfili, J. M., Melo, M. M. F., Andrade, L. A., Meira-Neto, J. A. A. (ed.) Fitossociologia no Brasil: métodos e estudos de caso. Viçosa: Editora UFV. 
[54] Navas, M. L., Roumet, C., Bellmann, A., Laurent, G., Garnier, E. (2010): Suites of plant traits in species from different stages of a Mediterranean secondary succession. - Plant Biology 12(1): 183-196.

[55] Oliveira-Filho, A. T. (2015): Um sistema de classificação fisionômico-ecológico da vegetação neotropical: segunda aproximação. - In: Eisenlohr, P. V., Felfili, J. M., Melo, M. M. F., Andrade, L. A., Meira-Neto, J. A. A. (ed.) Fitossociologia no Brasil: métodos e estudos de caso. Viçosa: Editora UFV.

[56] Palma, A. C., Laurence, S. G. W. (2015): A review of the use of direct seeding and seedling plantings in restoration: what dowe knowand where should we go?. - Applied Vegetation Science 18(4): 561-568.

[57] Pandolfo, C., Braga, H. J., Silva-Júnior, V. P., Massignan, A. M., Pereira, E. S., Thomé, V. M. R., Valci, F. V. (2002): Atlas Climatológico do Estado de Santa Catarina. Florianópolis: Epagri.

[58] Peh, K. S., Lewis, S. L., Lloyd, J. (2011): Mechanisms of monodominance in diverse tropical tree-dominated systems. - Journal of Ecology 99(4): 891-898.

[59] Pierce, S, G., Brusa, I., Vagge, Cerabolini, B. E. L. (2013): Allocating CSR plant functional types: the use of leaf economics and size traits to classify woody and herbaceous vascular plants. - Functional Ecology 27(4): 1002-1010.

[60] PPG I. (2016): A community-derived classification for extant lycophytes and ferns. Journal of Systematics and Evolution 54(6): 563-603.

[61] Pröll, G., Darabant, A., Gratzer, G., Katzensteiner, K. (2015): Unfavourable microsites, competing vegetation and browsing restrict post-disturbance tree regeneration on extreme sites in the Northern Calcareous Alps. - European Journal of Forest Research 134(2): 293-308.

[62] Reid, J. L., Holl, K. D., Zahawi, R. A. (2015): Seed dispersal limitations shift over time in tropical forest restoration. - Ecological Applications 24(4): 1072-1082.

[63] Reis, A., Fantini, A. C., Reis, M. S., Guerra, M. P., Doebeli, G. (1992): Aspectos sobre a conservação da biodiversidade e o manejo da Floresta Tropical Atlântica. - Revista do Instituto Florestal 4(1): 169-173.

[64] Ribeiro, M. C., Metzger, J. P., Martensen, A. C., Ponzoni, F. J., Hirota, M. M. (2009): The Brazilian Atlantic Forest: how much is left, and how is the remaining forest distributed? Implications for conservation. - Biological Conservation 142(6): 1141-1153.

[65] Rodrigues, R. R., Brancalion, P. H. S., Isernhagen, I. (2009): Pacto pela restauração da Mata Atlântica: referencial dos conceitos e ações de restauração florestal. - São Paulo: Instituto BioAtlântica.

[66] Rodrigues, R. R., Brancalion, P. H. S., Isernhagen, I. (2011): Pacto pela restauração da Mata Atlântica: mapa de áreas potenciais para restauração florestal. - São Paulo: Instituto BioAtlântica.

[67] Schorn, L. A., Galvão, F. (2009): Dynamics of arboreal strate in three successional stages of a fragment of the Atlantic Rain Forest in Blumenau, SC. - Cerne 15(2): 221-235.

[68] Siminski, A. (2009): A floresta do futuro: conhecimento, valorização e perspectivas de uso das formações florestais secundárias no estado de Santa Catarina. - Florianópolis: UFSC.

[69] Soares, C. P. B., Paula Neto, F. P., Souza, A. L. (2012): Dendrometria e Inventário Florestal. - Viçosa: Editora UFV.

[70] Sokal, R. R., Rohlf, F. J. (2011): Biometry. - New York: Freeman.

[71] Suding, K. N., Gross, K. L. (2006): The dynamic nature of ecological systems: multiple states and restoration trajectories. - In: Falk, D. A., Palmer, M. A., Zedler, J. B. (ed.) Foundations of restoration ecology. Washington: Island Press.

[72] Tabarelli, M. (2010): Prospects for biodiversity conservation in the Atlantic Forest: Lessons from aging human-modified landscapes. - Biological Conservation 143(10): 2328-2340. 
[73] ter Steege, H., Pitman, N. C. A., Sabatier, D., Baraloto, C., Salomão, R. P., Guevara, J. E., Phillips, O. L., Castilho, C. V., Magnusson, W. E., Molino, J. F., Monteagudo, A., Vargas, P. N., Montero, J. C., Feldpausch, T. R., Coronado, E. N. H., Killeen, T. J., Mostacedo, B., Vasquez, R., Assis, R. L., Terborgh, J., Wittmann, F., Andrade, A., Laurance, W. F., Laurance, S. G. W., Marimon, B. S., Marimon Jr., B. H., Vieira, I. C. G., Amaral, I. L., Brienen, R., Castellanos, H., López, D. C., Duivenvoorden, J. F., Mogollón, H. F., Matos, F. D. A., Dávila, N., Villacorta, R. G., Diaz, P. R. S., Costa, F., Emilio, T., Levis, C., Schietti, J., Souza, P., Alonso, A., Dallmeier, F., Montoya, A. J. D., Piedade, M. T. F., Araujo-Murakami, A., Arroyo, L., Gribel, R., Fine, P. V. A., Peres, C. A., Toledo, M., Aymard C., G. A., Baker, T. R., Cerón, C., Engel, J., Henkel, T. W., Maas, P., Petronelli, P., Stropp, J., Zartman, C. E., Daly, D., Neill, D., Silveira, M., Paredes, M. R., Chave, J., Lima Filho, D. A., Jørgensen, P. M., Fuentes, A., Schöngart, J., Valverde, F. C., Di Fiore, A., Jimenez, E. M., Mora, M. C. P., Phillips, J. F., Rivas, G., van Andel, T. R., von Hildebrand, P., Hoffman, B., Zent, E. L., Malhi, Y., Prieto, A., Rudas, A., Ruschell, A. R., Silva, N., Vos, V., Zent, S., Oliveira, A. A., Schutz, A. C., Gonzales, T., Nascimento, M. T., Ramirez-Angulo, H., Sierra, R., Tirado, M., Medina, M. N. U., van der Heijden, G., Vela, C. I. A., Torre, E. V., Vriesendorp, C., Wang, O., Young, K. R., Baider, C., Balslev, H., Ferreira, C., Mesones, I., Torres-Lezama, A., Giraldo, L. E. U., Zagt, R., Alexiades, M. N., Hernandez, L., Huamantupa-Chuquimaco, I., Milliken, W., Cuenca, W. P., Pauletto, D., Sandoval, E. V., Gamarra, L. V., Dexter, K. G., Feeley, K., Lopez-Gonzalez, G., Silman, M. R. (2013): Hyperdominance in the Amazonian Tree Flora. - Science 342(6156): 325-342.

[74] Thuiller, W. (2013): On the importance of edaphic variables to predict plant species distributions - limits and prospects. - Journal of Vegetation Science 24(4): 591-592.

[75] Tinoco-Ojanguren, C., Díaz, A., Martínez, J., Molina-Freaner, F. (2013): Species diversity and regeneration of native species in Pennisetum ciliare (buffelgrass) pastures from the thornscrub of Sonora, México. - Journal of Arid Environments 97(10): 26-37.

[76] Turchetto, F., Araujo, M. M., Callegaro, R. M., Griebeler, A. M., Mezzomo, J. C., Berghetti, A. L. P., Rorato, D. G. (2017): Phytosociology as a tool for forest restoration: a study case in the extreme South of Atlantic Forest Biome. - Biodiversity and Conservation 26(6): 1-18.

[77] Vibrans, A. C., McRoberts, R. E., Moser, P., Nicoletti, A. L. (2013a): Using satellite image-based maps and ground inventory data to estimate the area of the remaining Atlantic forest in the Brazilian state of Santa Catarina. - Remote Sensing of Environment 130(3): 87-95.

[78] Vibrans, A. C., Sevegnani, L., Gasper, A. L., Lingner, D. V. (2013b): Inventário Florístico Florestal de Santa Catarina: Floresta Ombrófila Densa. - Blumenau: Edifurb.

[79] Wright, J., Symstad, A., Bullock, J., Engelhardt, K. M., Jackson, L., Bernhardt, E. (2009): Restoring biodiversity and ecosystem function: will an integrated approach improve results? - In: Naeem, S., Bunker, D. E., Hector, A., Loreau, M., Perrings, C. (ed.) Biodiversity, ecosystem functioning and human wellbeing. Oxford: University Press.

[80] Zar, J. H. (2010): Biostatistical Analysis. - New Jersey: Upper Saddle River. 


\section{APPENDIX}

Appendix 1. Basic field data 1: species found in upper layer

\begin{tabular}{|c|c|c|c|c|}
\hline $\begin{array}{l}\text { Sample } \\
\text { plot }\end{array}$ & Individual & Species & DBH (cm) & Height (m) \\
\hline PO1 & 1 & Piptocarpha axillaris (Less.) Baker & 6,05 & 2,5 \\
\hline PO1 & 2 & Vernonanthura discolor (Spreng.) H.Rob. & 4,93 & 2,5 \\
\hline PO1 & 3 & Vernonanthura discolor (Spreng.) H.Rob. & 4,97 & 3 \\
\hline PO1 & 3 & Vernonanthura discolor (Spreng.) H.Rob. & 5,54 & 3 \\
\hline PO1 & 3 & Vernonanthura discolor (Spreng.) H.Rob. & 5,41 & 3 \\
\hline $\mathrm{PO} 2$ & 1 & Piptocarpha regnellii (Sch.Bip.) Cabrera & 5,41 & 3 \\
\hline $\mathrm{PO} 2$ & 1 & Piptocarpha regnellii (Sch.Bip.) Cabrera & 4,77 & 3 \\
\hline $\mathrm{PO} 2$ & 2 & Vernonanthura discolor (Spreng.) H.Rob. & 6,68 & 4 \\
\hline $\mathrm{PO} 2$ & 2 & Vernonanthura discolor (Spreng.) H.Rob. & 4,62 & 4 \\
\hline $\mathrm{PO} 2$ & 3 & Vernonanthura discolor (Spreng.) H.Rob. & 9,45 & 5 \\
\hline $\mathrm{PO} 2$ & 3 & Vernonanthura discolor (Spreng.) H.Rob. & 7,86 & 5 \\
\hline $\mathrm{PO} 2$ & 4 & Vernonanthura discolor (Spreng.) H.Rob. & 6,24 & 2,5 \\
\hline PO3 & 1 & Piptocarpha regnellii (Sch.Bip.) Cabrera & 5,25 & 2,5 \\
\hline PO3 & 2 & Vernonanthura discolor (Spreng.) H.Rob. & 5,25 & 3 \\
\hline PO4 & 1 & Piptocarpha regnellii (Sch.Bip.) Cabrera & 5,57 & 3 \\
\hline PO4 & 2 & Piptocarpha axillaris (Less.) Baker & 5,09 & 3 \\
\hline PO4 & 3 & Vernonanthura discolor (Spreng.) H.Rob. & 5,41 & 3 \\
\hline PO4 & 4 & Vernonanthura discolor (Spreng.) H.Rob. & 4,77 & 3,5 \\
\hline PO4 & 5 & Piptocarpha angustifolia Dusén ex Malme & 5,09 & 2,5 \\
\hline PO5 & 1 & Piptocarpha angustifolia Dusén ex Malme & 8,05 & 3 \\
\hline PO5 & 2 & Piptocarpha axillaris (Less.) Baker & 5,89 & 3 \\
\hline PO5 & 3 & Piptocarpha axillaris (Less.) Baker & 6,53 & 3,5 \\
\hline PO5 & 4 & Vernonanthura discolor (Spreng.) H.Rob. & 4,93 & 3 \\
\hline PO5 & 5 & Vernonanthura discolor (Spreng.) H.Rob. & 4,93 & 3 \\
\hline PO5 & 6 & Piptocarpha regnellii (Sch.Bip.) Cabrera & 4,93 & 3 \\
\hline PO5 & 7 & Piptocarpha angustifolia Dusén ex Malme & 5,73 & 3 \\
\hline PO5 & 8 & Piptocarpha angustifolia Dusén ex Malme & 5,19 & 2,5 \\
\hline PO5 & 9 & Piptocarpha angustifolia Dusén ex Malme & 5,19 & 3 \\
\hline PO5 & 10 & Piptocarpha angustifolia Dusén ex Malme & 5,09 & 3 \\
\hline PO5 & 11 & Vernonanthura discolor (Spreng.) H.Rob. & 6,05 & 3,5 \\
\hline PO5 & 11 & Vernonanthura discolor (Spreng.) H.Rob. & 5,25 & 3,5 \\
\hline PO5 & 11 & Vernonanthura discolor (Spreng.) H.Rob. & 5,57 & 3,5 \\
\hline PO6 & 1 & Vernonanthura discolor (Spreng.) H.Rob. & 4,77 & 2,5 \\
\hline PO6 & 2 & Vernonanthura discolor (Spreng.) H.Rob. & 5,89 & 3,5 \\
\hline PO6 & 3 & Piptocarpha axillaris (Less.) Baker & 4,77 & 3 \\
\hline PO6 & 4 & Piptocarpha angustifolia Dusén ex Malme & 6,53 & 3,5 \\
\hline PO6 & 4 & Piptocarpha angustifolia Dusén ex Malme & 4,93 & 3 \\
\hline PO6 & 5 & Piptocarpha axillaris (Less.) Baker & 4,77 & 3 \\
\hline PO6 & 6 & Piptocarpha angustifolia Dusén ex Malme & 4,93 & 3 \\
\hline PO6 & 7 & Vernonanthura discolor (Spreng.) H.Rob. & 4,93 & 3 \\
\hline PO6 & 8 & Vernonanthura discolor (Spreng.) H.Rob. & 5,51 & 3,5 \\
\hline PO6 & 9 & Piptocarpha axillaris (Less.) Baker & 4,90 & 3 \\
\hline PO6 & 10 & Piptocarpha axillaris (Less.) Baker & 4,77 & 3 \\
\hline PO6 & 11 & Piptocarpha angustifolia Dusén ex Malme & 7,54 & 4,5 \\
\hline PO6 & 12 & Vernonanthura discolor (Spreng.) H.Rob. & 7,96 & 4,5 \\
\hline
\end{tabular}




\begin{tabular}{|c|c|c|c|c|}
\hline PO6 & 13 & Vernonanthura discolor (Spreng.) H.Rob. & 5,25 & 3 \\
\hline PO6 & 14 & Piptocarpha regnellii (Sch.Bip.) Cabrera & 6,37 & 3,5 \\
\hline PO7 & 1 & Vernonanthura discolor (Spreng.) H.Rob. & 6,21 & 3,5 \\
\hline PO7 & 2 & Piptocarpha axillaris (Less.) Baker & 6,68 & 4 \\
\hline PO7 & 3 & Vernonanthura discolor (Spreng.) H.Rob. & 6,37 & 4,5 \\
\hline PO7 & 4 & Piptocarpha regnellii (Sch.Bip.) Cabrera & 7,32 & 3,5 \\
\hline PO7 & 4 & Piptocarpha regnellii (Sch.Bip.) Cabrera & 6,37 & 3 \\
\hline PO7 & 5 & Vernonanthura discolor (Spreng.) H.Rob. & 6,05 & 4 \\
\hline PO7 & 6 & Vernonanthura discolor (Spreng.) H.Rob. & 4,93 & 3 \\
\hline PO7 & 7 & Piptocarpha regnellii (Sch.Bip.) Cabrera & 5,92 & 3,5 \\
\hline PO7 & 8 & Vernonanthura discolor (Spreng.) H.Rob. & 4,77 & 3 \\
\hline PO7 & 9 & Vernonanthura discolor (Spreng.) H.Rob. & 6,37 & 3,5 \\
\hline PO7 & 10 & Vernonanthura discolor (Spreng.) H.Rob. & 6,05 & 4 \\
\hline PO7 & 10 & Vernonanthura discolor (Spreng.) H.Rob. & 5,41 & 4 \\
\hline PO7 & 11 & Vernonanthura discolor (Spreng.) H.Rob. & 7,16 & 4 \\
\hline PO7 & 12 & Vernonanthura discolor (Spreng.) H.Rob. & 5,09 & 4 \\
\hline PO7 & 13 & Vernonanthura discolor (Spreng.) H.Rob. & 5,89 & 3,5 \\
\hline PO7 & 14 & Piptocarpha angustifolia Dusén ex Malme & 6,37 & 4 \\
\hline PO7 & 15 & Vernonanthura discolor (Spreng.) H.Rob. & 7,00 & 4,5 \\
\hline PO7 & 16 & Piptocarpha angustifolia Dusén ex Malme & 5,09 & 3,5 \\
\hline PO8 & 1 & Vernonanthura discolor (Spreng.) H.Rob. & 5,41 & 3 \\
\hline PO8 & 2 & Piptocarpha regnellii (Sch.Bip.) Cabrera & 4,77 & 3,5 \\
\hline PO8 & 2 & Piptocarpha regnellii (Sch.Bip.) Cabrera & 5,09 & 3 \\
\hline PO8 & 3 & Piptocarpha angustifolia Dusén ex Malme & 5,32 & 3 \\
\hline PO8 & 4 & Piptocarpha angustifolia Dusén ex Malme & 5,63 & 3 \\
\hline PO8 & 5 & Vernonanthura discolor (Spreng.) H.Rob. & 6,21 & 3 \\
\hline PO8 & 6 & Piptocarpha angustifolia Dusén ex Malme & 5,73 & 4 \\
\hline PO8 & 6 & Piptocarpha angustifolia Dusén ex Malme & 5,25 & 4,5 \\
\hline PO8 & 7 & Vernonanthura discolor (Spreng.) H.Rob. & 4,77 & 3 \\
\hline PO8 & 8 & Piptocarpha angustifolia Dusén ex Malme & 9,87 & 4 \\
\hline PO9 & 1 & Vernonanthura discolor (Spreng.) H.Rob. & 5,09 & 3 \\
\hline PO9 & 2 & Vernonanthura discolor (Spreng.) H.Rob. & 5,89 & 3 \\
\hline PO9 & 2 & Vernonanthura discolor (Spreng.) H.Rob. & 4,93 & 3 \\
\hline PO9 & 3 & Piptocarpha angustifolia Dusén ex Malme & 6,37 & 3,5 \\
\hline PO9 & 4 & Piptocarpha regnellii (Sch.Bip.) Cabrera & 6,53 & 3 \\
\hline PO9 & 4 & Piptocarpha regnellii (Sch.Bip.) Cabrera & 5,41 & 3 \\
\hline PO9 & 4 & Piptocarpha regnellii (Sch.Bip.) Cabrera & 5,89 & 3 \\
\hline PO9 & 4 & Piptocarpha regnellii (Sch.Bip.) Cabrera & 6,21 & 3 \\
\hline PO9 & 5 & Vernonanthura discolor (Spreng.) H.Rob. & 5,09 & 3,5 \\
\hline PO9 & 6 & Piptocarpha regnellii (Sch.Bip.) Cabrera & 7,96 & 3,5 \\
\hline PO9 & 6 & Piptocarpha regnellii (Sch.Bip.) Cabrera & 6,68 & 3,5 \\
\hline PO9 & 7 & Vernonanthura discolor (Spreng.) H.Rob. & 5,25 & 3,5 \\
\hline PO9 & 8 & Piptocarpha regnellii (Sch.Bip.) Cabrera & 6,21 & 2,5 \\
\hline PO9 & 9 & Piptocarpha axillaris (Less.) Baker & 5,73 & 2,5 \\
\hline PO9 & 10 & Vernonanthura discolor (Spreng.) H.Rob. & 5,25 & 3 \\
\hline PO9 & 11 & Piptocarpha angustifolia Dusén ex Malme & 6,37 & 3 \\
\hline PO10 & 1 & Vernonanthura discolor (Spreng.) H.Rob. & 5,09 & 3,5 \\
\hline PO10 & 2 & Piptocarpha axillaris (Less.) Baker & 5,09 & 3 \\
\hline PO10 & 3 & Piptocarpha angustifolia Dusén ex Malme & 8,59 & $\overline{4,5}$ \\
\hline PO10 & 3 & Piptocarpha angustifolia Dusén ex Malme & 7,64 & 4,5 \\
\hline
\end{tabular}




\begin{tabular}{|c|c|c|c|c|}
\hline PO10 & 4 & Vernonanthura discolor (Spreng.) H.Rob. & 6,21 & 4,5 \\
\hline PO10 & 4 & Vernonanthura discolor (Spreng.) H.Rob. & 6,68 & 4,5 \\
\hline PO10 & 5 & Piptocarpha angustifolia Dusén ex Malme & 8,91 & 4,5 \\
\hline PO10 & 6 & Vernonanthura discolor (Spreng.) H.Rob. & 4,93 & 3 \\
\hline PO10 & 7 & Piptocarpha angustifolia Dusén ex Malme & 6,84 & 3,5 \\
\hline PO10 & 7 & Piptocarpha angustifolia Dusén ex Malme & 5,09 & 3 \\
\hline PO10 & 8 & Piptocarpha angustifolia Dusén ex Malme & 4,77 & 3,5 \\
\hline PO11 & 1 & Vernonanthura discolor (Spreng.) H.Rob. & 5,83 & 3 \\
\hline PO11 & 2 & Piptocarpha axillaris (Less.) Baker & 4,77 & 3 \\
\hline PO11 & 3 & Piptocarpha regnellii (Sch.Bip.) Cabrera & 4,77 & 2,5 \\
\hline PO11 & 4 & Piptocarpha axillaris (Less.) Baker & 4,77 & 2 \\
\hline PO11 & 5 & Vernonanthura discolor (Spreng.) H.Rob. & 6,84 & 4 \\
\hline PO11 & 6 & Vernonanthura discolor (Spreng.) H.Rob. & 8,91 & 5 \\
\hline PO11 & 7 & Piptocarpha axillaris (Less.) Baker & 5,41 & 4 \\
\hline PO11 & 7 & Piptocarpha axillaris (Less.) Baker & 4,77 & 3,5 \\
\hline PO11 & 8 & Vernonanthura discolor (Spreng.) H.Rob. & 4,77 & 3,5 \\
\hline PO11 & 9 & $\begin{array}{l}\text { Symphyopappus itatiayensis (Hieron.) R.M.King \& } \\
\text { H.Rob. }\end{array}$ & 4,93 & 2,5 \\
\hline PO11 & 10 & Piptocarpha regnellii (Sch.Bip.) Cabrera & 5,73 & 3 \\
\hline PO12 & 1 & Vernonanthura discolor (Spreng.) H.Rob. & 5,25 & 4 \\
\hline PO13 & 1 & Vernonanthura discolor (Spreng.) H.Rob. & 6,75 & 4,5 \\
\hline PO13 & 1 & Vernonanthura discolor (Spreng.) H.Rob. & 5,51 & 4,5 \\
\hline PO14 & 1 & Vernonanthura discolor (Spreng.) H.Rob. & 5,73 & 3,5 \\
\hline PO15 & 1 & Piptocarpha angustifolia Dusén ex Malme & 7,96 & 5 \\
\hline PO15 & 1 & Piptocarpha angustifolia Dusén ex Malme & 5,41 & 5 \\
\hline PM1 & 1 & $\begin{array}{l}\text { Symphyopappus itatiayensis (Hieron.) R.M.King \& } \\
\text { H.Rob. }\end{array}$ & 11,14 & 5 \\
\hline PM1 & 1 & $\begin{array}{l}\text { Symphyopappus itatiayensis (Hieron.) R.M.King \& } \\
\text { H.Rob. }\end{array}$ & 8,28 & 4 \\
\hline PM1 & 2 & Vernonanthura discolor (Spreng.) H.Rob. & 8,91 & 6 \\
\hline PM1 & 3 & Myrsine coriacea (Sw.) R.Br. ex Roem. \& Schult. & 6,68 & 6 \\
\hline PM1 & 4 & Vernonanthura discolor (Spreng.) H.Rob. & 11,30 & 6 \\
\hline PM1 & 4 & Vernonanthura discolor (Spreng.) H.Rob. & 8,91 & 6 \\
\hline PM1 & 5 & Vernonanthura discolor (Spreng.) H.Rob. & 14,48 & 8 \\
\hline PM1 & 5 & Vernonanthura discolor (Spreng.) H.Rob. & 12,57 & 8 \\
\hline PM1 & 6 & Vernonanthura discolor (Spreng.) H.Rob. & 12,57 & 4 \\
\hline PM1 & 7 & Vernonanthura discolor (Spreng.) H.Rob. & 10,35 & 6 \\
\hline PM1 & 7 & Vernonanthura discolor (Spreng.) H.Rob. & 12,25 & 7 \\
\hline PM1 & 7 & Vernonanthura discolor (Spreng.) H.Rob. & 6,68 & 6 \\
\hline PM1 & 7 & Vernonanthura discolor (Spreng.) H.Rob. & 10,66 & 6 \\
\hline PM1 & 8 & Vernonanthura discolor (Spreng.) H.Rob. & 10,19 & 6 \\
\hline PM1 & 9 & Vernonanthura discolor (Spreng.) H.Rob. & 8,75 & 6 \\
\hline PM2 & 1 & Annona emarginata (Schltdl.) H.Rainer & 8,28 & 4 \\
\hline PM2 & 1 & Annona emarginata (Schltdl.) H.Rainer & 6,37 & 4 \\
\hline PM2 & 2 & Myrsine coriacea (Sw.) R.Br. ex Roem. \& Schult. & 5,09 & 5 \\
\hline PM2 & 3 & Vernonanthura discolor (Spreng.) H.Rob. & 14,16 & 8 \\
\hline PM2 & 4 & Annona emarginata (Schltdl.) H.Rainer & 9,87 & 3 \\
\hline PM2 & 4 & Annona emarginata (Schltdl.) H.Rainer & 8,28 & 3 \\
\hline PM2 & 4 & Annona emarginata (Schltdl.) H.Rainer & 9,07 & 3,5 \\
\hline PM2 & 5 & Vernonanthura discolor (Spreng.) H.Rob. & 7,00 & 7 \\
\hline PM2 & 6 & Annona emarginata (Schltdl.) H.Rainer & 5,73 & 3 \\
\hline
\end{tabular}




\begin{tabular}{|c|c|c|c|c|}
\hline PM2 & 7 & Vernonanthura discolor (Spreng.) H.Rob. & 14,64 & 8 \\
\hline PM3 & 1 & Vernonanthura discolor (Spreng.) H.Rob. & 6,68 & 5 \\
\hline PM3 & 2 & Myrsine coriacea (Sw.) R.Br. ex Roem. \& Schult. & 8,59 & 8 \\
\hline PM3 & 2 & Myrsine coriacea (Sw.) R.Br. ex Roem. \& Schult. & 6,21 & 6 \\
\hline PM3 & 3 & Vernonanthura discolor (Spreng.) H.Rob. & 9,07 & 8 \\
\hline PM3 & 4 & Vernonanthura discolor (Spreng.) H.Rob. & 9,23 & 7 \\
\hline PM3 & 5 & Vernonanthura discolor (Spreng.) H.Rob. & 12,10 & 6 \\
\hline PM3 & 6 & Vernonanthura discolor (Spreng.) H.Rob. & 10,66 & 8 \\
\hline PM3 & 7 & Vernonanthura discolor (Spreng.) H.Rob. & 5,73 & 4 \\
\hline PM3 & 8 & Baccharis semiserrata DC. & 6,68 & 5 \\
\hline PM3 & 8 & Baccharis semiserrata DC. & 8,28 & 4,5 \\
\hline PM3 & 8 & Baccharis semiserrata DC. & 5,09 & 4,5 \\
\hline PM4 & 1 & Vernonanthura discolor (Spreng.) H.Rob. & 8,75 & 8 \\
\hline PM4 & 2 & Piptocarpha regnellii (Sch.Bip.) Cabrera & 8,91 & 8 \\
\hline PM4 & 2 & Piptocarpha regnellii (Sch.Bip.) Cabrera & 7,00 & 7 \\
\hline PM4 & 2 & Piptocarpha regnellii (Sch.Bip.) Cabrera & 6,84 & 7 \\
\hline PM4 & 3 & Myrsine coriacea (Sw.) R.Br. ex Roem. \& Schult. & 4,93 & 8 \\
\hline PM4 & 4 & Vernonanthura discolor (Spreng.) H.Rob. & 9,23 & 8 \\
\hline PM4 & 5 & Clethra scabra Pers. & 4,93 & 2,5 \\
\hline PM4 & 6 & Baccharis semiserrata DC. & 8,75 & 4 \\
\hline PM4 & 6 & Baccharis semiserrata DC. & 7,80 & 4 \\
\hline PM4 & 7 & Vernonanthura discolor (Spreng.) H.Rob. & 8,59 & 8 \\
\hline PM4 & 7 & Vernonanthura discolor (Spreng.) H.Rob. & 10,98 & 8 \\
\hline PM4 & 7 & Vernonanthura discolor (Spreng.) H.Rob. & 6,37 & 8 \\
\hline PM4 & 8 & Baccharis semiserrata DC. & 7,64 & 5 \\
\hline PM4 & 8 & Baccharis semiserrata DC. & 5,73 & 5 \\
\hline PM4 & 9 & Piptocarpha regnellii (Sch.Bip.) Cabrera & 6,53 & 6,5 \\
\hline PM4 & 9 & Piptocarpha regnellii (Sch.Bip.) Cabrera & 10,03 & 6,5 \\
\hline PM4 & 9 & Piptocarpha regnellii (Sch.Bip.) Cabrera & 7,64 & 6,5 \\
\hline PM4 & 10 & Baccharis semiserrata DC. & 7,00 & 5 \\
\hline PM4 & 10 & Baccharis semiserrata DC. & 6,21 & 4,5 \\
\hline PM4 & 10 & Baccharis semiserrata DC. & 6,37 & 4 \\
\hline PM4 & 11 & Vernonanthura discolor (Spreng.) H.Rob. & 6,05 & 5 \\
\hline PM4 & 11 & Vernonanthura discolor (Spreng.) H.Rob. & 11,65 & 8 \\
\hline PM4 & 12 & Vernonanthura discolor (Spreng.) H.Rob. & 13,05 & 9 \\
\hline PM5 & 1 & Vernonanthura discolor (Spreng.) H.Rob. & 6,05 & 8 \\
\hline PM5 & 1 & Vernonanthura discolor (Spreng.) H.Rob. & 6,84 & 8 \\
\hline PM5 & 1 & Vernonanthura discolor (Spreng.) H.Rob. & 4,77 & 6 \\
\hline PM5 & 2 & Vernonanthura discolor (Spreng.) H.Rob. & 7,32 & 8 \\
\hline PM5 & 3 & Vernonanthura discolor (Spreng.) H.Rob. & 11,62 & 8 \\
\hline PM5 & 3 & Vernonanthura discolor (Spreng.) H.Rob. & 7,96 & 7 \\
\hline PM5 & 3 & Vernonanthura discolor (Spreng.) H.Rob. & 9,39 & 9 \\
\hline PM5 & 3 & Vernonanthura discolor (Spreng.) H.Rob. & 12,73 & 9 \\
\hline PM5 & 4 & Vernonanthura discolor (Spreng.) H.Rob. & 6,37 & 8 \\
\hline PM5 & 5 & Vernonanthura discolor (Spreng.) H.Rob. & 15,60 & 10 \\
\hline PM5 & 6 & Vernonanthura discolor (Spreng.) H.Rob. & 13,05 & 9 \\
\hline PM5 & 6 & Vernonanthura discolor (Spreng.) H.Rob. & 4,77 & 5 \\
\hline PM5 & 6 & Vernonanthura discolor (Spreng.) H.Rob. & 13,21 & 9 \\
\hline PM5 & 7 & Vernonanthura discolor (Spreng.) H.Rob. & 8,91 & 8 \\
\hline PM5 & 8 & Clethra scabra Pers. & 4,93 & 3,5 \\
\hline
\end{tabular}




\begin{tabular}{|c|c|c|c|c|}
\hline PM5 & 9 & Vernonanthura discolor (Spreng.) H.Rob. & 9,87 & 9 \\
\hline PM5 & 10 & $\begin{array}{l}\text { Symphyopappus itatiayensis (Hieron.) R.M.King \& } \\
\text { H.Rob. }\end{array}$ & 6,53 & 5 \\
\hline PM5 & 10 & $\begin{array}{l}\text { Symphyopappus itatiayensis (Hieron.) R.M.King \& } \\
\text { H.Rob. }\end{array}$ & 4,77 & 5 \\
\hline PM5 & 11 & $\begin{array}{l}\text { Symphyopappus itatiayensis (Hieron.) R.M.King \& } \\
\text { H.Rob. }\end{array}$ & 5,09 & 6 \\
\hline PM5 & 11 & $\begin{array}{l}\text { Symphyopappus itatiayensis (Hieron.) R.M.King \& } \\
\text { H.Rob. }\end{array}$ & 4,77 & 2 \\
\hline PM5 & 12 & Vernonanthura discolor (Spreng.) H.Rob. & 4,93 & 7 \\
\hline PM5 & 12 & Vernonanthura discolor (Spreng.) H.Rob. & 7,48 & 8 \\
\hline PM5 & 13 & Clethra scabra Pers. & 5,73 & 4 \\
\hline PM5 & 13 & Clethra scabra Pers. & 5,19 & 4 \\
\hline PM5 & 14 & Vernonanthura discolor (Spreng.) H.Rob. & 15,28 & 9 \\
\hline PM5 & 15 & Piptocarpha axillaris (Less.) Baker & 8,28 & 7 \\
\hline PM5 & 15 & Piptocarpha axillaris (Less.) Baker & 9,23 & 6 \\
\hline PM6 & 1 & Vernonanthura discolor (Spreng.) H.Rob. & 12,89 & 8 \\
\hline PM6 & 2 & Vernonanthura discolor (Spreng.) H.Rob. & 9,55 & 7 \\
\hline PM6 & 3 & Vernonanthura discolor (Spreng.) H.Rob. & 5,09 & 7 \\
\hline PM6 & 4 & Vernonanthura discolor (Spreng.) H.Rob. & 15,44 & 10 \\
\hline PM6 & 5 & Piptocarpha regnellii (Sch.Bip.) Cabrera & 10,82 & 6 \\
\hline PM6 & 6 & Vernonanthura discolor (Spreng.) H.Rob. & 6,84 & 8 \\
\hline PM6 & 7 & Vernonanthura discolor (Spreng.) H.Rob. & 6,68 & 7 \\
\hline PM6 & 8 & Vernonanthura discolor (Spreng.) H.Rob. & 9,07 & 9 \\
\hline PM6 & 9 & Vernonanthura discolor (Spreng.) H.Rob. & 10,82 & 8 \\
\hline PM6 & 9 & Vernonanthura discolor (Spreng.) H.Rob. & 10,03 & 7 \\
\hline PM6 & 10 & Piptocarpha regnellii (Sch.Bip.) Cabrera & 6,21 & 5 \\
\hline PM6 & 10 & Piptocarpha regnellii (Sch.Bip.) Cabrera & 5,09 & 5 \\
\hline PM6 & 10 & Piptocarpha regnellii (Sch.Bip.) Cabrera & 5,89 & 5 \\
\hline PM6 & 11 & Vernonanthura discolor (Spreng.) H.Rob. & 8,91 & 7 \\
\hline PM6 & 12 & Piptocarpha regnellii (Sch.Bip.) Cabrera & 7,32 & 6 \\
\hline PM6 & 12 & Piptocarpha regnellii (Sch.Bip.) Cabrera & 9,39 & 6 \\
\hline PM6 & 12 & Piptocarpha regnellii (Sch.Bip.) Cabrera & 6,37 & 6 \\
\hline PM6 & 13 & Vernonanthura discolor (Spreng.) H.Rob. & 6,53 & 7 \\
\hline PM6 & 14 & Piptocarpha regnellii (Sch.Bip.) Cabrera & 9,71 & 6 \\
\hline PM6 & 14 & Piptocarpha regnellii (Sch.Bip.) Cabrera & 8,59 & 6 \\
\hline PM6 & 15 & Vernonanthura discolor (Spreng.) H.Rob. & 10,35 & 7 \\
\hline PM6 & 16 & Vernonanthura discolor (Spreng.) H.Rob. & 6,05 & 6 \\
\hline PM6 & 17 & Clethra scabra Pers. & 5,89 & 4 \\
\hline PM6 & 18 & Clethra scabra Pers. & 4,93 & 3 \\
\hline PM6 & 19 & Vernonanthura discolor (Spreng.) H.Rob. & 6,68 & 7 \\
\hline PM6 & 20 & Vernonanthura discolor (Spreng.) H.Rob. & 7,64 & 7 \\
\hline PM7 & 1 & Vernonanthura discolor (Spreng.) H.Rob. & 12,25 & 9 \\
\hline PM7 & 1 & Vernonanthura discolor (Spreng.) H.Rob. & 10,66 & 8 \\
\hline PM7 & 1 & Vernonanthura discolor (Spreng.) H.Rob. & 9,55 & 9 \\
\hline PM7 & 2 & Piptocarpha regnellii (Sch.Bip.) Cabrera & 10,50 & 5 \\
\hline PM7 & 2 & Myrsine coriacea (Sw.) R.Br. ex Roem. \& Schult. & 8,12 & 7 \\
\hline PM7 & 3 & Vernonanthura discolor (Spreng.) H.Rob. & 8,12 & 6 \\
\hline PM7 & 3 & Vernonanthura discolor (Spreng.) H.Rob. & 7,96 & 6 \\
\hline PM7 & 4 & Myrsine coriacea (Sw.) R.Br. ex Roem. \& Schult. & 12,41 & 7 \\
\hline PM7 & 5 & Vernonanthura discolor (Spreng.) H.Rob. & 9,87 & 9 \\
\hline
\end{tabular}




\begin{tabular}{|c|c|c|c|c|}
\hline PM7 & 6 & Vernonanthura discolor (Spreng.) H.Rob. & 10,35 & 9 \\
\hline PM7 & 7 & Myrsine coriacea (Sw.) R.Br. ex Roem. \& Schult. & 4,93 & 6 \\
\hline PM7 & 8 & Solanum lacerdae Dusén & 6,68 & 4 \\
\hline PM7 & 9 & Vernonanthura discolor (Spreng.) H.Rob. & 10,50 & 7 \\
\hline PM7 & 10 & Myrsine coriacea (Sw.) R.Br. ex Roem. \& Schult. & 5,19 & 4 \\
\hline PM7 & 11 & Vernonanthura discolor (Spreng.) H.Rob. & 15,60 & 9 \\
\hline PM7 & 11 & Vernonanthura discolor (Spreng.) H.Rob. & 11,62 & 8 \\
\hline PM7 & 12 & Clethra scabra Pers. & 3,98 & 4 \\
\hline PM7 & 12 & Clethra scabra Pers. & 4,93 & 4 \\
\hline PM7 & 13 & Myrsine coriacea (Sw.) R.Br. ex Roem. \& Schult. & 10,98 & 10 \\
\hline PM8 & 1 & Piptocarpha regnellii (Sch.Bip.) Cabrera & 9,07 & 5 \\
\hline PM8 & 2 & Vernonanthura discolor (Spreng.) H.Rob. & 7,32 & 9 \\
\hline PM8 & 2 & Vernonanthura discolor (Spreng.) H.Rob. & 8,59 & 9 \\
\hline PM8 & 2 & Vernonanthura discolor (Spreng.) H.Rob. & 9,39 & 9 \\
\hline PM8 & 3 & Vernonanthura discolor (Spreng.) H.Rob. & 6,37 & 9 \\
\hline PM8 & 4 & Vernonanthura discolor (Spreng.) H.Rob. & 12,57 & 10 \\
\hline PM8 & 4 & Vernonanthura discolor (Spreng.) H.Rob. & 14,96 & 10 \\
\hline PM8 & 5 & Vernonanthura discolor (Spreng.) H.Rob. & 10,66 & 8 \\
\hline PM8 & 5 & Vernonanthura discolor (Spreng.) H.Rob. & 7,16 & 8 \\
\hline PM8 & 6 & Vernonanthura discolor (Spreng.) H.Rob. & 5,73 & 7 \\
\hline PM8 & 7 & Vernonanthura discolor (Spreng.) H.Rob. & 7,96 & 9 \\
\hline PM8 & 8 & Vernonanthura discolor (Spreng.) H.Rob. & 6,68 & 9 \\
\hline PM8 & 9 & Vernonanthura discolor (Spreng.) H.Rob. & 11,62 & 10 \\
\hline PM8 & 9 & Vernonanthura discolor (Spreng.) H.Rob. & 5,73 & 7 \\
\hline PM8 & 10 & Vernonanthura discolor (Spreng.) H.Rob. & 12,41 & 10 \\
\hline PM8 & 11 & Piptocarpha regnellii (Sch.Bip.) Cabrera & 9,39 & 7 \\
\hline PM8 & 12 & Vernonanthura discolor (Spreng.) H.Rob. & 18,46 & 12 \\
\hline PM8 & 13 & Vernonanthura discolor (Spreng.) H.Rob. & 9,87 & 11 \\
\hline PM8 & 14 & Piptocarpha regnellii (Sch.Bip.) Cabrera & 7,48 & 6 \\
\hline PM8 & 15 & Vernonanthura discolor (Spreng.) H.Rob. & 12,57 & 9 \\
\hline PM8 & 16 & Vernonanthura discolor (Spreng.) H.Rob. & 10,82 & 9 \\
\hline PM8 & 17 & Myrsine coriacea (Sw.) R.Br. ex Roem. \& Schult. & 7,32 & 8 \\
\hline PM8 & 18 & Piptocarpha regnellii (Sch.Bip.) Cabrera & 8,59 & 5 \\
\hline PM8 & 19 & Vernonanthura discolor (Spreng.) H.Rob. & 6,21 & 5 \\
\hline PM8 & 20 & Vernonanthura discolor (Spreng.) H.Rob. & 5,25 & 6 \\
\hline PM8 & 21 & Vernonanthura discolor (Spreng.) H.Rob. & 3,82 & 10 \\
\hline PM8 & 22 & Vernonanthura discolor (Spreng.) H.Rob. & 6,53 & 7 \\
\hline PM8 & 23 & Vernonanthura discolor (Spreng.) H.Rob. & 5,57 & 6 \\
\hline PM8 & 24 & Piptocarpha axillaris (Less.) Baker & 7,16 & 6 \\
\hline PM8 & 25 & Piptocarpha axillaris (Less.) Baker & 7,00 & 6 \\
\hline PM8 & 26 & Piptocarpha axillaris (Less.) Baker & 12,41 & 8 \\
\hline PM8 & 27 & Piptocarpha axillaris (Less.) Baker & 9,55 & 8 \\
\hline PM8 & 28 & Vernonanthura discolor (Spreng.) H.Rob. & 5,09 & 6 \\
\hline PM8 & 29 & Piptocarpha regnellii (Sch.Bip.) Cabrera & 9,07 & 7 \\
\hline PM8 & 30 & Vernonanthura discolor (Spreng.) H.Rob. & 9,23 & 9 \\
\hline PM8 & 31 & Piptocarpha regnellii (Sch.Bip.) Cabrera & 10,50 & 8 \\
\hline PM8 & 32 & Piptocarpha regnellii (Sch.Bip.) Cabrera & 8,91 & 8 \\
\hline PM8 & 33 & Myrsine coriacea (Sw.) R.Br. ex Roem. \& Schult. & 6,68 & 9 \\
\hline PM8 & 34 & Vernonanthura discolor (Spreng.) H.Rob. & 11,46 & 12 \\
\hline PM8 & 34 & Vernonanthura discolor (Spreng.) H.Rob. & 6,05 & 8 \\
\hline
\end{tabular}




\begin{tabular}{|c|c|c|c|c|}
\hline PM8 & 35 & Piptocarpha regnellii (Sch.Bip.) Cabrera & 5,09 & 6 \\
\hline PM9 & 1 & Vernonanthura discolor (Spreng.) H.Rob. & 8,12 & 8 \\
\hline PM9 & 2 & Piptocarpha regnellii (Sch.Bip.) Cabrera & 8,44 & 7 \\
\hline PM9 & 3 & Piptocarpha regnellii (Sch.Bip.) Cabrera & 5,89 & 5 \\
\hline PM9 & 4 & Vernonanthura discolor (Spreng.) H.Rob. & 7,64 & 9 \\
\hline PM9 & 5 & Vernonanthura discolor (Spreng.) H.Rob. & 9,07 & 9 \\
\hline PM9 & 6 & Piptocarpha regnellii (Sch.Bip.) Cabrera & 11,62 & 7 \\
\hline PM9 & 7 & Piptocarpha regnellii (Sch.Bip.) Cabrera & 7,16 & 5 \\
\hline PM9 & 8 & Piptocarpha regnellii (Sch.Bip.) Cabrera & 7,00 & 4,5 \\
\hline PM9 & 8 & Piptocarpha regnellii (Sch.Bip.) Cabrera & 8,44 & 6 \\
\hline PM9 & 9 & Piptocarpha regnellii (Sch.Bip.) Cabrera & 6,84 & 7 \\
\hline PM9 & 10 & Piptocarpha regnellii (Sch.Bip.) Cabrera & 6,05 & 6 \\
\hline PM9 & 10 & Piptocarpha regnellii (Sch.Bip.) Cabrera & 5,41 & 7 \\
\hline PM9 & 10 & Piptocarpha regnellii (Sch.Bip.) Cabrera & 5,57 & 6 \\
\hline PM9 & 11 & Myrsine coriacea (Sw.) R.Br. ex Roem. \& Schult. & 5,41 & 8 \\
\hline PM9 & 12 & Vernonanthura discolor (Spreng.) H.Rob. & 6,68 & 8 \\
\hline PM9 & 13 & Vernonanthura discolor (Spreng.) H.Rob. & 7,16 & 8 \\
\hline PM9 & 13 & Vernonanthura discolor (Spreng.) H.Rob. & 6,05 & 7 \\
\hline PM9 & 14 & Piptocarpha regnellii (Sch.Bip.) Cabrera & 7,48 & 8 \\
\hline PM9 & 15 & Vernonanthura discolor (Spreng.) H.Rob. & 5,09 & 6 \\
\hline PM9 & 15 & Vernonanthura discolor (Spreng.) H.Rob. & 7,96 & 6 \\
\hline PM9 & 15 & Vernonanthura discolor (Spreng.) H.Rob. & 5,89 & 5 \\
\hline PM9 & 16 & Vernonanthura discolor (Spreng.) H.Rob. & 6,68 & 8 \\
\hline PM9 & 17 & Piptocarpha regnellii (Sch.Bip.) Cabrera & 7,48 & 6 \\
\hline PM9 & 17 & Piptocarpha regnellii (Sch.Bip.) Cabrera & 7,64 & 6 \\
\hline PM9 & 17 & Piptocarpha regnellii (Sch.Bip.) Cabrera & 7,80 & 6 \\
\hline PM9 & 18 & Piptocarpha regnellii (Sch.Bip.) Cabrera & 8,59 & 7 \\
\hline PM9 & 19 & Piptocarpha regnellii (Sch.Bip.) Cabrera & 7,00 & 6 \\
\hline PM9 & 20 & Vernonanthura discolor (Spreng.) H.Rob. & 4,93 & 6 \\
\hline PM9 & 21 & Vernonanthura discolor (Spreng.) H.Rob. & 10,19 & 9 \\
\hline PM9 & 22 & Piptocarpha regnellii (Sch.Bip.) Cabrera & 5,57 & 5 \\
\hline PM9 & 23 & Vernonanthura discolor (Spreng.) H.Rob. & 7,32 & 7 \\
\hline PM9 & 24 & Vernonanthura discolor (Spreng.) H.Rob. & 5,57 & 6 \\
\hline PM9 & 25 & Vernonanthura discolor (Spreng.) H.Rob. & 6,53 & 7 \\
\hline PM9 & 26 & Piptocarpha regnellii (Sch.Bip.) Cabrera & 9,07 & 8 \\
\hline PM9 & 27 & Myrsine coriacea (Sw.) R.Br. ex Roem. \& Schult. & 5,19 & 7 \\
\hline PM9 & 28 & Myrsine coriacea (Sw.) R.Br. ex Roem. \& Schult. & 4,77 & 7 \\
\hline PM9 & 29 & Piptocarpha axillaris (Less.) Baker & 8,59 & 7 \\
\hline PM9 & 29 & Piptocarpha axillaris (Less.) Baker & 7,64 & 7 \\
\hline PM9 & 30 & Vernonanthura discolor (Spreng.) H.Rob. & 7,48 & 8 \\
\hline PM9 & 30 & Vernonanthura discolor (Spreng.) H.Rob. & 9,87 & 8 \\
\hline PM9 & 30 & Vernonanthura discolor (Spreng.) H.Rob. & 9,07 & 8 \\
\hline PM9 & 31 & Vernonanthura discolor (Spreng.) H.Rob. & 9,39 & 8 \\
\hline PM9 & 32 & Piptocarpha regnellii (Sch.Bip.) Cabrera & 7,80 & 7 \\
\hline PM9 & 33 & Piptocarpha regnellii (Sch.Bip.) Cabrera & 6,53 & 7 \\
\hline PM9 & 33 & Piptocarpha regnellii (Sch.Bip.) Cabrera & 6,68 & 7 \\
\hline PM9 & 33 & Piptocarpha regnellii (Sch.Bip.) Cabrera & 7,48 & 7 \\
\hline PM10 & 1 & Vernonanthura discolor (Spreng.) H.Rob. & 7,00 & 8 \\
\hline PM10 & 2 & Piptocarpha regnellii (Sch.Bip.) Cabrera & 10,98 & 7 \\
\hline PM10 & 3 & Vernonanthura discolor (Spreng.) H.Rob. & 4,77 & 4 \\
\hline
\end{tabular}




\begin{tabular}{|c|c|c|c|c|}
\hline PM10 & 4 & Piptocarpha regnellii (Sch.Bip.) Cabrera & 10,50 & 6 \\
\hline PM10 & 5 & Piptocarpha regnellii (Sch.Bip.) Cabrera & 5,89 & 5 \\
\hline PM10 & 6 & Baccharis semiserrata DC. & 5,41 & 5 \\
\hline PM10 & 7 & Baccharis semiserrata DC. & 7,96 & 6 \\
\hline PM10 & 7 & Baccharis semiserrata DC. & 8,12 & 6 \\
\hline PM10 & 8 & Vernonanthura discolor (Spreng.) H.Rob. & 7,96 & 5 \\
\hline PM10 & 9 & $\begin{array}{l}\text { Symphyopappus itatiayensis (Hieron.) R.M.King \& } \\
\text { H.Rob. }\end{array}$ & 4,97 & 5 \\
\hline PM10 & 9 & $\begin{array}{l}\text { Symphyopappus itatiayensis (Hieron.) R.M.King \& } \\
\text { H.Rob. }\end{array}$ & 5,09 & 5 \\
\hline PM10 & 10 & Vernonanthura discolor (Spreng.) H.Rob. & 5,47 & 4 \\
\hline PM10 & 11 & Myrsine coriacea (Sw.) R.Br. ex Roem. \& Schult. & 5,25 & 4 \\
\hline PM10 & 12 & Piptocarpha axillaris (Less.) Baker & 4,93 & 5 \\
\hline PM10 & 12 & Piptocarpha axillaris (Less.) Baker & 4,93 & 5 \\
\hline PM10 & 13 & Piptocarpha axillaris (Less.) Baker & 8,12 & 6 \\
\hline PM10 & 14 & Piptocarpha regnellii (Sch.Bip.) Cabrera & 7,00 & 4,5 \\
\hline PM10 & 14 & Piptocarpha regnellii (Sch.Bip.) Cabrera & 7,80 & 6 \\
\hline PM10 & 14 & Piptocarpha regnellii (Sch.Bip.) Cabrera & 6,68 & 5 \\
\hline PM10 & 14 & Piptocarpha regnellii (Sch.Bip.) Cabrera & 8,44 & 7 \\
\hline PM10 & 15 & Myrsine coriacea (Sw.) R.Br. ex Roem. \& Schult. & 5,09 & 3,5 \\
\hline PM10 & 16 & Vernonanthura discolor (Spreng.) H.Rob. & 6,84 & 7 \\
\hline PM10 & 17 & Piptocarpha regnellii (Sch.Bip.) Cabrera & 7,64 & 6 \\
\hline PM10 & 17 & Piptocarpha regnellii (Sch.Bip.) Cabrera & 5,89 & 7 \\
\hline PM10 & 17 & Piptocarpha regnellii (Sch.Bip.) Cabrera & 9,17 & 7 \\
\hline PM10 & 18 & Piptocarpha regnellii (Sch.Bip.) Cabrera & 6,84 & 6 \\
\hline PM10 & 19 & Piptocarpha regnellii (Sch.Bip.) Cabrera & 7,00 & 6 \\
\hline PM10 & 19 & Piptocarpha regnellii (Sch.Bip.) Cabrera & 6,37 & 6 \\
\hline PM10 & 20 & Piptocarpha regnellii (Sch.Bip.) Cabrera & 10,03 & 6 \\
\hline PM10 & 21 & Piptocarpha axillaris (Less.) Baker & 5,09 & 5 \\
\hline PM10 & 22 & Piptocarpha regnellii (Sch.Bip.) Cabrera & 5,41 & 4 \\
\hline PM11 & 1 & Piptocarpha regnellii (Sch.Bip.) Cabrera & 7,32 & 7 \\
\hline PM11 & 2 & Piptocarpha regnellii (Sch.Bip.) Cabrera & 18,46 & 8 \\
\hline PM11 & 2 & Piptocarpha regnellii (Sch.Bip.) Cabrera & 12,57 & 8 \\
\hline PM11 & 3 & Piptocarpha regnellii (Sch.Bip.) Cabrera & 12,73 & 8 \\
\hline PM11 & 4 & Piptocarpha regnellii (Sch.Bip.) Cabrera & 4,77 & 4 \\
\hline PM11 & 5 & Vernonanthura discolor (Spreng.) H.Rob. & 6,05 & 8 \\
\hline PM11 & 6 & Piptocarpha regnellii (Sch.Bip.) Cabrera & 8,91 & 8 \\
\hline PM11 & 7 & Piptocarpha regnellii (Sch.Bip.) Cabrera & 6,21 & 6 \\
\hline PM11 & 8 & Piptocarpha angustifolia Dusén ex Malme & 8,98 & 8 \\
\hline PM11 & 8 & Piptocarpha angustifolia Dusén ex Malme & 7,32 & 8 \\
\hline PM11 & 9 & Vernonanthura discolor (Spreng.) H.Rob. & 5,73 & 8 \\
\hline PM11 & 10 & Piptocarpha regnellii (Sch.Bip.) Cabrera & 10,50 & 7 \\
\hline PM11 & 11 & Piptocarpha regnellii (Sch.Bip.) Cabrera & 7,32 & 6 \\
\hline PM11 & 12 & Vernonanthura discolor (Spreng.) H.Rob. & 5,89 & 9 \\
\hline PM11 & 13 & Ocotea odorifera (Vell.) Rohwer & 17,19 & 6 \\
\hline PM11 & 13 & Ocotea odorifera (Vell.) Rohwer & 12,83 & 6 \\
\hline PM11 & 14 & Myrsine coriacea (Sw.) R.Br. ex Roem. \& Schult. & 5,41 & 9 \\
\hline PM11 & 15 & Piptocarpha regnellii (Sch.Bip.) Cabrera & 5,73 & 5 \\
\hline PM11 & 16 & Vernonanthura discolor (Spreng.) H.Rob. & 4,93 & 5 \\
\hline PM11 & 17 & Piptocarpha regnellii (Sch.Bip.) Cabrera & 8,75 & 7 \\
\hline
\end{tabular}




\begin{tabular}{|c|c|c|c|c|}
\hline PM11 & 18 & Piptocarpha regnellii (Sch.Bip.) Cabrera & 12,10 & 9 \\
\hline PM11 & 19 & Vernonanthura discolor (Spreng.) H.Rob. & 8,91 & 8 \\
\hline PM11 & 20 & Piptocarpha angustifolia Dusén ex Malme & 9,87 & 8 \\
\hline PM11 & 20 & Piptocarpha angustifolia Dusén ex Malme & 10,19 & 8 \\
\hline PM11 & 21 & Vernonanthura discolor (Spreng.) H.Rob. & 5,41 & 8 \\
\hline PM11 & 22 & Piptocarpha axillaris (Less.) Baker & 6,21 & 8 \\
\hline PM11 & 22 & Piptocarpha axillaris (Less.) Baker & 4,93 & 8 \\
\hline PM11 & 23 & Myrsine coriacea (Sw.) R.Br. ex Roem. \& Schult. & 4,77 & 7 \\
\hline PM11 & 24 & Vernonanthura discolor (Spreng.) H.Rob. & 14,01 & 10 \\
\hline PM11 & 25 & Piptocarpha regnellii (Sch.Bip.) Cabrera & 14,64 & 8 \\
\hline PM11 & 25 & Piptocarpha regnellii (Sch.Bip.) Cabrera & 7,00 & 8 \\
\hline PM11 & 25 & Piptocarpha regnellii (Sch.Bip.) Cabrera & 5,57 & 6 \\
\hline PM12 & 1 & Vernonanthura discolor (Spreng.) H.Rob. & 9,55 & 8 \\
\hline PM12 & 2 & Clethra scabra Pers. & 4,93 & 5 \\
\hline PM12 & 3 & Vernonanthura discolor (Spreng.) H.Rob. & 7,64 & 5 \\
\hline PM12 & 4 & Vernonanthura discolor (Spreng.) H.Rob. & 10,50 & 7 \\
\hline PM12 & 5 & Vernonanthura discolor (Spreng.) H.Rob. & 7,70 & 7 \\
\hline PM12 & 6 & $\begin{array}{l}\text { Symphyopappus itatiayensis (Hieron.) R.M.King \& } \\
\text { H.Rob. }\end{array}$ & 11,78 & 5 \\
\hline PM12 & 7 & Vernonanthura discolor (Spreng.) H.Rob. & 8,28 & 8 \\
\hline PM12 & 7 & Vernonanthura discolor (Spreng.) H.Rob. & 6,84 & 8 \\
\hline PM12 & 8 & Vernonanthura discolor (Spreng.) H.Rob. & 7,19 & 7 \\
\hline PM12 & 9 & Vernonanthura discolor (Spreng.) H.Rob. & 11,62 & 8 \\
\hline PM12 & 10 & Baccharis semiserrata DC. & 7,00 & 5 \\
\hline PM13 & 1 & Baccharis semiserrata DC. & 8,28 & 5 \\
\hline PM13 & 2 & Piptocarpha regnellii (Sch.Bip.) Cabrera & 11,78 & 6 \\
\hline PM13 & 2 & Piptocarpha regnellii (Sch.Bip.) Cabrera & 7,80 & 4 \\
\hline PM13 & 3 & Vernonanthura discolor (Spreng.) H.Rob. & 5,41 & 5 \\
\hline PM13 & 4 & Vernonanthura discolor (Spreng.) H.Rob. & 8,12 & 7 \\
\hline PM13 & 5 & Vernonanthura discolor (Spreng.) H.Rob. & 8,75 & 6 \\
\hline PM13 & 6 & Vernonanthura discolor (Spreng.) H.Rob. & 9,87 & 7,5 \\
\hline PM13 & 7 & Vernonanthura discolor (Spreng.) H.Rob. & 7,70 & 6 \\
\hline PM13 & 7 & Vernonanthura discolor (Spreng.) H.Rob. & 7,32 & 6 \\
\hline PM13 & 7 & Vernonanthura discolor (Spreng.) H.Rob. & 6,91 & 6 \\
\hline PM13 & 8 & Piptocarpha regnellii (Sch.Bip.) Cabrera & 5,86 & 4 \\
\hline PM13 & 8 & Piptocarpha regnellii (Sch.Bip.) Cabrera & 8,28 & 6 \\
\hline PM13 & 8 & Piptocarpha regnellii (Sch.Bip.) Cabrera & 7,96 & 5 \\
\hline PM14 & - & - & - & - \\
\hline PM15 & 1 & Piptocarpha regnellii (Sch.Bip.) Cabrera & 5,73 & 3,5 \\
\hline PM15 & 2 & Vernonanthura discolor (Spreng.) H.Rob. & 8,09 & 7 \\
\hline PM15 & 3 & Vernonanthura discolor (Spreng.) H.Rob. & 5,73 & 7 \\
\hline PM15 & 3 & Vernonanthura discolor (Spreng.) H.Rob. & 8,12 & 7 \\
\hline PM15 & 4 & Piptocarpha regnellii (Sch.Bip.) Cabrera & 8,59 & 7 \\
\hline PM15 & 4 & Piptocarpha regnellii (Sch.Bip.) Cabrera & 10,60 & 7 \\
\hline PM15 & 5 & Vernonanthura discolor (Spreng.) H.Rob. & 8,12 & 7 \\
\hline PM15 & 5 & Vernonanthura discolor (Spreng.) H.Rob. & 9,01 & 7 \\
\hline PM15 & 6 & Piptocarpha regnellii (Sch.Bip.) Cabrera & 6,68 & 5 \\
\hline PM15 & 7 & Vernonanthura discolor (Spreng.) H.Rob. & 10,98 & 8 \\
\hline PM15 & 8 & Vernonanthura discolor (Spreng.) H.Rob. & 10,66 & 6,5 \\
\hline PM15 & 8 & Vernonanthura discolor (Spreng.) H.Rob. & 8,59 & 6,5 \\
\hline
\end{tabular}




\begin{tabular}{|c|c|c|c|c|}
\hline PM15 & 9 & Piptocarpha regnellii (Sch.Bip.) Cabrera & 11,87 & 7,5 \\
\hline R1 & 1 & Vernonanthura discolor (Spreng.) H.Rob. & 7,48 & 6 \\
\hline $\mathrm{R} 1$ & 2 & Vernonanthura discolor (Spreng.) H.Rob. & 9,23 & 7 \\
\hline R1 & 3 & Vernonanthura discolor (Spreng.) H.Rob. & 9,71 & 7 \\
\hline R1 & 3 & Vernonanthura discolor (Spreng.) H.Rob. & 8,12 & 6 \\
\hline $\mathrm{R} 1$ & 4 & Vernonanthura discolor (Spreng.) H.Rob. & 5,09 & 4 \\
\hline R1 & 5 & Vernonanthura discolor (Spreng.) H.Rob. & 8,91 & 6 \\
\hline $\mathrm{R} 1$ & 6 & Piptocarpha regnellii (Sch.Bip.) Cabrera & 11,78 & 5 \\
\hline R1 & 7 & Vernonanthura discolor (Spreng.) H.Rob. & 9,07 & 7 \\
\hline R1 & 7 & Vernonanthura discolor (Spreng.) H.Rob. & 6,21 & 5 \\
\hline $\mathrm{R} 1$ & 7 & Vernonanthura discolor (Spreng.) H.Rob. & 7,32 & 6 \\
\hline $\mathrm{R} 1$ & 8 & Vernonanthura discolor (Spreng.) H.Rob. & 6,05 & 4 \\
\hline $\mathrm{R} 1$ & 8 & Vernonanthura discolor (Spreng.) H.Rob. & 10,66 & 7 \\
\hline $\mathrm{R} 1$ & 9 & Vernonanthura discolor (Spreng.) H.Rob. & 4,84 & 4 \\
\hline $\mathrm{R} 1$ & 9 & Vernonanthura discolor (Spreng.) H.Rob. & 4,93 & 4 \\
\hline $\mathrm{R} 1$ & 9 & Vernonanthura discolor (Spreng.) H.Rob. & 4,93 & 4 \\
\hline R1 & 10 & Piptocarpha axillaris (Less.) Baker & 5,57 & 3 \\
\hline $\mathrm{R} 1$ & 11 & Vernonanthura discolor (Spreng.) H.Rob. & 10,19 & 6 \\
\hline R2 & 1 & Vernonanthura discolor (Spreng.) H.Rob. & 8,75 & 7 \\
\hline R2 & 1 & Vernonanthura discolor (Spreng.) H.Rob. & 5,25 & 5 \\
\hline $\mathrm{R} 2$ & 1 & Vernonanthura discolor (Spreng.) H.Rob. & 5,57 & 6 \\
\hline $\mathrm{R} 2$ & 2 & Piptocarpha axillaris (Less.) Baker & 5,16 & 4 \\
\hline $\mathrm{R} 2$ & 3 & Vernonanthura discolor (Spreng.) H.Rob. & 9,80 & 8 \\
\hline $\mathrm{R} 2$ & 3 & Vernonanthura discolor (Spreng.) H.Rob. & 11,78 & 8 \\
\hline R2 & 4 & Piptocarpha regnellii (Sch.Bip.) Cabrera & 6,11 & 4 \\
\hline R2 & 5 & Vernonanthura discolor (Spreng.) H.Rob. & 7,96 & 5 \\
\hline $\mathrm{R} 2$ & 6 & Myrsine coriacea (Sw.) R.Br. ex Roem. \& Schult. & 7,32 & 7 \\
\hline $\mathrm{R} 2$ & 7 & Piptocarpha regnellii (Sch.Bip.) Cabrera & 8,05 & 6 \\
\hline R2 & 7 & Piptocarpha regnellii (Sch.Bip.) Cabrera & 7,16 & 5 \\
\hline R2 & 8 & Piptocarpha regnellii (Sch.Bip.) Cabrera & 4,93 & 4 \\
\hline $\mathrm{R} 2$ & 9 & Aspidosperma tomentosum Mart. & 6,05 & 3,5 \\
\hline R3 & 1 & Vernonanthura discolor (Spreng.) H.Rob. & 5,41 & 5 \\
\hline R3 & 2 & Vernonanthura discolor (Spreng.) H.Rob. & 5,25 & 5 \\
\hline R3 & 3 & Vernonanthura discolor (Spreng.) H.Rob. & 6,84 & 7 \\
\hline R3 & 4 & Vernonanthura discolor (Spreng.) H.Rob. & 6,05 & 7 \\
\hline R3 & 5 & Vernonanthura discolor (Spreng.) H.Rob. & 7,64 & 6 \\
\hline $\mathrm{R} 4$ & 1 & Piptocarpha axillaris (Less.) Baker & 8,69 & 7 \\
\hline $\mathrm{R} 4$ & 1 & Piptocarpha axillaris (Less.) Baker & 7,00 & 7 \\
\hline $\mathrm{R} 4$ & 2 & Myrsine coriacea (Sw.) R.Br. ex Roem. \& Schult. & 6,75 & 6 \\
\hline $\mathrm{R} 4$ & 3 & Piptocarpha axillaris (Less.) Baker & 8,12 & 7 \\
\hline $\mathrm{R} 4$ & 4 & Vernonanthura discolor (Spreng.) H.Rob. & 10,82 & 10 \\
\hline $\mathrm{R} 4$ & 5 & Piptocarpha axillaris (Less.) Baker & 5,67 & 6 \\
\hline $\mathrm{R} 4$ & 6 & Piptocarpha axillaris (Less.) Baker & 8,91 & 7 \\
\hline R4 & 6 & Piptocarpha axillaris (Less.) Baker & 6,37 & 6 \\
\hline $\mathrm{R} 4$ & 7 & Vernonanthura discolor (Spreng.) H.Rob. & 7,16 & 8 \\
\hline $\mathrm{R} 4$ & 8 & Myrsine coriacea (Sw.) R.Br. ex Roem. \& Schult. & 6,05 & 7 \\
\hline $\mathrm{R} 4$ & 9 & Piptocarpha axillaris (Less.) Baker & 5,09 & 4 \\
\hline $\mathrm{R} 4$ & 10 & Vernonanthura discolor (Spreng.) H.Rob. & 7,86 & 8 \\
\hline R4 & 11 & Myrsine coriacea (Sw.) R.Br. ex Roem. \& Schult. & 6,46 & 8 \\
\hline R4 & 12 & Vernonanthura discolor (Spreng.) H.Rob. & 7,73 & 7 \\
\hline
\end{tabular}




\begin{tabular}{|c|c|c|c|c|}
\hline R4 & 13 & Piptocarpha axillaris (Less.) Baker & 5,79 & 4,5 \\
\hline R4 & 14 & Vernonanthura discolor (Spreng.) H.Rob. & 5,25 & 6 \\
\hline R4 & 15 & Vernonanthura discolor (Spreng.) H.Rob. & 5,89 & 8 \\
\hline R4 & 16 & Vernonanthura discolor (Spreng.) H.Rob. & 8,44 & 10 \\
\hline $\mathrm{R} 4$ & 16 & Vernonanthura discolor (Spreng.) H.Rob. & 8,28 & 10 \\
\hline R4 & 17 & Piptocarpha axillaris (Less.) Baker & 8,75 & 7 \\
\hline $\mathrm{R} 4$ & 18 & Ocotea puberula (Rich.) Nees & 5,57 & 5 \\
\hline R4 & 19 & Vernonanthura discolor (Spreng.) H.Rob. & 8,59 & 10 \\
\hline R4 & 20 & Piptocarpha axillaris (Less.) Baker & 9,17 & 10 \\
\hline R4 & 21 & Vernonanthura discolor (Spreng.) H.Rob. & 15,12 & 10 \\
\hline $\mathrm{R} 4$ & 22 & Myrsine coriacea (Sw.) R.Br. ex Roem. \& Schult. & 10,44 & 9 \\
\hline $\mathrm{R} 4$ & 23 & Piptocarpha axillaris (Less.) Baker & 6,68 & 5 \\
\hline $\mathrm{R} 4$ & 24 & Piptocarpha axillaris (Less.) Baker & 7,48 & 7 \\
\hline R4 & 25 & Vernonanthura discolor (Spreng.) H.Rob. & 9,07 & 9 \\
\hline $\mathrm{R} 4$ & 26 & Piptocarpha axillaris (Less.) Baker & 6,05 & 5 \\
\hline R5 & 1 & Vernonanthura discolor (Spreng.) H.Rob. & 6,84 & 7 \\
\hline R5 & 2 & Vernonanthura discolor (Spreng.) H.Rob. & 15,76 & 10 \\
\hline R5 & 2 & Vernonanthura discolor (Spreng.) H.Rob. & 12,67 & 10 \\
\hline R5 & 3 & Vernonanthura discolor (Spreng.) H.Rob. & 5,16 & 4 \\
\hline R5 & 3 & Vernonanthura discolor (Spreng.) H.Rob. & 8,28 & 7 \\
\hline R5 & 3 & Vernonanthura discolor (Spreng.) H.Rob. & 8,91 & 8 \\
\hline R5 & 4 & Vernonanthura discolor (Spreng.) H.Rob. & 6,68 & 7 \\
\hline R5 & 5 & Clethra scabra Pers. & 7,16 & 5 \\
\hline R5 & 6 & Vernonanthura discolor (Spreng.) H.Rob. & 12,10 & 9 \\
\hline $\mathrm{R} 5$ & 6 & Vernonanthura discolor (Spreng.) H.Rob. & 7,16 & 8 \\
\hline R5 & 7 & Vernonanthura discolor (Spreng.) H.Rob. & 10,66 & 7 \\
\hline R5 & 8 & Vernonanthura discolor (Spreng.) H.Rob. & 10,82 & 9 \\
\hline R5 & 9 & Vernonanthura discolor (Spreng.) H.Rob. & 9,87 & 7 \\
\hline R5 & 10 & Vernonanthura discolor (Spreng.) H.Rob. & 9,87 & 9 \\
\hline R5 & 11 & Vernonanthura discolor (Spreng.) H.Rob. & 6,53 & 8 \\
\hline R5 & 12 & Vernonanthura discolor (Spreng.) H.Rob. & 9,80 & 9 \\
\hline $\mathrm{R} 5$ & 13 & Piptocarpha axillaris (Less.) Baker & 9,93 & 8 \\
\hline R5 & 14 & Myrsine coriacea (Sw.) R.Br. ex Roem. \& Schult. & 6,05 & 8 \\
\hline R5 & 15 & Vernonanthura discolor (Spreng.) H.Rob. & 11,62 & 9 \\
\hline $\mathrm{R} 5$ & 16 & Vernonanthura discolor (Spreng.) H.Rob. & 9,93 & 10 \\
\hline R5 & 16 & Vernonanthura discolor (Spreng.) H.Rob. & 5,41 & 8 \\
\hline R5 & 17 & Vernonanthura discolor (Spreng.) H.Rob. & 8,47 & 10 \\
\hline $\mathrm{R} 5$ & 18 & Vernonanthura discolor (Spreng.) H.Rob. & 8,21 & 10 \\
\hline R5 & 18 & Vernonanthura discolor (Spreng.) H.Rob. & 10,82 & 10 \\
\hline $\mathrm{R} 5$ & 19 & Vernonanthura discolor (Spreng.) H.Rob. & 7,32 & 6 \\
\hline R5 & 19 & Vernonanthura discolor (Spreng.) H.Rob. & 13,05 & 9 \\
\hline R6 & 1 & Piptocarpha axillaris (Less.) Baker & 4,84 & 4 \\
\hline R6 & 2 & Piptocarpha axillaris (Less.) Baker & 8,05 & 7 \\
\hline R6 & 3 & Piptocarpha regnellii (Sch.Bip.) Cabrera & 8,40 & 6 \\
\hline R6 & 4 & Piptocarpha axillaris (Less.) Baker & 6,68 & 7 \\
\hline R6 & 5 & Vernonanthura discolor (Spreng.) H.Rob. & 9,87 & 9 \\
\hline R6 & 5 & Vernonanthura discolor (Spreng.) H.Rob. & 8,12 & 8 \\
\hline R6 & 6 & Piptocarpha axillaris (Less.) Baker & 5,25 & 5 \\
\hline R6 & 7 & Vernonanthura discolor (Spreng.) H.Rob. & 6,43 & 7 \\
\hline R6 & 8 & Vernonanthura discolor (Spreng.) H.Rob. & 5,73 & 7 \\
\hline
\end{tabular}




\begin{tabular}{|c|c|c|c|c|}
\hline R6 & 9 & Piptocarpha axillaris (Less.) Baker & 5,41 & 5 \\
\hline R6 & 10 & Piptocarpha axillaris (Less.) Baker & 5,89 & 7 \\
\hline R6 & 11 & Vernonanthura discolor (Spreng.) H.Rob. & 5,89 & 6 \\
\hline R6 & 12 & Piptocarpha regnellii (Sch.Bip.) Cabrera & 8,28 & 6 \\
\hline R6 & 13 & Myrsine coriacea (Sw.) R.Br. ex Roem. \& Schult. & 4,84 & 6 \\
\hline R6 & 14 & Vernonanthura discolor (Spreng.) H.Rob. & 6,65 & 6 \\
\hline R6 & 15 & Vernonanthura discolor (Spreng.) H.Rob. & 6,11 & 5 \\
\hline R6 & 16 & Piptocarpha axillaris (Less.) Baker & 9,87 & 8 \\
\hline R6 & 17 & Piptocarpha axillaris (Less.) Baker & 5,35 & 5 \\
\hline R6 & 17 & Piptocarpha axillaris (Less.) Baker & 6,68 & 5 \\
\hline R6 & 18 & Myrsine coriacea (Sw.) R.Br. ex Roem. \& Schult. & 6,84 & 6 \\
\hline R6 & 18 & Myrsine coriacea (Sw.) R.Br. ex Roem. \& Schult. & 8,75 & 10 \\
\hline R6 & 19 & Piptocarpha angustifolia Dusén ex Malme & 6,43 & 6 \\
\hline R6 & 19 & Piptocarpha angustifolia Dusén ex Malme & 8,91 & 6 \\
\hline R6 & 20 & Vernonanthura discolor (Spreng.) H.Rob. & 7,64 & 7 \\
\hline R6 & 20 & Vernonanthura discolor (Spreng.) H.Rob. & 6,37 & 6 \\
\hline R6 & 21 & Piptocarpha regnellii (Sch.Bip.) Cabrera & 7,00 & 5 \\
\hline R6 & 21 & Piptocarpha regnellii (Sch.Bip.) Cabrera & 7,00 & 6 \\
\hline R6 & 21 & Piptocarpha regnellii (Sch.Bip.) Cabrera & 10,35 & 6 \\
\hline R6 & 22 & Myrsine coriacea (Sw.) R.Br. ex Roem. \& Schult. & 5,73 & 8 \\
\hline R6 & 23 & Vernonanthura discolor (Spreng.) H.Rob. & 8,28 & 7 \\
\hline R6 & 24 & Piptocarpha axillaris (Less.) Baker & 7,70 & 6 \\
\hline R6 & 25 & Vernonanthura discolor (Spreng.) H.Rob. & 6,81 & 5 \\
\hline R6 & 26 & Piptocarpha axillaris (Less.) Baker & 4,77 & 4 \\
\hline R6 & 27 & Piptocarpha axillaris (Less.) Baker & 6,68 & 6 \\
\hline R6 & 28 & Vernonanthura discolor (Spreng.) H.Rob. & 5,73 & 5 \\
\hline R6 & 29 & Piptocarpha axillaris (Less.) Baker & 6,02 & 5 \\
\hline R6 & 30 & Piptocarpha regnellii (Sch.Bip.) Cabrera & 10,89 & 7 \\
\hline R6 & 31 & Vernonanthura discolor (Spreng.) H.Rob. & 9,23 & 7 \\
\hline R6 & 31 & Vernonanthura discolor (Spreng.) H.Rob. & 4,93 & 4 \\
\hline R6 & 31 & Vernonanthura discolor (Spreng.) H.Rob. & 7,96 & 6 \\
\hline R6 & 32 & Piptocarpha axillaris (Less.) Baker & 7,64 & 5 \\
\hline R6 & 33 & Vernonanthura discolor (Spreng.) H.Rob. & 6,37 & 6 \\
\hline R6 & 34 & Vernonanthura discolor (Spreng.) H.Rob. & 6,53 & 6 \\
\hline R6 & 35 & Piptocarpha regnellii (Sch.Bip.) Cabrera & 6,37 & 5 \\
\hline R6 & 36 & Piptocarpha axillaris (Less.) Baker & 5,57 & 5 \\
\hline R6 & 36 & Piptocarpha axillaris (Less.) Baker & 5,57 & 4 \\
\hline R7 & 1 & Piptocarpha axillaris (Less.) Baker & 7,00 & 4 \\
\hline R7 & 2 & Vernonanthura discolor (Spreng.) H.Rob. & 7,00 & 4 \\
\hline R7 & 2 & Vernonanthura discolor (Spreng.) H.Rob. & 5,09 & 4 \\
\hline R7 & 3 & Vernonanthura discolor (Spreng.) H.Rob. & 8,75 & 6 \\
\hline R8 & 1 & Vernonanthura discolor (Spreng.) H.Rob. & 6,46 & 5 \\
\hline R8 & 2 & Ocotea puberula (Rich.) Nees & 5,57 & 3 \\
\hline R8 & 3 & Vernonanthura discolor (Spreng.) H.Rob. & 7,32 & 5 \\
\hline R8 & 4 & Vernonanthura discolor (Spreng.) H.Rob. & 6,84 & 6 \\
\hline $\mathrm{R} 8$ & 5 & Vernonanthura discolor (Spreng.) H.Rob. & 7,16 & 6 \\
\hline R8 & 5 & Vernonanthura discolor (Spreng.) H.Rob. & 9,39 & 7 \\
\hline $\mathrm{R} 8$ & 5 & Vernonanthura discolor (Spreng.) H.Rob. & 9,17 & 5 \\
\hline R9 & 1 & Myrsine coriacea (Sw.) R.Br. ex Roem. \& Schult. & 4,77 & 3,5 \\
\hline $\mathrm{R} 10$ & 1 & Vernonanthura discolor (Spreng.) H.Rob. & 5,41 & 4 \\
\hline
\end{tabular}




\begin{tabular}{|l|c|l|c|c|} 
R10 & 2 & Vernonanthura discolor (Spreng.) H.Rob. & 10,03 & 6 \\
\hline R10 & 2 & Vernonanthura discolor (Spreng.) H.Rob. & 8,15 & 6 \\
\hline R11 & - & - & - & - \\
\hline R12 & 1 & Vernonanthura discolor (Spreng.) H.Rob. & 5,09 & 4,5 \\
\hline R12 & 2 & Ocotea puberula (Rich.) Nees & 7,00 & 3 \\
\hline R13 & 1 & Vernonanthura discolor (Spreng.) H.Rob. & 5,09 & 5 \\
\hline R13 & 2 & Vernonanthura discolor (Spreng.) H.Rob. & 7,80 & 7 \\
\hline R13 & 3 & Vernonanthura discolor (Spreng.) H.Rob. & 6,53 & 6 \\
\hline R13 & 3 & Vernonanthura discolor (Spreng.) H.Rob. & 7,64 & 6 \\
\hline R13 & 4 & Clethra scabra Pers. & 4,87 & 3 \\
\hline R14 & 1 & Myrsine coriacea (Sw.) R.Br. ex Roem. \& Schult. & 6,37 & 5 \\
\hline R15 & 1 & Vernonanthura discolor (Spreng.) H.Rob. & 4,93 & 4 \\
\hline R15 & 1 & Vernonanthura discolor (Spreng.) H.Rob. & 4,93 & 4 \\
\hline R15 & 2 & Baccharis dracunculifolia DC. & 6,53 & 5 \\
\hline R15 & 2 & Baccharis dracunculifolia DC. & 4,93 & 5 \\
\hline R15 & 2 & Baccharis dracunculifolia DC. & 5,16 & 5 \\
\hline
\end{tabular}

Appendix 2. Basic field data 2: species found in lower layer

\begin{tabular}{|c|c|c|c|}
\hline $\begin{array}{l}\text { Sample } \\
\text { plot }\end{array}$ & Individual & Species & Height (m) \\
\hline PO1 & 1 & Vernonanthura discolor (Spreng.) H.Rob. & 1,8 \\
\hline PO1 & 2 & Vernonanthura discolor (Spreng.) H.Rob. & 1,8 \\
\hline PO1 & 3 & Piptocarpha angustifolia Dusén ex Malme & 3 \\
\hline PO1 & 3 & Piptocarpha angustifolia Dusén ex Malme & 3 \\
\hline PO1 & 4 & Piptocarpha axillaris (Less.) Baker & 2,5 \\
\hline PO1 & 4 & Piptocarpha axillaris (Less.) Baker & 2,5 \\
\hline PO1 & 5 & Vernonanthura discolor (Spreng.) H.Rob. & 1,8 \\
\hline PO1 & 6 & Piptocarpha regnellii (Sch.Bip.) Cabrera & 1,7 \\
\hline PO1 & 7 & Vernonanthura discolor (Spreng.) H.Rob. & 1,1 \\
\hline PO1 & 8 & $\begin{array}{l}\text { Symphyopappus itatiayensis (Hieron.) R.M.King \& } \\
\text { H.Rob. }\end{array}$ & 1,8 \\
\hline PO1 & 9 & Piptocarpha axillaris (Less.) Baker & 1,3 \\
\hline PO1 & 10 & Vernonanthura discolor (Spreng.) H.Rob. & 1,5 \\
\hline PO1 & 11 & Piptocarpha regnellii (Sch.Bip.) Cabrera & 1,9 \\
\hline PO1 & 12 & $\begin{array}{l}\text { Symphyopappus itatiayensis (Hieron.) R.M.King \& } \\
\text { H.Rob. }\end{array}$ & 2,5 \\
\hline PO1 & 13 & Vernonanthura discolor (Spreng.) H.Rob. & 2 \\
\hline PO1 & 14 & Ficus luschnathiana (Miq.) Miq. & 1,1 \\
\hline $\mathrm{PO} 2$ & 1 & Vernonanthura discolor (Spreng.) H.Rob. & 3 \\
\hline PO2 & 2 & Vernonanthura discolor (Spreng.) H.Rob. & 2,5 \\
\hline $\mathrm{PO} 2$ & 2 & Vernonanthura discolor (Spreng.) H.Rob. & 2,5 \\
\hline $\mathrm{PO} 2$ & 3 & Piptocarpha regnellii (Sch.Bip.) Cabrera & 3 \\
\hline $\mathrm{PO} 2$ & 3 & Piptocarpha regnellii (Sch.Bip.) Cabrera & 3 \\
\hline PO2 & 3 & Piptocarpha regnellii (Sch.Bip.) Cabrera & 2,5 \\
\hline $\mathrm{PO} 2$ & 4 & Vernonanthura discolor (Spreng.) H.Rob. & 0,6 \\
\hline $\mathrm{PO} 2$ & 5 & Piptocarpha axillaris (Less.) Baker & 0,8 \\
\hline $\mathrm{PO} 2$ & 6 & Baccharis dracunculifolia DC. & 1,5 \\
\hline $\mathrm{PO} 2$ & 7 & Leandra glazioviana Cogn. & 0,6 \\
\hline $\mathrm{PO} 2$ & 8 & Vernonanthura discolor (Spreng.) H.Rob. & 1,8 \\
\hline
\end{tabular}




\begin{tabular}{|c|c|c|c|}
\hline $\mathrm{PO} 2$ & 9 & Vernonanthura discolor (Spreng.) H.Rob. & 1,8 \\
\hline $\mathrm{PO} 2$ & 10 & Vernonanthura discolor (Spreng.) H.Rob. & 0,7 \\
\hline $\mathrm{PO} 2$ & 11 & Piptocarpha angustifolia Dusén ex Malme & 1,5 \\
\hline $\mathrm{PO} 2$ & 12 & Piptocarpha angustifolia Dusén ex Malme & 2 \\
\hline $\mathrm{PO} 2$ & 13 & Baccharis oblongifolia (Ruiz \& Pav.) Pers. & 2 \\
\hline $\mathrm{PO} 2$ & 14 & Vernonanthura discolor (Spreng.) H.Rob. & 2,5 \\
\hline $\mathrm{PO} 2$ & 14 & Vernonanthura discolor (Spreng.) H.Rob. & 2 \\
\hline $\mathrm{PO} 2$ & 14 & Vernonanthura discolor (Spreng.) H.Rob. & 1,8 \\
\hline $\mathrm{PO} 2$ & 15 & Myrsine coriacea (Sw.) R.Br. ex Roem. \& Schult. & 2 \\
\hline $\mathrm{PO} 2$ & 16 & Piptocarpha angustifolia Dusén ex Malme & 3 \\
\hline $\mathrm{PO} 2$ & 17 & Piptocarpha axillaris (Less.) Baker & 2,5 \\
\hline $\mathrm{PO} 2$ & 18 & Piptocarpha regnellii (Sch.Bip.) Cabrera & 1,5 \\
\hline $\mathrm{PO} 2$ & 19 & Piptocarpha axillaris (Less.) Baker & 2 \\
\hline $\mathrm{PO} 2$ & 20 & Vernonanthura discolor (Spreng.) H.Rob. & 0,6 \\
\hline $\mathrm{PO} 2$ & 21 & Solanum pseudoquina A.St.-Hil. & 2 \\
\hline $\mathrm{PO} 2$ & 21 & Solanum pseudoquina A.St.-Hil. & 2 \\
\hline $\mathrm{PO} 2$ & 22 & Clethra scabra Pers. & 0,7 \\
\hline $\mathrm{PO} 2$ & 23 & Piptocarpha angustifolia Dusén ex Malme & 3 \\
\hline $\mathrm{PO} 2$ & 24 & Vernonanthura discolor (Spreng.) H.Rob. & 1,8 \\
\hline $\mathrm{PO} 2$ & 25 & Vernonanthura discolor (Spreng.) H.Rob. & 3 \\
\hline $\mathrm{PO} 2$ & 26 & Vernonanthura discolor (Spreng.) H.Rob. & 2 \\
\hline $\mathrm{PO} 2$ & 27 & Piptocarpha axillaris (Less.) Baker & 0,8 \\
\hline $\mathrm{PO} 2$ & 28 & Piptocarpha regnellii (Sch.Bip.) Cabrera & 2,5 \\
\hline $\mathrm{PO} 2$ & 29 & Clethra scabra Pers. & 1,3 \\
\hline $\mathrm{PO} 2$ & 30 & Piptocarpha regnellii (Sch.Bip.) Cabrera & 2,5 \\
\hline $\mathrm{PO} 2$ & 31 & Piptocarpha regnellii (Sch.Bip.) Cabrera & 2,5 \\
\hline $\mathrm{PO} 2$ & 32 & Vernonanthura discolor (Spreng.) H.Rob. & 3 \\
\hline $\mathrm{PO} 2$ & 33 & Solanum pseudoquina A.St.-Hil. & 1,9 \\
\hline $\mathrm{PO} 2$ & 33 & Solanum pseudoquina A.St.-Hil. & 1,9 \\
\hline $\mathrm{PO} 2$ & 34 & Vernonanthura discolor (Spreng.) H.Rob. & 3 \\
\hline $\mathrm{PO} 2$ & 35 & Jacaranda puberula Cham. & 1 \\
\hline $\mathrm{PO} 2$ & 36 & Vernonanthura discolor (Spreng.) H.Rob. & $\overline{0,6}$ \\
\hline $\mathrm{PO} 2$ & 37 & Baccharis oblongifolia (Ruiz \& Pav.) Pers. & 1,8 \\
\hline $\mathrm{PO} 3$ & 1 & Vernonanthura discolor (Spreng.) H.Rob. & 2 \\
\hline $\mathrm{PO} 3$ & 2 & Piptocarpha regnellii (Sch.Bip.) Cabrera & 2 \\
\hline $\mathrm{PO} 3$ & 3 & Vernonanthura discolor (Spreng.) H.Rob. & 2,1 \\
\hline $\mathrm{PO} 3$ & 4 & Vernonanthura discolor (Spreng.) H.Rob. & 2,5 \\
\hline $\mathrm{PO} 3$ & 5 & Piptocarpha regnellii (Sch.Bip.) Cabrera & 2,5 \\
\hline $\mathrm{PO} 3$ & 6 & Vernonanthura discolor (Spreng.) H.Rob. & 3 \\
\hline $\mathrm{PO} 3$ & 7 & Vernonanthura discolor (Spreng.) H.Rob. & 3 \\
\hline PO3 & 8 & $\begin{array}{l}\text { Symphyopappus itatiayensis (Hieron.) R.M.King \& } \\
\text { H.Rob. }\end{array}$ & 1,8 \\
\hline $\mathrm{PO} 3$ & 9 & Vernonanthura discolor (Spreng.) H.Rob. & 1,3 \\
\hline $\mathrm{PO} 3$ & 10 & Vernonanthura discolor (Spreng.) H.Rob. & 1 \\
\hline $\mathrm{PO} 3$ & 11 & Vernonanthura discolor (Spreng.) H.Rob. & 1,8 \\
\hline $\mathrm{PO} 3$ & 12 & Vernonanthura discolor (Spreng.) H.Rob. & 1,5 \\
\hline $\mathrm{PO} 3$ & 13 & Vernonanthura discolor (Spreng.) H.Rob. & 2,5 \\
\hline $\mathrm{PO} 3$ & 14 & Vernonanthura discolor (Spreng.) H.Rob. & 2,5 \\
\hline $\mathrm{PO} 3$ & 15 & Piptocarpha regnellii (Sch.Bip.) Cabrera & 3 \\
\hline $\mathrm{PO} 3$ & 15 & Piptocarpha regnellii (Sch.Bip.) Cabrera & 2,5 \\
\hline
\end{tabular}




\begin{tabular}{|c|c|c|c|}
\hline PO3 & 16 & Vernonanthura discolor (Spreng.) H.Rob. & 2 \\
\hline PO3 & 17 & Vernonanthura discolor (Spreng.) H.Rob. & 2 \\
\hline PO3 & 18 & Vernonanthura discolor (Spreng.) H.Rob. & 1,8 \\
\hline PO3 & 19 & Miconia sellowiana Naudin & 1,5 \\
\hline PO3 & 20 & Vernonanthura discolor (Spreng.) H.Rob. & 2,5 \\
\hline PO4 & 1 & Myrsine umbellata Mart. & 1,3 \\
\hline PO4 & 2 & Vernonanthura discolor (Spreng.) H.Rob. & 1,9 \\
\hline PO4 & 3 & Piptocarpha axillaris (Less.) Baker & 2 \\
\hline PO4 & 4 & Vernonanthura discolor (Spreng.) H.Rob. & 2 \\
\hline PO4 & 4 & Vernonanthura discolor (Spreng.) H.Rob. & 2 \\
\hline PO4 & 4 & Vernonanthura discolor (Spreng.) H.Rob. & 2 \\
\hline PO4 & 4 & Vernonanthura discolor (Spreng.) H.Rob. & 2 \\
\hline PO4 & 4 & Vernonanthura discolor (Spreng.) H.Rob. & 1 \\
\hline PO4 & 4 & Vernonanthura discolor (Spreng.) H.Rob. & 1 \\
\hline PO4 & 4 & Vernonanthura discolor (Spreng.) H.Rob. & 0,8 \\
\hline PO4 & 4 & Vernonanthura discolor (Spreng.) H.Rob. & 0,8 \\
\hline PO4 & 5 & Myrsine umbellata Mart. & 1 \\
\hline PO4 & 6 & Myrsine umbellata Mart. & 0,6 \\
\hline PO4 & 7 & Myrsine umbellata Mart. & 0,9 \\
\hline PO4 & 8 & Myrsine umbellata Mart. & 0,8 \\
\hline PO4 & 9 & Vernonanthura discolor (Spreng.) H.Rob. & 1,8 \\
\hline PO4 & 10 & Vernonanthura discolor (Spreng.) H.Rob. & 1 \\
\hline PO4 & 11 & Piptocarpha angustifolia Dusén ex Malme & 2,5 \\
\hline PO4 & 12 & $\begin{array}{l}\text { Symphyopappus itatiayensis (Hieron.) R.M.King \& } \\
\text { H.Rob. }\end{array}$ & 1 \\
\hline PO4 & 13 & Vernonanthura discolor (Spreng.) H.Rob. & 1,6 \\
\hline PO4 & 14 & Baccharis dracunculifolia DC. & 2,5 \\
\hline PO4 & 15 & Piptocarpha axillaris (Less.) Baker & 1,6 \\
\hline $\mathrm{PO} 4$ & 16 & Piptocarpha axillaris (Less.) Baker & 2,5 \\
\hline PO4 & 16 & Piptocarpha axillaris (Less.) Baker & 2,5 \\
\hline PO4 & 17 & Vernonanthura discolor (Spreng.) H.Rob. & 1,8 \\
\hline PO4 & 17 & Vernonanthura discolor (Spreng.) H.Rob. & 1,8 \\
\hline PO4 & 18 & Vernonanthura discolor (Spreng.) H.Rob. & 1,8 \\
\hline PO4 & 18 & Vernonanthura discolor (Spreng.) H.Rob. & 1,8 \\
\hline PO4 & 18 & Vernonanthura discolor (Spreng.) H.Rob. & 1,8 \\
\hline PO4 & 18 & Vernonanthura discolor (Spreng.) H.Rob. & 1,8 \\
\hline PO4 & 19 & Solanum lacerdae Dusén & 2,5 \\
\hline PO4 & 20 & Piptocarpha angustifolia Dusén ex Malme & 1,5 \\
\hline PO4 & 21 & Vernonanthura discolor (Spreng.) H.Rob. & 2,5 \\
\hline PO4 & 21 & Vernonanthura discolor (Spreng.) H.Rob. & 0,5 \\
\hline PO4 & 21 & Vernonanthura discolor (Spreng.) H.Rob. & 1 \\
\hline PO4 & 21 & Vernonanthura discolor (Spreng.) H.Rob. & 2 \\
\hline PO4 & 21 & Vernonanthura discolor (Spreng.) H.Rob. & 0,8 \\
\hline PO4 & 21 & Vernonanthura discolor (Spreng.) H.Rob. & 0,7 \\
\hline PO4 & 21 & Vernonanthura discolor (Spreng.) H.Rob. & 2 \\
\hline PO4 & 21 & Vernonanthura discolor (Spreng.) H.Rob. & 2 \\
\hline $\mathrm{PO} 4$ & 22 & Piptocarpha regnellii (Sch.Bip.) Cabrera & 2 \\
\hline PO4 & 23 & Piptocarpha regnellii (Sch.Bip.) Cabrera & 1 \\
\hline $\mathrm{PO} 4$ & 24 & Piptocarpha regnellii (Sch.Bip.) Cabrera & 1,8 \\
\hline PO4 & 24 & Piptocarpha regnellii (Sch.Bip.) Cabrera & 2 \\
\hline
\end{tabular}




\begin{tabular}{|c|c|c|c|}
\hline PO4 & 25 & Piptocarpha angustifolia Dusén ex Malme & 1 \\
\hline PO4 & 26 & Vernonanthura discolor (Spreng.) H.Rob. & 2,5 \\
\hline $\mathrm{PO} 4$ & 26 & Vernonanthura discolor (Spreng.) H.Rob. & 2 \\
\hline PO5 & 1 & Vernonanthura discolor (Spreng.) H.Rob. & 2 \\
\hline PO5 & 2 & Vernonanthura discolor (Spreng.) H.Rob. & 1,8 \\
\hline PO5 & 2 & Vernonanthura discolor (Spreng.) H.Rob. & 2 \\
\hline PO5 & 2 & Vernonanthura discolor (Spreng.) H.Rob. & 2 \\
\hline PO5 & 3 & Clethra scabra Pers. & 0,8 \\
\hline PO5 & 4 & Piptocarpha axillaris (Less.) Baker & 3 \\
\hline PO5 & 5 & Vernonanthura discolor (Spreng.) H.Rob. & 2 \\
\hline PO5 & 6 & Clethra scabra Pers. & 2 \\
\hline PO5 & 7 & Handroanthus chrysotrichus (Mart. ex DC.) Mattos & 0,6 \\
\hline PO5 & 8 & Vernonanthura discolor (Spreng.) H.Rob. & 2,5 \\
\hline PO5 & 9 & Vernonanthura discolor (Spreng.) H.Rob. & 2,5 \\
\hline PO5 & 9 & Vernonanthura discolor (Spreng.) H.Rob. & 2 \\
\hline PO5 & 10 & $\begin{array}{l}\text { Symphyopappus itatiayensis (Hieron.) R.M.King \& } \\
\text { H.Rob. }\end{array}$ & 2 \\
\hline PO5 & 11 & $\begin{array}{l}\text { Symphyopappus itatiayensis (Hieron.) R.M.King \& } \\
\text { H.Rob. }\end{array}$ & 2 \\
\hline PO5 & 12 & Vernonanthura discolor (Spreng.) H.Rob. & 3 \\
\hline PO5 & 13 & Piptocarpha angustifolia Dusén ex Malme & 2,5 \\
\hline PO5 & 14 & Piptocarpha axillaris (Less.) Baker & 2 \\
\hline PO5 & 15 & Vernonanthura discolor (Spreng.) H.Rob. & 2,5 \\
\hline PO5 & 16 & Ficus luschnathiana (Miq.) Miq. & 2 \\
\hline PO6 & 1 & Piptocarpha angustifolia Dusén ex Malme & 2,5 \\
\hline PO6 & 2 & Vernonanthura discolor (Spreng.) H.Rob. & 2 \\
\hline PO6 & 3 & Clethra scabra Pers. & 1 \\
\hline PO6 & 4 & Vernonanthura discolor (Spreng.) H.Rob. & 1,8 \\
\hline PO6 & 5 & Zanthoxylum rhoifolium Lam. & 1,3 \\
\hline PO6 & 6 & Vernonanthura discolor (Spreng.) H.Rob. & 2,5 \\
\hline PO6 & 7 & Vernonanthura discolor (Spreng.) H.Rob. & 2 \\
\hline PO6 & 8 & Piptocarpha angustifolia Dusén ex Malme & 0,8 \\
\hline PO6 & 9 & Vernonanthura discolor (Spreng.) H.Rob. & 1,8 \\
\hline PO6 & 10 & Zanthoxylum rhoifolium Lam. & 1,8 \\
\hline PO6 & 11 & Piptocarpha regnellii (Sch.Bip.) Cabrera & 3 \\
\hline PO6 & 11 & Piptocarpha regnellii (Sch.Bip.) Cabrera & 2 \\
\hline PO6 & 11 & Piptocarpha regnellii (Sch.Bip.) Cabrera & 1,8 \\
\hline PO6 & 12 & Piptocarpha regnellii (Sch.Bip.) Cabrera & 2,5 \\
\hline PO6 & 13 & Piptocarpha regnellii (Sch.Bip.) Cabrera & 2 \\
\hline PO6 & 14 & Piptocarpha angustifolia Dusén ex Malme & 3,5 \\
\hline PO6 & 15 & Clethra scabra Pers. & 0,6 \\
\hline PO6 & 16 & Vernonanthura discolor (Spreng.) H.Rob. & 0,7 \\
\hline PO6 & 17 & Vernonanthura discolor (Spreng.) H.Rob. & 1,3 \\
\hline PO6 & 18 & Vernonanthura discolor (Spreng.) H.Rob. & 3 \\
\hline PO6 & 19 & Piptocarpha angustifolia Dusén ex Malme & 3 \\
\hline PO6 & 19 & Piptocarpha angustifolia Dusén ex Malme & 3 \\
\hline PO6 & 19 & Piptocarpha angustifolia Dusén ex Malme & 2 \\
\hline PO6 & 20 & Piptocarpha angustifolia Dusén ex Malme & 2,5 \\
\hline PO6 & 21 & Piptocarpha axillaris (Less.) Baker & 2 \\
\hline PO6 & 22 & Piptocarpha angustifolia Dusén ex Malme & 1 \\
\hline PO6 & 23 & Vernonanthura discolor (Spreng.) H.Rob. & 1,5 \\
\hline
\end{tabular}




\begin{tabular}{|c|c|c|c|}
\hline PO6 & 24 & Solanum mauritianum Scop. & 0,7 \\
\hline PO7 & 1 & Vernonanthura discolor (Spreng.) H.Rob. & 1,8 \\
\hline PO7 & 2 & Vernonanthura discolor (Spreng.) H.Rob. & 4 \\
\hline PO7 & 2 & Vernonanthura discolor (Spreng.) H.Rob. & 4 \\
\hline PO7 & 2 & Vernonanthura discolor (Spreng.) H.Rob. & 3,5 \\
\hline PO7 & 2 & Vernonanthura discolor (Spreng.) H.Rob. & 2,5 \\
\hline PO7 & 3 & Vernonanthura discolor (Spreng.) H.Rob. & 3,5 \\
\hline PO7 & 3 & Vernonanthura discolor (Spreng.) H.Rob. & 3 \\
\hline PO7 & 4 & Vernonanthura discolor (Spreng.) H.Rob. & 3,5 \\
\hline PO7 & 4 & Vernonanthura discolor (Spreng.) H.Rob. & 3,5 \\
\hline PO7 & 4 & Vernonanthura discolor (Spreng.) H.Rob. & 3 \\
\hline PO7 & 5 & Vernonanthura discolor (Spreng.) H.Rob. & 2,5 \\
\hline PO7 & 5 & Vernonanthura discolor (Spreng.) H.Rob. & 3,5 \\
\hline PO7 & 6 & Vernonanthura discolor (Spreng.) H.Rob. & 2,5 \\
\hline PO7 & 7 & Vernonanthura discolor (Spreng.) H.Rob. & 3,5 \\
\hline PO7 & 8 & Clethra scabra Pers. & 2 \\
\hline PO7 & 9 & Piptocarpha axillaris (Less.) Baker & 3 \\
\hline PO7 & 9 & Piptocarpha axillaris (Less.) Baker & 3,5 \\
\hline $\mathrm{PO} 7$ & 10 & $\begin{array}{l}\text { Symphyopappus itatiayensis (Hieron.) R.M.King \& } \\
\text { H.Rob. }\end{array}$ & 1,8 \\
\hline PO7 & 11 & Myrsine umbellata Mart. & 1,8 \\
\hline PO7 & 12 & Myrsine umbellata Mart. & 0,8 \\
\hline PO7 & 13 & Myrsine umbellata Mart. & 1 \\
\hline PO7 & 13 & Vernonanthura discolor (Spreng.) H.Rob. & 2,5 \\
\hline PO7 & 14 & Vernonanthura discolor (Spreng.) H.Rob. & 2,5 \\
\hline PO7 & 15 & Piptocarpha angustifolia Dusén ex Malme & 3 \\
\hline PO7 & 16 & $\begin{array}{l}\text { Symphyopappus itatiayensis (Hieron.) R.M.King \& } \\
\text { H.Rob. }\end{array}$ & 3 \\
\hline PO7 & 17 & Piptocarpha axillaris (Less.) Baker & 1,5 \\
\hline PO7 & 18 & Clethra scabra Pers. & 0,8 \\
\hline PO8 & 1 & Vernonanthura discolor (Spreng.) H.Rob. & 2,5 \\
\hline PO8 & 1 & Vernonanthura discolor (Spreng.) H.Rob. & 3 \\
\hline PO8 & 2 & Vernonanthura discolor (Spreng.) H.Rob. & 2 \\
\hline PO8 & 2 & Vernonanthura discolor (Spreng.) H.Rob. & 2 \\
\hline PO8 & 3 & Vernonanthura discolor (Spreng.) H.Rob. & 2 \\
\hline PO8 & 4 & $\begin{array}{l}\text { Symphyopappus itatiayensis (Hieron.) R.M.King \& } \\
\text { H.Rob. }\end{array}$ & 2,5 \\
\hline PO8 & 5 & Solanum mauritianum Scop. & 2,5 \\
\hline PO8 & 6 & $\begin{array}{l}\text { Symphyopappus itatiayensis (Hieron.) R.M.King \& } \\
\text { H.Rob. }\end{array}$ & 2 \\
\hline PO8 & 7 & Vernonanthura discolor (Spreng.) H.Rob. & 3 \\
\hline PO8 & 8 & Baccharis dracunculifolia DC. & 1,5 \\
\hline PO8 & 9 & Piptocarpha regnellii (Sch.Bip.) Cabrera & 2 \\
\hline PO8 & 10 & Vernonanthura discolor (Spreng.) H.Rob. & 2 \\
\hline PO8 & 11 & Piptocarpha angustifolia Dusén ex Malme & 2,5 \\
\hline PO8 & 12 & Vernonanthura discolor (Spreng.) H.Rob. & 2,5 \\
\hline PO8 & 12 & Vernonanthura discolor (Spreng.) H.Rob. & 2,5 \\
\hline PO8 & 13 & Piptocarpha angustifolia Dusén ex Malme & 2,5 \\
\hline PO8 & 14 & Miconia inconspicua Miq. & 1,8 \\
\hline PO8 & 15 & Vernonanthura discolor (Spreng.) H.Rob. & 1,5 \\
\hline PO8 & 16 & Piptocarpha axillaris (Less.) Baker & 0,7 \\
\hline
\end{tabular}




\begin{tabular}{|c|c|c|c|}
\hline PO8 & 17 & $\begin{array}{l}\text { Symphyopappus itatiayensis (Hieron.) R.M.King \& } \\
\text { H.Rob. }\end{array}$ & 3,5 \\
\hline PO8 & 18 & Vernonanthura discolor (Spreng.) H.Rob. & 1,5 \\
\hline PO8 & 19 & Myrsine coriacea (Sw.) R.Br. ex Roem. \& Schult. & 2,5 \\
\hline PO8 & 19 & Myrsine coriacea (Sw.) R.Br. ex Roem. \& Schult. & 2 \\
\hline PO8 & 20 & Piptocarpha axillaris (Less.) Baker & 2,5 \\
\hline PO8 & 21 & Piptocarpha angustifolia Dusén ex Malme & 1,5 \\
\hline PO9 & 1 & Solanum variabile Mart. & 2 \\
\hline PO9 & 2 & Piptocarpha regnellii (Sch.Bip.) Cabrera & 2 \\
\hline PO9 & 3 & Piptocarpha axillaris (Less.) Baker & 2 \\
\hline PO9 & 3 & Piptocarpha axillaris (Less.) Baker & 1,8 \\
\hline PO9 & 4 & Baccharis semiserrata DC. & 3 \\
\hline PO9 & 4 & Baccharis semiserrata DC. & 3 \\
\hline PO9 & 5 & Vernonanthura discolor (Spreng.) H.Rob. & 2 \\
\hline PO9 & 6 & Vernonanthura discolor (Spreng.) H.Rob. & 3 \\
\hline PO9 & 6 & Vernonanthura discolor (Spreng.) H.Rob. & 3 \\
\hline PO9 & 7 & Piptocarpha regnellii (Sch.Bip.) Cabrera & 1,5 \\
\hline PO9 & 8 & Piptocarpha axillaris (Less.) Baker & 2,5 \\
\hline PO9 & 9 & Piptocarpha axillaris (Less.) Baker & 1 \\
\hline PO9 & 10 & Solanum lacerdae Dusén & 2 \\
\hline PO9 & 11 & Piptocarpha axillaris (Less.) Baker & 2 \\
\hline PO9 & 12 & Vernonanthura discolor (Spreng.) H.Rob. & 2 \\
\hline PO9 & 13 & Vernonanthura discolor (Spreng.) H.Rob. & 2 \\
\hline PO9 & 14 & Vernonanthura discolor (Spreng.) H.Rob. & 2,3 \\
\hline PO9 & 15 & Piptocarpha axillaris (Less.) Baker & 2 \\
\hline PO9 & 16 & Vernonanthura discolor (Spreng.) H.Rob. & 0,7 \\
\hline PO9 & 17 & Vernonanthura discolor (Spreng.) H.Rob. & 2 \\
\hline PO9 & 17 & Vernonanthura discolor (Spreng.) H.Rob. & 2 \\
\hline PO9 & 18 & Vernonanthura discolor (Spreng.) H.Rob. & 2,5 \\
\hline PO9 & 19 & Vernonanthura discolor (Spreng.) H.Rob. & 1 \\
\hline PO9 & 20 & Vernonanthura discolor (Spreng.) H.Rob. & 3 \\
\hline PO9 & 20 & Vernonanthura discolor (Spreng.) H.Rob. & 3 \\
\hline PO9 & 20 & Vernonanthura discolor (Spreng.) H.Rob. & 2,5 \\
\hline PO9 & 21 & Baccharis semiserrata DC. & 2,5 \\
\hline PO9 & 21 & Baccharis semiserrata DC. & 2,5 \\
\hline PO9 & 22 & Baccharis semiserrata DC. & 3 \\
\hline PO10 & 1 & $\begin{array}{l}\text { Symphyopappus itatiayensis (Hieron.) R.M.King \& } \\
\text { H.Rob. }\end{array}$ & 1,5 \\
\hline PO10 & 2 & Vernonanthura discolor (Spreng.) H.Rob. & 2,5 \\
\hline PO10 & 3 & Piptocarpha angustifolia Dusén ex Malme & 2,5 \\
\hline PO10 & 4 & Vernonanthura discolor (Spreng.) H.Rob. & 1,8 \\
\hline PO10 & 5 & Vernonanthura discolor (Spreng.) H.Rob. & 1,6 \\
\hline PO10 & 6 & Solanum mauritianum Scop. & 2 \\
\hline PO10 & 6 & Solanum mauritianum Scop. & 2 \\
\hline PO10 & 7 & Vernonanthura discolor (Spreng.) H.Rob. & 2 \\
\hline PO10 & 8 & Vernonanthura discolor (Spreng.) H.Rob. & 3 \\
\hline PO10 & 9 & Piptocarpha angustifolia Dusén ex Malme & 2 \\
\hline PO10 & 10 & Vernonanthura discolor (Spreng.) H.Rob. & 2 \\
\hline PO10 & 11 & Baccharis semiserrata DC. & 3 \\
\hline PO10 & 12 & $\begin{array}{l}\text { Symphyopappus itatiayensis (Hieron.) R.M.King \& } \\
\text { H.Rob. }\end{array}$ & 3 \\
\hline
\end{tabular}




\begin{tabular}{|c|c|c|c|}
\hline PO10 & 12 & $\begin{array}{l}\text { Symphyopappus itatiayensis (Hieron.) R.M.King \& } \\
\text { H.Rob. }\end{array}$ & 2,5 \\
\hline PO10 & 13 & Vernonanthura discolor (Spreng.) H.Rob. & 3 \\
\hline PO10 & 13 & Vernonanthura discolor (Spreng.) H.Rob. & 2,5 \\
\hline PO10 & 13 & Vernonanthura discolor (Spreng.) H.Rob. & 2,5 \\
\hline PO10 & 14 & Vernonanthura discolor (Spreng.) H.Rob. & 3 \\
\hline PO11 & 1 & Piptocarpha regnellii (Sch.Bip.) Cabrera & 2,5 \\
\hline PO11 & 2 & Vernonanthura discolor (Spreng.) H.Rob. & 1,8 \\
\hline PO11 & 3 & Annona emarginata (Schltdl.) H.Rainer & 0,6 \\
\hline PO11 & 4 & Piptocarpha axillaris (Less.) Baker & 2,5 \\
\hline PO11 & 5 & Piptocarpha axillaris (Less.) Baker & 1,5 \\
\hline PO11 & 6 & Vernonanthura discolor (Spreng.) H.Rob. & 2 \\
\hline PO11 & 7 & Piptocarpha axillaris (Less.) Baker & 2,5 \\
\hline PO11 & 8 & Piptocarpha axillaris (Less.) Baker & 2,5 \\
\hline PO11 & 9 & Vernonanthura discolor (Spreng.) H.Rob. & 3 \\
\hline PO11 & 9 & Vernonanthura discolor (Spreng.) H.Rob. & 3 \\
\hline PO11 & 9 & Vernonanthura discolor (Spreng.) H.Rob. & 2 \\
\hline PO11 & 9 & Vernonanthura discolor (Spreng.) H.Rob. & 2 \\
\hline PO11 & 10 & Piptocarpha regnellii (Sch.Bip.) Cabrera & 2 \\
\hline PO11 & 10 & Piptocarpha regnellii (Sch.Bip.) Cabrera & 1,5 \\
\hline PO11 & 10 & Piptocarpha regnellii (Sch.Bip.) Cabrera & 1 \\
\hline PO11 & 11 & Piptocarpha axillaris (Less.) Baker & 2 \\
\hline PO11 & 12 & Vernonanthura discolor (Spreng.) H.Rob. & 3 \\
\hline PO11 & 13 & Baccharis semiserrata DC. & 3,5 \\
\hline PO11 & 14 & Piptocarpha regnellii (Sch.Bip.) Cabrera & 2 \\
\hline PO11 & 14 & Piptocarpha regnellii (Sch.Bip.) Cabrera & 1,5 \\
\hline PO11 & 15 & Piptocarpha axillaris (Less.) Baker & 3 \\
\hline PO11 & 16 & Piptocarpha regnellii (Sch.Bip.) Cabrera & 1 \\
\hline PO11 & 17 & Vernonanthura discolor (Spreng.) H.Rob. & 3 \\
\hline PO11 & 17 & Vernonanthura discolor (Spreng.) H.Rob. & 3 \\
\hline PO11 & 17 & Vernonanthura discolor (Spreng.) H.Rob. & 2,5 \\
\hline PO11 & 17 & Vernonanthura discolor (Spreng.) H.Rob. & 2,5 \\
\hline PO11 & 18 & Piptocarpha axillaris (Less.) Baker & 1,8 \\
\hline PO11 & 19 & Vernonanthura discolor (Spreng.) H.Rob. & 3 \\
\hline PO11 & 19 & Vernonanthura discolor (Spreng.) H.Rob. & 2,5 \\
\hline PO11 & 20 & Piptocarpha axillaris (Less.) Baker & 3 \\
\hline PO11 & 21 & Piptocarpha axillaris (Less.) Baker & 2,5 \\
\hline PO11 & 22 & $\begin{array}{l}\text { Symphyopappus itatiayensis (Hieron.) R.M.King \& } \\
\text { H.Rob. }\end{array}$ & 3 \\
\hline PO11 & 23 & Vernonanthura discolor (Spreng.) H.Rob. & 2,5 \\
\hline PO11 & 24 & Vernonanthura discolor (Spreng.) H.Rob. & 2,5 \\
\hline PO11 & 24 & Vernonanthura discolor (Spreng.) H.Rob. & 2 \\
\hline PO11 & 24 & Vernonanthura discolor (Spreng.) H.Rob. & 1,5 \\
\hline PO11 & 24 & Vernonanthura discolor (Spreng.) H.Rob. & 1,5 \\
\hline PO11 & 25 & Piptocarpha regnellii (Sch.Bip.) Cabrera & 3 \\
\hline PO11 & 26 & Piptocarpha axillaris (Less.) Baker & 1 \\
\hline PO11 & 27 & Vernonanthura discolor (Spreng.) H.Rob. & 1,5 \\
\hline PO11 & 28 & Baccharis semiserrata DC. & 5 \\
\hline PO11 & 28 & Baccharis semiserrata DC. & 2,5 \\
\hline PO11 & 29 & Vernonanthura discolor (Spreng.) H.Rob. & 2,5 \\
\hline PO11 & 30 & Vernonanthura discolor (Spreng.) H.Rob. & 1,8 \\
\hline
\end{tabular}




\begin{tabular}{|c|c|c|c|}
\hline PO11 & 31 & Piptocarpha angustifolia Dusén ex Malme & 2 \\
\hline PO11 & 32 & Piptocarpha axillaris (Less.) Baker & 2 \\
\hline PO11 & 32 & Piptocarpha axillaris (Less.) Baker & 2 \\
\hline PO11 & 32 & Piptocarpha axillaris (Less.) Baker & 1,5 \\
\hline PO11 & 33 & Vernonanthura discolor (Spreng.) H.Rob. & 2,5 \\
\hline PO11 & 34 & Baccharis oblongifolia (Ruiz \& Pav.) Pers. & 2,5 \\
\hline PO11 & 34 & Baccharis oblongifolia (Ruiz \& Pav.) Pers. & 2 \\
\hline PO11 & 34 & Baccharis oblongifolia (Ruiz \& Pav.) Pers. & 2 \\
\hline PO11 & 35 & Piptocarpha regnellii (Sch.Bip.) Cabrera & 1,8 \\
\hline PO11 & 36 & Clethra scabra Pers. & 1,8 \\
\hline PO11 & 36 & Clethra scabra Pers. & 1,8 \\
\hline PO11 & 37 & Piptocarpha regnellii (Sch.Bip.) Cabrera & 1,5 \\
\hline PO11 & 38 & Vernonanthura discolor (Spreng.) H.Rob. & 1 \\
\hline PO11 & 39 & Vernonanthura discolor (Spreng.) H.Rob. & 1,5 \\
\hline PO11 & 40 & Piptocarpha axillaris (Less.) Baker & 3,5 \\
\hline PO11 & 40 & Piptocarpha axillaris (Less.) Baker & 3,5 \\
\hline PO11 & 41 & Piptocarpha regnellii (Sch.Bip.) Cabrera & 3 \\
\hline PO11 & 42 & Myrsine coriacea (Sw.) R.Br. ex Roem. \& Schult. & 3 \\
\hline PO11 & 43 & Vernonanthura discolor (Spreng.) H.Rob. & 1 \\
\hline PO12 & 1 & Myrsine coriacea (Sw.) R.Br. ex Roem. \& Schult. & 1,8 \\
\hline PO12 & 2 & Baccharis semiserrata DC. & 1,8 \\
\hline PO12 & 3 & Vernonanthura discolor (Spreng.) H.Rob. & 2,5 \\
\hline PO12 & 4 & Vernonanthura discolor (Spreng.) H.Rob. & 2 \\
\hline PO12 & 5 & Vernonanthura discolor (Spreng.) H.Rob. & 1 \\
\hline PO12 & 6 & Piptocarpha axillaris (Less.) Baker & 1,8 \\
\hline PO12 & 6 & Piptocarpha axillaris (Less.) Baker & 1,5 \\
\hline PO12 & 7 & Piptocarpha axillaris (Less.) Baker & 2 \\
\hline PO12 & 7 & Piptocarpha axillaris (Less.) Baker & 1,8 \\
\hline PO12 & 8 & Clethra scabra Pers. & 0,5 \\
\hline PO12 & 9 & Piptocarpha regnellii (Sch.Bip.) Cabrera & 1 \\
\hline PO12 & 9 & Piptocarpha regnellii (Sch.Bip.) Cabrera & 1 \\
\hline PO12 & 10 & Vernonanthura discolor (Spreng.) H.Rob. & 0,5 \\
\hline PO12 & 11 & Baccharis semiserrata DC. & 1,5 \\
\hline PO12 & 12 & Clethra scabra Pers. & 0,6 \\
\hline PO12 & 13 & Myrsine umbellata Mart. & 0,5 \\
\hline PO12 & 14 & Baccharis semiserrata DC. & 4 \\
\hline PO12 & 14 & Baccharis semiserrata DC. & 4 \\
\hline PO12 & 14 & Baccharis semiserrata DC. & 4 \\
\hline PO12 & 14 & Baccharis semiserrata DC. & 4 \\
\hline PO12 & 14 & Baccharis semiserrata DC. & 4 \\
\hline PO12 & 14 & Baccharis semiserrata DC. & 4 \\
\hline PO12 & 15 & Baccharis semiserrata DC. & 4 \\
\hline PO12 & 16 & Clethra scabra Pers. & 1 \\
\hline PO12 & 17 & Baccharis semiserrata DC. & 4 \\
\hline PO12 & 17 & Baccharis semiserrata DC. & 4 \\
\hline PO12 & 17 & Baccharis semiserrata DC. & 4 \\
\hline PO12 & 17 & Baccharis semiserrata DC. & 4 \\
\hline PO12 & 17 & Baccharis semiserrata DC. & 3 \\
\hline PO12 & 17 & Baccharis semiserrata DC. & 3 \\
\hline PO12 & 17 & Baccharis semiserrata DC. & 3 \\
\hline
\end{tabular}




\begin{tabular}{|c|c|c|c|}
\hline PO12 & 17 & Baccharis semiserrata DC. & 3 \\
\hline PO13 & 1 & Myrsine umbellata Mart. & 1 \\
\hline PO13 & 2 & Baccharis semiserrata DC. & 3 \\
\hline PO13 & 3 & Piptocarpha axillaris (Less.) Baker & 3 \\
\hline PO13 & 3 & Piptocarpha axillaris (Less.) Baker & 2,5 \\
\hline PO13 & 4 & Piptocarpha angustifolia Dusén ex Malme & 1,7 \\
\hline PO13 & 5 & Vernonanthura discolor (Spreng.) H.Rob. & 1,7 \\
\hline PO13 & 6 & Myrsine umbellata Mart. & 1 \\
\hline PO14 & 1 & Solanum mauritianum Scop. & 1,8 \\
\hline PO14 & 2 & Piptocarpha angustifolia Dusén ex Malme & 1,8 \\
\hline PO14 & 3 & Vernonanthura discolor (Spreng.) H.Rob. & 1,5 \\
\hline PO15 & 1 & Baccharis semiserrata DC. & 4 \\
\hline PO15 & 2 & Piptocarpha angustifolia Dusén ex Malme & 3,5 \\
\hline PM1 & 1 & Piptocarpha regnellii (Sch.Bip.) Cabrera & 3 \\
\hline PM1 & 1 & Piptocarpha regnellii (Sch.Bip.) Cabrera & 3 \\
\hline PM1 & 2 & Myrsine coriacea (Sw.) R.Br. ex Roem. \& Schult. & 3 \\
\hline PM1 & 3 & Syagrus romanzoffiana (Cham.) Glassman & 1,8 \\
\hline PM1 & 4 & Miconia sellowiana Naudin & 1,8 \\
\hline PM1 & 5 & Myrcia splendens (Sw.) DC. & 0,6 \\
\hline PM1 & 6 & Myrsine coriacea (Sw.) R.Br. ex Roem. \& Schult. & 0,6 \\
\hline PM1 & 7 & Myrcia splendens (Sw.) DC. & 0,8 \\
\hline PM1 & 8 & Myrcia splendens (Sw.) DC. & 0,5 \\
\hline PM1 & 9 & Myrsine coriacea (Sw.) R.Br. ex Roem. \& Schult. & 0,6 \\
\hline PM1 & 10 & Inga vera subsp. affinis (DC.) T.D.Penn. & 0,5 \\
\hline PM1 & 11 & Vernonanthura discolor (Spreng.) H.Rob. & 0,5 \\
\hline PM1 & 12 & Vernonanthura discolor (Spreng.) H.Rob. & 0,6 \\
\hline PM1 & 13 & Vernonanthura discolor (Spreng.) H.Rob. & 5 \\
\hline PM1 & 14 & Myrsine coriacea (Sw.) R.Br. ex Roem. \& Schult. & 2 \\
\hline PM1 & 15 & Myrsine coriacea (Sw.) R.Br. ex Roem. \& Schult. & 2,5 \\
\hline PM1 & 16 & Vernonanthura discolor (Spreng.) H.Rob. & 4 \\
\hline PM2 & 1 & Vernonanthura discolor (Spreng.) H.Rob. & 1 \\
\hline PM2 & 2 & Campomanesia reitziana D.Legrand & 0,5 \\
\hline PM2 & 3 & Vernonanthura discolor (Spreng.) H.Rob. & 0,8 \\
\hline PM2 & 4 & Clethra scabra Pers. & 3 \\
\hline PM2 & 4 & Clethra scabra Pers. & 3 \\
\hline PM2 & 5 & Vernonanthura discolor (Spreng.) H.Rob. & 0,8 \\
\hline PM2 & 6 & Myrsine coriacea (Sw.) R.Br. ex Roem. \& Schult. & 2 \\
\hline PM2 & 7 & Syagrus romanzoffiana (Cham.) Glassman & 0,8 \\
\hline PM2 & 8 & Myrsine coriacea (Sw.) R.Br. ex Roem. \& Schult. & 1,5 \\
\hline PM2 & 9 & Syagrus romanzoffiana (Cham.) Glassman & 0,5 \\
\hline PM2 & 10 & Inga vera subsp. affinis (DC.) T.D.Penn. & 0,8 \\
\hline PM2 & 11 & Vernonanthura discolor (Spreng.) H.Rob. & 0,8 \\
\hline PM2 & 12 & Clethra scabra Pers. & 3 \\
\hline PM3 & 1 & Miconia tristis Spring & 0,8 \\
\hline PM3 & 2 & Myrsine coriacea (Sw.) R.Br. ex Roem. \& Schult. & 1,5 \\
\hline PM3 & 3 & Miconia sellowiana Naudin & 0,6 \\
\hline PM3 & 4 & Miconia tristis Spring & 0,6 \\
\hline PM3 & 5 & Myrsine coriacea (Sw.) R.Br. ex Roem. \& Schult. & 2,5 \\
\hline PM3 & 6 & Myrsine coriacea (Sw.) R.Br. ex Roem. \& Schult. & 3 \\
\hline PM3 & 7 & Myrsine coriacea (Sw.) R.Br. ex Roem. \& Schult. & 3 \\
\hline
\end{tabular}




\begin{tabular}{|c|c|c|c|}
\hline PM3 & 8 & Myrsine coriacea (Sw.) R.Br. ex Roem. \& Schult. & 3 \\
\hline PM3 & 9 & Solanum lacerdae Dusén & 3 \\
\hline PM3 & 10 & Clethra scabra Pers. & 2,5 \\
\hline PM3 & 10 & Clethra scabra Pers. & 2,5 \\
\hline PM3 & 11 & Vernonanthura discolor (Spreng.) H.Rob. & 0,8 \\
\hline PM3 & 12 & Vernonanthura discolor (Spreng.) H.Rob. & 0,5 \\
\hline PM4 & 1 & Clethra scabra Pers. & 3 \\
\hline PM4 & 1 & Clethra scabra Pers. & 3 \\
\hline PM4 & 1 & Clethra scabra Pers. & 3 \\
\hline PM4 & 2 & Vernonanthura discolor (Spreng.) H.Rob. & 2 \\
\hline PM4 & 3 & Myrsine coriacea (Sw.) R.Br. ex Roem. \& Schult. & 3 \\
\hline PM4 & 4 & Myrsine coriacea (Sw.) R.Br. ex Roem. \& Schult. & 3,5 \\
\hline PM4 & 4 & Myrsine coriacea (Sw.) R.Br. ex Roem. \& Schult. & 3,5 \\
\hline PM4 & 5 & Myrsine coriacea (Sw.) R.Br. ex Roem. \& Schult. & 2 \\
\hline PM4 & 6 & Vernonanthura discolor (Spreng.) H.Rob. & 2 \\
\hline PM4 & 7 & Vernonanthura discolor (Spreng.) H.Rob. & 2 \\
\hline PM4 & 8 & Myrsine coriacea (Sw.) R.Br. ex Roem. \& Schult. & 4 \\
\hline PM4 & 9 & Piptocarpha regnellii (Sch.Bip.) Cabrera & 2 \\
\hline PM4 & 10 & Clethra scabra Pers. & 3 \\
\hline PM4 & 11 & Vernonanthura discolor (Spreng.) H.Rob. & 1,5 \\
\hline PM4 & 12 & Dalbergia brasiliensis Vogel & 2 \\
\hline PM4 & 13 & Vernonanthura discolor (Spreng.) H.Rob. & 0,8 \\
\hline PM4 & 14 & Myrsine coriacea (Sw.) R.Br. ex Roem. \& Schult. & 1,5 \\
\hline PM5 & 1 & Clethra scabra Pers. & 2,5 \\
\hline PM5 & 1 & Clethra scabra Pers. & 2,5 \\
\hline PM5 & 2 & Myrsine coriacea (Sw.) R.Br. ex Roem. \& Schult. & 3 \\
\hline PM5 & 3 & Vernonanthura discolor (Spreng.) H.Rob. & 2 \\
\hline PM5 & 4 & Clethra scabra Pers. & 3 \\
\hline PM5 & 4 & Clethra scabra Pers. & 3 \\
\hline PM5 & 4 & Clethra scabra Pers. & 3 \\
\hline PM5 & 5 & Myrsine coriacea (Sw.) R.Br. ex Roem. \& Schult. & 1,5 \\
\hline PM5 & 6 & Myrsine coriacea (Sw.) R.Br. ex Roem. \& Schult. & 4 \\
\hline PM5 & 7 & Leandra carassana (DC.) Cogn. & 1,5 \\
\hline PM5 & 8 & Miconia tristis Spring & 0,6 \\
\hline PM5 & 9 & Miconia tristis Spring & 0,8 \\
\hline PM5 & 10 & Myrsine coriacea (Sw.) R.Br. ex Roem. \& Schult. & 2 \\
\hline PM5 & 11 & Vernonanthura discolor (Spreng.) H.Rob. & 1,5 \\
\hline PM5 & 12 & Miconia tristis Spring & 0,6 \\
\hline PM5 & 13 & Miconia tristis Spring & 0,8 \\
\hline PM5 & 14 & Miconia tristis Spring & 1 \\
\hline PM5 & 15 & Clethra scabra Pers. & 2 \\
\hline PM5 & 16 & Piptocarpha regnellii (Sch.Bip.) Cabrera & 3,5 \\
\hline PM5 & 17 & Nectandra oppositifolia Nees & 0,6 \\
\hline PM5 & 18 & Vernonanthura discolor (Spreng.) H.Rob. & 1 \\
\hline PM5 & 19 & Miconia tristis Spring & 0,6 \\
\hline PM5 & 20 & Myrsine coriacea (Sw.) R.Br. ex Roem. \& Schult. & 4 \\
\hline PM5 & 21 & Myrsine coriacea (Sw.) R.Br. ex Roem. \& Schult. & 3,5 \\
\hline PM5 & 21 & Myrsine coriacea (Sw.) R.Br. ex Roem. \& Schult. & 3,5 \\
\hline PM5 & 22 & Clethra scabra Pers. & 1,5 \\
\hline PM5 & 23 & Vernonanthura discolor (Spreng.) H.Rob. & 1 \\
\hline
\end{tabular}




\begin{tabular}{|c|c|c|c|}
\hline PM5 & 24 & Vernonanthura discolor (Spreng.) H.Rob. & 4 \\
\hline PM5 & 25 & Piptocarpha regnellii (Sch.Bip.) Cabrera & 3 \\
\hline PM5 & 26 & Piptocarpha regnellii (Sch.Bip.) Cabrera & 2 \\
\hline PM5 & 27 & Miconia tristis Spring & 4 \\
\hline PM5 & 28 & Vernonanthura discolor (Spreng.) H.Rob. & 2 \\
\hline PM5 & 29 & Myrsine coriacea (Sw.) R.Br. ex Roem. \& Schult. & 1,5 \\
\hline PM6 & 1 & Myrsine umbellata Mart. & 4 \\
\hline PM6 & 1 & Myrsine umbellata Mart. & 4 \\
\hline PM6 & 1 & Myrsine umbellata Mart. & 4 \\
\hline PM6 & 2 & Vernonanthura discolor (Spreng.) H.Rob. & 0,6 \\
\hline PM6 & 3 & Vernonanthura discolor (Spreng.) H.Rob. & 1,5 \\
\hline PM6 & 4 & Inga vera subsp. affinis (DC.) T.D.Penn. & 0,8 \\
\hline PM6 & 5 & Clethra scabra Pers. & 3 \\
\hline PM6 & 6 & Piptocarpha regnellii (Sch.Bip.) Cabrera & 5 \\
\hline PM6 & 7 & Miconia tristis Spring & 0,7 \\
\hline PM6 & 8 & Clethra scabra Pers. & 3,5 \\
\hline PM6 & 9 & Vernonanthura discolor (Spreng.) H.Rob. & 5 \\
\hline PM7 & 1 & Myrsine coriacea (Sw.) R.Br. ex Roem. \& Schult. & 1,5 \\
\hline PM7 & 2 & Vernonanthura discolor (Spreng.) H.Rob. & 1 \\
\hline PM7 & 3 & Myrsine coriacea (Sw.) R.Br. ex Roem. \& Schult. & 1 \\
\hline PM7 & 4 & Piptocarpha regnellii (Sch.Bip.) Cabrera & 3 \\
\hline PM7 & 5 & Myrsine coriacea (Sw.) R.Br. ex Roem. \& Schult. & 1,5 \\
\hline PM7 & 6 & Miconia sellowiana Naudin & 1,5 \\
\hline PM7 & 7 & Myrsine coriacea (Sw.) R.Br. ex Roem. \& Schult. & 0,6 \\
\hline PM7 & 8 & Myrsine coriacea (Sw.) R.Br. ex Roem. \& Schult. & 0,3 \\
\hline PM7 & 9 & Myrsine coriacea (Sw.) R.Br. ex Roem. \& Schult. & 3 \\
\hline PM7 & 10 & Myrsine coriacea (Sw.) R.Br. ex Roem. \& Schult. & 1,8 \\
\hline PM7 & 11 & Myrsine coriacea (Sw.) R.Br. ex Roem. \& Schult. & 1,8 \\
\hline PM7 & 12 & Vernonanthura discolor (Spreng.) H.Rob. & 0,6 \\
\hline PM7 & 13 & Vernonanthura discolor (Spreng.) H.Rob. & 3 \\
\hline PM8 & 1 & Ficus luschnathiana (Miq.) Miq. & 3 \\
\hline PM8 & 2 & Guatteria australis A.St.-Hil. & 1,8 \\
\hline PM8 & 3 & Myrsine coriacea (Sw.) R.Br. ex Roem. \& Schult. & 3,5 \\
\hline PM8 & 4 & Alchornea triplinervia (Spreng.) Müll.Arg. & 0,8 \\
\hline PM8 & 5 & Piptocarpha axillaris (Less.) Baker & 2 \\
\hline PM8 & 6 & Piptocarpha regnellii (Sch.Bip.) Cabrera & 2 \\
\hline PM8 & 7 & Myrsine coriacea (Sw.) R.Br. ex Roem. \& Schult. & 3,5 \\
\hline PM8 & 8 & Myrsine coriacea (Sw.) R.Br. ex Roem. \& Schult. & 4 \\
\hline PM8 & 9 & Myrsine coriacea (Sw.) R.Br. ex Roem. \& Schult. & 1,5 \\
\hline PM8 & 10 & Annona emarginata (Schltdl.) H.Rainer & 0,6 \\
\hline PM8 & 11 & Myrsine coriacea (Sw.) R.Br. ex Roem. \& Schult. & 5 \\
\hline PM8 & 12 & Campomanesia guaviroba (DC.) Kiaersk. & 1,5 \\
\hline PM8 & 13 & Clethra scabra Pers. & 4 \\
\hline PM8 & 14 & Clethra scabra Pers. & 3 \\
\hline PM8 & 14 & Clethra scabra Pers. & 3 \\
\hline PM8 & 14 & Clethra scabra Pers. & 3 \\
\hline PM8 & 15 & Vernonanthura discolor (Spreng.) H.Rob. & 0,8 \\
\hline PM8 & 16 & Myrsine coriacea (Sw.) R.Br. ex Roem. \& Schult. & 1,5 \\
\hline PM8 & 17 & Myrcia splendens (Sw.) DC. & 2,5 \\
\hline PM8 & 18 & Myrsine coriacea (Sw.) R.Br. ex Roem. \& Schult. & 4 \\
\hline
\end{tabular}




\begin{tabular}{|c|c|c|c|}
\hline PM8 & 19 & Piptocarpha regnellii (Sch.Bip.) Cabrera & 4 \\
\hline PM8 & 20 & Vernonanthura discolor (Spreng.) H.Rob. & 5,5 \\
\hline PM8 & 21 & Piptocarpha regnellii (Sch.Bip.) Cabrera & 4 \\
\hline PM8 & 22 & Piptocarpha axillaris (Less.) Baker & 2,5 \\
\hline PM8 & 23 & Piptocarpha axillaris (Less.) Baker & 2 \\
\hline PM8 & 24 & Myrsine coriacea (Sw.) R.Br. ex Roem. \& Schult. & 4 \\
\hline PM8 & 25 & Clethra scabra Pers. & 3,5 \\
\hline PM8 & 26 & Miconia cabucu Hoehne & 1,5 \\
\hline PM9 & 1 & Myrsine coriacea (Sw.) R.Br. ex Roem. \& Schult. & 0,8 \\
\hline PM9 & 2 & Miconia tristis Spring & 0,6 \\
\hline PM9 & 3 & Myrsine coriacea (Sw.) R.Br. ex Roem. \& Schult. & 1,5 \\
\hline PM9 & 4 & Myrsine coriacea (Sw.) R.Br. ex Roem. \& Schult. & 4,5 \\
\hline PM9 & 5 & Myrsine coriacea (Sw.) R.Br. ex Roem. \& Schult. & 1 \\
\hline PM9 & 6 & Vernonanthura discolor (Spreng.) H.Rob. & 2,5 \\
\hline PM9 & 7 & Piptocarpha regnellii (Sch.Bip.) Cabrera & 2 \\
\hline PM9 & 8 & Miconia tristis Spring & 0,6 \\
\hline PM9 & 9 & Miconia cabucu Hoehne & 1,8 \\
\hline PM9 & 10 & Vernonanthura discolor (Spreng.) H.Rob. & 1,5 \\
\hline PM10 & 1 & Vernonanthura discolor (Spreng.) H.Rob. & 1,5 \\
\hline PM10 & 2 & Clethra scabra Pers. & 3 \\
\hline PM10 & 2 & Clethra scabra Pers. & 3 \\
\hline PM10 & 3 & Clethra scabra Pers. & 1 \\
\hline PM10 & 4 & Clethra scabra Pers. & 0,8 \\
\hline PM10 & 5 & Clethra scabra Pers. & 3 \\
\hline PM10 & 5 & Clethra scabra Pers. & 3 \\
\hline PM10 & 5 & Clethra scabra Pers. & 3 \\
\hline PM10 & 5 & Clethra scabra Pers. & 3 \\
\hline PM10 & 6 & Ocotea puberula (Rich.) Nees & 1,6 \\
\hline PM10 & 7 & Piptocarpha axillaris (Less.) Baker & 1,5 \\
\hline PM10 & 8 & Piptocarpha regnellii (Sch.Bip.) Cabrera & 3 \\
\hline PM10 & 9 & Piptocarpha regnellii (Sch.Bip.) Cabrera & 3 \\
\hline PM10 & 10 & Clethra scabra Pers. & 3 \\
\hline PM10 & 10 & Clethra scabra Pers. & 3 \\
\hline PM10 & 11 & Myrsine coriacea (Sw.) R.Br. ex Roem. \& Schult. & 6 \\
\hline PM10 & 12 & Miconia sellowiana Naudin & 1 \\
\hline PM10 & 13 & Myrsine coriacea (Sw.) R.Br. ex Roem. \& Schult. & 5 \\
\hline PM10 & 14 & Myrsine coriacea (Sw.) R.Br. ex Roem. \& Schult. & 1,5 \\
\hline PM10 & 15 & Piptocarpha regnellii (Sch.Bip.) Cabrera & 5 \\
\hline PM11 & 1 & Piptocarpha regnellii (Sch.Bip.) Cabrera & 2,5 \\
\hline PM11 & 2 & Myrsine coriacea (Sw.) R.Br. ex Roem. \& Schult. & 0,9 \\
\hline PM11 & 3 & Vernonanthura discolor (Spreng.) H.Rob. & 3 \\
\hline PM11 & 4 & Miconia sellowiana Naudin & 0,7 \\
\hline PM11 & 5 & Piptocarpha regnellii (Sch.Bip.) Cabrera & 3,5 \\
\hline PM11 & 6 & Clethra scabra Pers. & 3,5 \\
\hline PM11 & 6 & Clethra scabra Pers. & 3,5 \\
\hline PM11 & 6 & Clethra scabra Pers. & 3,5 \\
\hline PM11 & 7 & Clethra scabra Pers. & 0,7 \\
\hline PM11 & 8 & Piptocarpha regnellii (Sch.Bip.) Cabrera & 2 \\
\hline PM11 & 9 & Vernonanthura discolor (Spreng.) H.Rob. & 0,8 \\
\hline PM11 & 10 & Myrsine coriacea (Sw.) R.Br. ex Roem. \& Schult. & 3 \\
\hline
\end{tabular}




\begin{tabular}{|c|c|c|c|}
\hline PM11 & 11 & Piptocarpha regnellii (Sch.Bip.) Cabrera & 3,5 \\
\hline PM11 & 12 & Piptocarpha regnellii (Sch.Bip.) Cabrera & 2 \\
\hline PM11 & 13 & Myrsine coriacea (Sw.) R.Br. ex Roem. \& Schult. & 3,5 \\
\hline PM11 & 14 & Vernonanthura discolor (Spreng.) H.Rob. & 3,5 \\
\hline PM11 & 15 & Vernonanthura discolor (Spreng.) H.Rob. & 2 \\
\hline PM11 & 16 & Myrsine umbellata Mart. & 1 \\
\hline PM12 & 1 & Piptocarpha regnellii (Sch.Bip.) Cabrera & 0,8 \\
\hline PM12 & 2 & Clethra scabra Pers. & 1 \\
\hline PM12 & 3 & Rubus brasiliensis Mart. & 2 \\
\hline PM12 & 4 & Vernonanthura discolor (Spreng.) H.Rob. & 3 \\
\hline PM12 & 5 & Piptocarpha axillaris (Less.) Baker & 1 \\
\hline PM12 & 6 & Baccharis semiserrata DC. & 4 \\
\hline PM12 & 6 & Baccharis semiserrata DC. & 4 \\
\hline PM12 & 6 & Baccharis semiserrata DC. & 4 \\
\hline PM12 & 6 & Baccharis semiserrata DC. & 4 \\
\hline PM12 & 7 & Piptocarpha regnellii (Sch.Bip.) Cabrera & 1,2 \\
\hline PM12 & 8 & Baccharis semiserrata DC. & 2,5 \\
\hline PM12 & 8 & Baccharis semiserrata DC. & 2,5 \\
\hline PM12 & 9 & Myrsine coriacea (Sw.) R.Br. ex Roem. \& Schult. & 2,5 \\
\hline PM12 & 10 & Vernonanthura discolor (Spreng.) H.Rob. & 3 \\
\hline PM12 & 10 & Vernonanthura discolor (Spreng.) H.Rob. & 3 \\
\hline PM12 & 11 & Clethra scabra Pers. & 2 \\
\hline PM12 & 12 & Myrsine coriacea (Sw.) R.Br. ex Roem. \& Schult. & 2,5 \\
\hline PM12 & 13 & Alchornea triplinervia (Spreng.) Müll.Arg. & 1 \\
\hline PM12 & 14 & Baccharis oblongifolia (Ruiz \& Pav.) Pers. & 0,7 \\
\hline PM13 & 1 & Piptocarpha regnellii (Sch.Bip.) Cabrera & 2 \\
\hline PM13 & 2 & Vernonanthura discolor (Spreng.) H.Rob. & 1 \\
\hline PM13 & 3 & Clethra scabra Pers. & 3,5 \\
\hline PM13 & 4 & Myrsine coriacea (Sw.) R.Br. ex Roem. \& Schult. & 3 \\
\hline PM13 & 5 & Vernonanthura discolor (Spreng.) H.Rob. & 3 \\
\hline PM13 & 6 & Annona emarginata (Schltdl.) H.Rainer & 1,5 \\
\hline PM13 & 7 & Miconia tristis Spring & 1 \\
\hline PM13 & 8 & Myrsine coriacea (Sw.) R.Br. ex Roem. \& Schult. & 2,5 \\
\hline PM13 & 9 & Vernonanthura discolor (Spreng.) H.Rob. & 4,5 \\
\hline PM13 & 10 & Baccharis semiserrata DC. & 4 \\
\hline PM14 & 1 & $\begin{array}{l}\text { Symphyopappus itatiayensis (Hieron.) R.M.King \& } \\
\text { H.Rob. }\end{array}$ & 1,7 \\
\hline PM14 & 1 & $\begin{array}{l}\text { Symphyopappus itatiayensis (Hieron.) R.M.King \& } \\
\text { H.Rob. }\end{array}$ & 1,4 \\
\hline PM15 & 1 & Baccharis semiserrata DC. & 3,5 \\
\hline PM15 & 1 & Baccharis semiserrata DC. & 3,5 \\
\hline PM15 & 1 & Baccharis semiserrata DC. & 3,5 \\
\hline PM15 & 1 & Baccharis semiserrata DC. & 3 \\
\hline PM15 & 1 & Baccharis semiserrata DC. & 3 \\
\hline PM15 & 1 & Baccharis semiserrata DC. & 3 \\
\hline PM15 & 2 & Miconia tristis Spring & 0,5 \\
\hline PM15 & 3 & Miconia tristis Spring & 0,5 \\
\hline PM15 & 4 & Miconia tristis Spring & 0,5 \\
\hline PM15 & 5 & Vernonanthura discolor (Spreng.) H.Rob. & 3,5 \\
\hline PM15 & 5 & Vernonanthura discolor (Spreng.) H.Rob. & 2 \\
\hline PM15 & 6 & Vernonanthura discolor (Spreng.) H.Rob. & 1,8 \\
\hline
\end{tabular}




\begin{tabular}{|c|c|c|c|}
\hline PM15 & 7 & Piptocarpha regnellii (Sch.Bip.) Cabrera & 4 \\
\hline PM15 & 7 & Piptocarpha regnellii (Sch.Bip.) Cabrera & 4 \\
\hline PM15 & 8 & Myrsine coriacea (Sw.) R.Br. ex Roem. \& Schult. & 4 \\
\hline PM15 & 9 & Vernonanthura discolor (Spreng.) H.Rob. & 4 \\
\hline PM15 & 10 & Clethra scabra Pers. & 3,5 \\
\hline PM15 & 11 & Vernonanthura discolor (Spreng.) H.Rob. & 2 \\
\hline PM15 & 12 & Vernonanthura discolor (Spreng.) H.Rob. & 5 \\
\hline PM15 & 13 & Myrsine coriacea (Sw.) R.Br. ex Roem. \& Schult. & 3 \\
\hline PM15 & 14 & Myrsine coriacea (Sw.) R.Br. ex Roem. \& Schult. & 4 \\
\hline PM15 & 15 & Myrsine coriacea (Sw.) R.Br. ex Roem. \& Schult. & 2 \\
\hline $\mathrm{R} 1$ & 1 & Vernonanthura discolor (Spreng.) H.Rob. & 3 \\
\hline $\mathrm{R} 1$ & 2 & Vernonanthura discolor (Spreng.) H.Rob. & 1 \\
\hline $\mathrm{R} 1$ & 3 & Myrsine umbellata Mart. & 2,5 \\
\hline R1 & 4 & Miconia lymanii Wurdack & 2 \\
\hline $\mathrm{R} 1$ & 4 & Miconia lymanii Wurdack & 2 \\
\hline $\mathrm{R} 1$ & 4 & Miconia lymanii Wurdack & 2 \\
\hline $\mathrm{R} 1$ & 5 & Vernonanthura discolor (Spreng.) H.Rob. & 2,5 \\
\hline R1 & 6 & Vernonanthura discolor (Spreng.) H.Rob. & 1,5 \\
\hline $\mathrm{R} 1$ & 7 & Myrsine coriacea (Sw.) R.Br. ex Roem. \& Schult. & 1,8 \\
\hline $\mathrm{R} 1$ & 8 & Clethra scabra Pers. & 1,5 \\
\hline $\mathrm{R} 1$ & 9 & Critoniopsis quinqueflora (Less.) H.Rob. & 1,8 \\
\hline $\mathrm{R} 2$ & 1 & Vernonanthura discolor (Spreng.) H.Rob. & 2 \\
\hline R2 & 2 & Vernonanthura discolor (Spreng.) H.Rob. & 4 \\
\hline $\mathrm{R} 2$ & 3 & Clethra scabra Pers. & 2,5 \\
\hline R2 & 3 & Clethra scabra Pers. & 2,5 \\
\hline R2 & 3 & Clethra scabra Pers. & 2,5 \\
\hline $\mathrm{R} 2$ & 4 & Clethra scabra Pers. & 2,5 \\
\hline R2 & 4 & Clethra scabra Pers. & 2,5 \\
\hline R2 & 5 & Cedrela fissilis Vell. & 1,5 \\
\hline R3 & 1 & Ocotea puberula (Rich.) Nees & 3 \\
\hline R3 & 2 & Vernonanthura discolor (Spreng.) H.Rob. & 3 \\
\hline R3 & 3 & Vernonanthura discolor (Spreng.) H.Rob. & 3 \\
\hline R3 & 4 & Vernonanthura discolor (Spreng.) H.Rob. & 3 \\
\hline R3 & 5 & Clethra scabra Pers. & 2,5 \\
\hline R3 & 5 & Clethra scabra Pers. & 2,5 \\
\hline R3 & 5 & Clethra scabra Pers. & 2,5 \\
\hline R4 & 1 & Vernonanthura discolor (Spreng.) H.Rob. & 1,8 \\
\hline $\mathrm{R} 4$ & 2 & Vernonanthura discolor (Spreng.) H.Rob. & 2 \\
\hline $\mathrm{R} 4$ & 3 & Vernonanthura discolor (Spreng.) H.Rob. & 5 \\
\hline $\mathrm{R} 4$ & 4 & Vernonanthura discolor (Spreng.) H.Rob. & 5 \\
\hline $\mathrm{R} 4$ & 5 & Vernonanthura discolor (Spreng.) H.Rob. & 3 \\
\hline $\mathrm{R} 4$ & 5 & Vernonanthura discolor (Spreng.) H.Rob. & 3,5 \\
\hline R4 & 6 & Vernonanthura discolor (Spreng.) H.Rob. & 2,5 \\
\hline $\mathrm{R} 4$ & 7 & Vernonanthura discolor (Spreng.) H.Rob. & 2,5 \\
\hline $\mathrm{R} 4$ & 8 & Piptocarpha axillaris (Less.) Baker & 3,5 \\
\hline $\mathrm{R} 4$ & 9 & Piptocarpha regnellii (Sch.Bip.) Cabrera & 4 \\
\hline $\mathrm{R} 4$ & 10 & Piptocarpha axillaris (Less.) Baker & 5 \\
\hline R5 & 1 & Cyathea phalerata Mart. & 2 \\
\hline $\mathrm{R} 5$ & 2 & Vernonanthura discolor (Spreng.) H.Rob. & 4 \\
\hline R5 & 3 & Myrsine umbellata Mart. & 1,6 \\
\hline
\end{tabular}




\begin{tabular}{|c|c|c|c|}
\hline R5 & 4 & Vernonanthura discolor (Spreng.) H.Rob. & 0,7 \\
\hline $\mathrm{R} 5$ & 5 & Myrsine coriacea (Sw.) R.Br. ex Roem. \& Schult. & 0,7 \\
\hline $\mathrm{R} 5$ & 6 & Vernonanthura discolor (Spreng.) H.Rob. & 2,5 \\
\hline R5 & 7 & Vernonanthura discolor (Spreng.) H.Rob. & 4 \\
\hline R5 & 8 & Vernonanthura discolor (Spreng.) H.Rob. & 4 \\
\hline $\mathrm{R} 5$ & 9 & Vernonanthura discolor (Spreng.) H.Rob. & 1 \\
\hline $\mathrm{R} 5$ & 10 & Cyathea phalerata Mart. & 1 \\
\hline R5 & 11 & Vernonanthura discolor (Spreng.) H.Rob. & 5 \\
\hline R6 & 1 & Vernonanthura discolor (Spreng.) H.Rob. & 4 \\
\hline R6 & 1 & Vernonanthura discolor (Spreng.) H.Rob. & 3 \\
\hline R6 & 1 & Vernonanthura discolor (Spreng.) H.Rob. & 2,5 \\
\hline R6 & 2 & Piptocarpha axillaris (Less.) Baker & 3 \\
\hline R6 & 2 & Piptocarpha axillaris (Less.) Baker & 3 \\
\hline R6 & 3 & Myrsine umbellata Mart. & 4,5 \\
\hline R6 & 4 & Ocotea elegans Mez & 1 \\
\hline R6 & 5 & Vernonanthura discolor (Spreng.) H.Rob. & 4 \\
\hline R6 & 6 & Piptocarpha axillaris (Less.) Baker & 4,5 \\
\hline R6 & 7 & Piptocarpha angustifolia Dusén ex Malme & 4 \\
\hline R6 & 8 & Piptocarpha axillaris (Less.) Baker & 4 \\
\hline R6 & 9 & Myrsine coriacea (Sw.) R.Br. ex Roem. \& Schult. & 0,6 \\
\hline R6 & 10 & Myrsine coriacea (Sw.) R.Br. ex Roem. \& Schult. & 0,8 \\
\hline R6 & 11 & Myrsine coriacea (Sw.) R.Br. ex Roem. \& Schult. & 0,6 \\
\hline R6 & 12 & Ocotea elegans $\mathrm{Mez}$ & 0,6 \\
\hline R6 & 13 & Piptocarpha axillaris (Less.) Baker & 4 \\
\hline R6 & 14 & Vernonanthura discolor (Spreng.) H.Rob. & 6 \\
\hline R6 & 15 & Vernonanthura discolor (Spreng.) H.Rob. & 4 \\
\hline R6 & 16 & Vernonanthura discolor (Spreng.) H.Rob. & 3 \\
\hline R6 & 17 & Piptocarpha axillaris (Less.) Baker & 3 \\
\hline R6 & 18 & Ocotea elegans $\mathrm{Mez}$ & 1,5 \\
\hline R6 & 19 & Myrsine coriacea (Sw.) R.Br. ex Roem. \& Schult. & 5 \\
\hline R6 & 20 & Piptocarpha axillaris (Less.) Baker & 3 \\
\hline R6 & 21 & Piptocarpha axillaris (Less.) Baker & 3 \\
\hline R6 & 22 & Vernonanthura discolor (Spreng.) H.Rob. & 2,5 \\
\hline $\mathrm{R} 7$ & 1 & Myrsine coriacea (Sw.) R.Br. ex Roem. \& Schult. & 3,5 \\
\hline $\mathrm{R} 7$ & 1 & Myrsine coriacea (Sw.) R.Br. ex Roem. \& Schult. & 3,5 \\
\hline $\mathrm{R} 7$ & 3 & Ocotea puberula (Rich.) Nees & 1 \\
\hline $\mathrm{R} 7$ & 4 & Ocotea puberula (Rich.) Nees & 1 \\
\hline $\mathrm{R} 8$ & - & - & - \\
\hline R9 & & Solanum mauritianum Scop. & 3,5 \\
\hline $\mathrm{R} 10$ & 1 & Miconia tristis Spring & 0,6 \\
\hline $\mathrm{R} 10$ & 2 & Clethra scabra Pers. & 1 \\
\hline $\mathrm{R} 10$ & 2 & Clethra scabra Pers. & 1 \\
\hline $\mathrm{R} 10$ & 3 & Vernonanthura discolor (Spreng.) H.Rob. & 1 \\
\hline $\mathrm{R} 10$ & 4 & Myrsine coriacea (Sw.) R.Br. ex Roem. \& Schult. & 0,6 \\
\hline $\mathrm{R} 10$ & 5 & Miconia tristis Spring & 0,5 \\
\hline $\mathrm{R} 10$ & 6 & Clethra scabra Pers. & 1,5 \\
\hline $\mathrm{R} 10$ & 7 & Clethra scabra Pers. & 1 \\
\hline $\mathrm{R} 10$ & 8 & Vernonanthura discolor (Spreng.) H.Rob. & 1,5 \\
\hline $\mathrm{R} 10$ & 9 & Miconia tristis Spring & 0,5 \\
\hline $\mathrm{R} 10$ & 10 & Clethra scabra Pers. & 1,8 \\
\hline
\end{tabular}




\begin{tabular}{|c|c|c|c|}
\hline $\mathrm{R} 10$ & 12 & Clethra scabra Pers. & 1,2 \\
\hline $\mathrm{R} 10$ & 13 & Clethra scabra Pers. & 0,5 \\
\hline $\mathrm{R} 10$ & 14 & Clethra scabra Pers. & 1,2 \\
\hline $\mathrm{R} 10$ & 15 & Ocotea puberula (Rich.) Nees & 1,2 \\
\hline $\mathrm{R} 10$ & 16 & Solanum pseudoquina A.St.-Hil. & 1 \\
\hline $\mathrm{R} 10$ & 17 & Solanum pseudoquina A.St.-Hil. & 0,5 \\
\hline $\mathrm{R} 10$ & 18 & Solanum pseudoquina A.St.-Hil. & 1 \\
\hline $\mathrm{R} 10$ & 19 & Solanum pseudoquina A.St.-Hil. & 1,2 \\
\hline $\mathrm{R} 10$ & 20 & Casearia sylvestris $\mathrm{Sw}$. & 1,2 \\
\hline $\mathrm{R} 10$ & 21 & Clethra scabra Pers. & 2 \\
\hline $\mathrm{R} 10$ & 22 & Solanum mauritianum Scop. & 1,2 \\
\hline $\mathrm{R} 10$ & 23 & Solanum pseudoquina A.St.-Hil. & 1 \\
\hline $\mathrm{R} 10$ & 24 & Solanum pseudoquina A.St.-Hil. & 1 \\
\hline $\mathrm{R} 10$ & 25 & Ocotea puberula (Rich.) Nees & 0,7 \\
\hline $\mathrm{R} 10$ & 26 & Casearia sylvestris $\mathrm{Sw}$. & 1,7 \\
\hline $\mathrm{R} 10$ & 27 & Clethra scabra Pers. & 1,8 \\
\hline $\mathrm{R} 10$ & 27 & Clethra scabra Pers. & 1,8 \\
\hline $\mathrm{R} 10$ & 27 & Clethra scabra Pers. & 1,8 \\
\hline $\mathrm{R} 10$ & 28 & Miconia tristis Spring & 0,8 \\
\hline $\mathrm{R} 10$ & 29 & Solanum pseudoquina A.St.-Hil. & 0,5 \\
\hline $\mathrm{R} 10$ & 30 & Solanum pseudoquina A.St.-Hil. & 1 \\
\hline $\mathrm{R} 10$ & 31 & Solanum pseudoquina A.St.-Hil. & 0,5 \\
\hline $\mathrm{R} 10$ & 32 & Solanum pseudoquina A.St.-Hil. & 0,6 \\
\hline $\mathrm{R} 10$ & 33 & Solanum pseudoquina A.St.-Hil. & 0,7 \\
\hline $\mathrm{R} 10$ & 34 & Solanum pseudoquina A.St.-Hil. & 0,8 \\
\hline $\mathrm{R} 10$ & 35 & Solanum pseudoquina A.St.-Hil. & 0,8 \\
\hline $\mathrm{R} 10$ & 36 & Solanum pseudoquina A.St.-Hil. & 0,7 \\
\hline $\mathrm{R} 10$ & 37 & Solanum pseudoquina A.St.-Hil. & 0,5 \\
\hline $\mathrm{R} 10$ & 38 & Solanum pseudoquina A.St.-Hil. & 0,5 \\
\hline $\mathrm{R} 10$ & 39 & Solanum pseudoquina A.St.-Hil. & 0,7 \\
\hline $\mathrm{R} 10$ & 40 & Solanum pseudoquina A.St.-Hil. & 0,7 \\
\hline $\mathrm{R} 10$ & 41 & Solanum pseudoquina A.St.-Hil. & 0,8 \\
\hline $\mathrm{R} 10$ & 42 & Solanum pseudoquina A.St.-Hil. & 0,8 \\
\hline $\mathrm{R} 10$ & 43 & Solanum pseudoquina A.St.-Hil. & 0,8 \\
\hline $\mathrm{R} 10$ & 44 & Solanum pseudoquina A.St.-Hil. & 0,8 \\
\hline $\mathrm{R} 10$ & 45 & Campomanesia guaviroba (DC.) Kiaersk. & 2 \\
\hline $\mathrm{R} 10$ & 46 & Campomanesia guaviroba (DC.) Kiaersk. & 1,8 \\
\hline $\mathrm{R} 10$ & 47 & Campomanesia guaviroba (DC.) Kiaersk. & 1,8 \\
\hline $\mathrm{R} 10$ & 48 & Clethra scabra Pers. & 1,8 \\
\hline $\mathrm{R} 10$ & 49 & Clethra scabra Pers. & 1,8 \\
\hline $\mathrm{R} 10$ & 50 & Clethra scabra Pers. & 1,6 \\
\hline $\mathrm{R} 10$ & 51 & Clethra scabra Pers. & 1,5 \\
\hline $\mathrm{R} 10$ & 52 & Miconia tristis Spring & 0,6 \\
\hline $\mathrm{R} 11$ & 1 & Myrsine coriacea (Sw.) R.Br. ex Roem. \& Schult. & 1,8 \\
\hline $\mathrm{R} 11$ & 2 & Aspidosperma tomentosum Mart. & 1,5 \\
\hline $\mathrm{R} 11$ & 3 & Aspidosperma tomentosum Mart. & 1,8 \\
\hline $\mathrm{R} 12$ & 1 & Myrsine coriacea (Sw.) R.Br. ex Roem. \& Schult. & 4 \\
\hline $\mathrm{R} 12$ & 2 & Myrsine coriacea (Sw.) R.Br. ex Roem. \& Schult. & 3 \\
\hline $\mathrm{R} 13$ & 1 & Myrsine coriacea (Sw.) R.Br. ex Roem. \& Schult. & 1,5 \\
\hline $\mathrm{R} 13$ & 2 & Myrsine coriacea (Sw.) R.Br. ex Roem. \& Schult. & 1,8 \\
\hline
\end{tabular}




\begin{tabular}{|l|c|l|c|} 
R13 & 3 & Myrsine coriacea (Sw.) R.Br. ex Roem. \& Schult. & 0,9 \\
\hline R13 & 4 & Myrsine coriacea (Sw.) R.Br. ex Roem. \& Schult. & 5 \\
\hline R13 & 5 & Myrsine coriacea (Sw.) R.Br. ex Roem. \& Schult. & 3,5 \\
\hline R13 & 6 & Myrsine coriacea (Sw.) R.Br. ex Roem. \& Schult. & 2,5 \\
\hline R13 & 7 & Myrsine coriacea (Sw.) R.Br. ex Roem. \& Schult. & 3 \\
\hline R13 & 8 & Miconia tristis Spring & 0,8 \\
\hline R13 & 9 & Clethra scabra Pers. & 0,6 \\
\hline R13 & 10 & Clethra scabra Pers. & 0,6 \\
\hline R14 & 11 & Vernonanthura discolor (Spreng.) H.Rob. & 2,5 \\
\hline R15 & 1 & Vernonanthura discolor (Spreng.) H.Rob. & 2,5 \\
\hline R15 & 2 & Vernonanthura discolor (Spreng.) H.Rob. & 4 \\
\hline R15 & 3 & Miconia tristis Spring & 1 \\
\hline
\end{tabular}

